\title{
Rational prescribing behaviour in general practice : development and implementation of guidelines, an evaluation
}

Citation for published version (APA):

Martens, J. D. (2007). Rational prescribing behaviour in general practice : development and implementation of guidelines, an evaluation. [Doctoral Thesis, Maastricht University]. Universiteit Maastricht. https://doi.org/10.26481/dis.20071107jm

Document status and date:

Published: 01/01/2007

DOI:

10.26481/dis.20071107jm

Document Version:

Publisher's PDF, also known as Version of record

\section{Please check the document version of this publication:}

- A submitted manuscript is the version of the article upon submission and before peer-review. There can be important differences between the submitted version and the official published version of record. People interested in the research are advised to contact the author for the final version of the publication, or visit the DOI to the publisher's website.

- The final author version and the galley proof are versions of the publication after peer review.

- The final published version features the final layout of the paper including the volume, issue and page numbers.

Link to publication

\footnotetext{
General rights rights.

- You may freely distribute the URL identifying the publication in the public portal. please follow below link for the End User Agreement:

www.umlib.nl/taverne-license

Take down policy

If you believe that this document breaches copyright please contact us at:

repository@maastrichtuniversity.nl

providing details and we will investigate your claim.
}

Copyright and moral rights for the publications made accessible in the public portal are retained by the authors and/or other copyright owners and it is a condition of accessing publications that users recognise and abide by the legal requirements associated with these

- Users may download and print one copy of any publication from the public portal for the purpose of private study or research.

- You may not further distribute the material or use it for any profit-making activity or commercial gain

If the publication is distributed under the terms of Article 25fa of the Dutch Copyright Act, indicated by the "Taverne" license above, 


\section{Rational Prescribing BehaVIOUR in General Practice}

Development and Implementation of Guidelines, an Evaluation 
The studies presented in this thesis were performed at the Care and Public Health Research Institute (CAPHRI), which participates in the Netherlands School of Primary Care research (Care), acknowledged in 1995 by the Royal Dutch Academy of Science (KNAW).

These studies are supported by the Dutch insurance companies VGZ and CZ, providing financial support and data for this study.
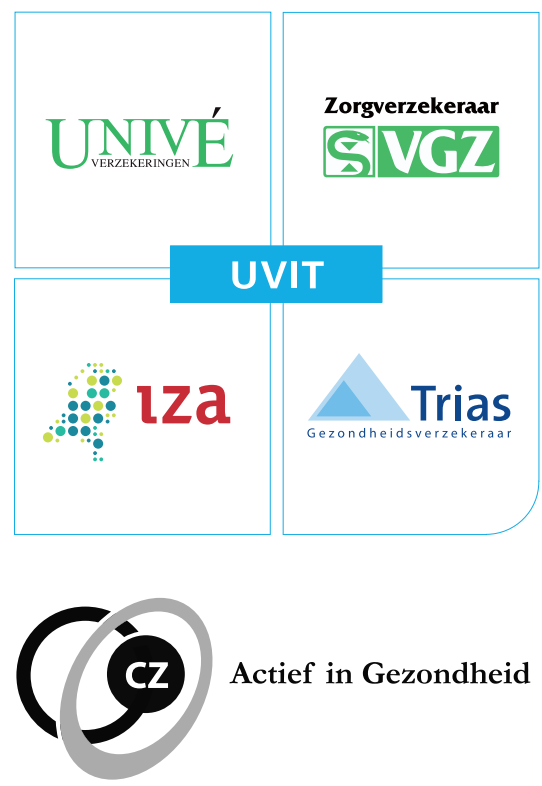

Printing of this thesis was financially supported by the Dutch insurance company VGZ

Rational Prescribing Behaviour in General Practice; Development and Implementation of Guidelines, an Evaluation. JD Martens. Thesis, University Hospital Maastricht - With references - With summary in Dutch.

MeSH subject headings: General Practice; Practice guidelines; Drug therapy; Computer reminders; Quality Assurance, Health Care.

ISBN: 978-90-5278-673-5

() 2007, JD Martens, University Hospital Maastricht. Department of Integrated Care (RVE Transmurale Zorg) P.O. Box 5800, 6202 AZ Maastricht, the Netherlands.

E-mail: jd.martens@caphri.unimaas.nl

Cover Design by: Chantal Arnoldussen

Printed by Datawyse / Universitaire Pers Maastricht. 


\title{
Rational Prescribing Behaviour in General Practice
}

Development and Implementation of Guidelines, an Evaluation

\author{
Proefschrift \\ ter verkrijging van de graad van doctor \\ aan de Universiteit Maastricht, \\ op gezag van de Rector Magnificus, \\ Prof.Mr. G.P.M.F. Mols, \\ volgens het besluit van het College van Decanen, \\ in het openbaar te verdedigen \\ op woensdag 7 november 2007 om 16.00 uur \\ door \\ Jody Désirée Martens
}

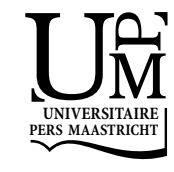




\section{Promotor:}

Prof.dr. J.L. Severens

Copromotores:

Dr. R.A.G. Winkens

Dr. T. van der Weijden

\section{Beoordelingscommissie:}

Prof. dr. J. Metsemakers (voorzitter)

Prof.dr.ir. A. Hasman (AMC/Universiteit van Amsterdam)

Prof. dr. F.M. Haaijer-Ruskamp (Universitair Medisch Centrum Groningen)

Prof. dr. G.G. van Merode 
Voor mijn lieve vader

"Good night, good night! Parting is such sweet sorrow, that I shall say: Good night, till it be morrow." William Shakespeare

"Elk afscheid is de geboorte van een mooie herinnering." Michelangelo 



\section{ConTEnTS}

\begin{tabular}{l|l} 
CHAPTER 1 & General Introduction
\end{tabular}

\begin{tabular}{l|ll} 
CHAPTER 2 & Effects of a Behaviour Independent Financial Incentive on & 21
\end{tabular} Prescribing Behaviour

\begin{tabular}{l|ll} 
CHAPTER 3 & Computer Reminders on Prescribing Behaviour. Description of a 33
\end{tabular} Multi-Design Study

\begin{tabular}{l|ll} 
CHAPTER 4 & Development and Dissemination of Multidisciplinary Guidelines to $\quad 51$
\end{tabular} Improve Prescribing Behaviour

\begin{tabular}{l|lr} 
CHAPTER 5 & The Effect of Computer Reminders on Prescribing Behaviour 63
\end{tabular}

CHAPTER 6 | Cost Effects of Computer Reminders to Improve Prescribing 83 Behaviour

\begin{tabular}{l|ll} 
CHAPTER 7 & Feasibility and Acceptability of a Computerised System with & 105
\end{tabular} Automated Reminders for Prescribing Behaviour

\begin{tabular}{l|ll} 
CHAPTER 8 & General Discussion & 121
\end{tabular}

\begin{tabular}{l|lr} 
CHAPTER 9 & Summary & 143
\end{tabular}

Samenvatting 153

Dankwoord 163

Curriculum Vitae $\quad 169$

$\begin{array}{ll}\text { Publications } & 171\end{array}$ 

General Introduction 



\section{GENERAL INTRODUCTION}

Clinical practice guidelines (after this referred to as clinical guidelines) are an increasingly common element of clinical care throughout the world. The aim of clinical guidelines is to improve patient care by providing appropriate recommendations for daily practice. Preferably, these guidelines are based on the best-available evidence, supplemented with clinical expertise ${ }^{1}$. The definition of clinical guidelines from the Institutes of Medicine is widely accepted: Clinical guidelines are 'systematically developed statements to assist practitioner and patient decisions about appropriate health care for specific clinical circumstances' ${ }^{2}$. An important characteristic of guidelines is that the provided recommendations are not meant to be used in a compelling way. In daily practice a care provider should at each opportunity for clinical decision making balance between adherence or purposeful deviation from the guideline in translating the population-based recommendations to unique individuals.

Guidelines can be developed at a national level (central) or at a local level (regional). Each level has its advantages and disadvantages ${ }^{1}$. The central approach has a higher guarantee for a solid scientific basis because of the likely involvement of all national experts. This leads to the disadvantage that the users are less directly involved and thus may feel less committed to adhere to the guidelines. Furthermore, it is not always possible within national guidelines to define the desired performance based on relevant local practice conditions. Although the development of local guidelines is time consuming, the local approach facilitates the involvement of local care providers and adjustment to local contextual or organisational conditions. The advantage is that this involvement of local professionals is an instructive process. Interlinking both methods whereby centrally produced clinical guidelines are translated into locally adapted versions might offer an approach that strengthens the advantages of both methods ${ }^{3}$. To promote their implementation, guidelines could be used as a template for local protocols, clinical pathways and interprofessional agreements ${ }^{4}$. At the local level, the central clinical guidelines can be used to develop local guidelines, protocols, which are generally more specific and describe the recommendations more in detail. The emphasis in this combination of methods is on involvement of the local group of end users and producing local agreements.

Prescribing recommendations have often been subject of guideline development. Medication is not always prescribed effectively: drugs may be prescribed unnecessarily and lower-cost alternatives are not always taken into consideration. The introduction of prescribing guidelines in clinical practise is expected to influence prescribing behaviour. Often, guidelines have been developed by one discipline: primary care physicians or specialists. In general we know that there is a lack in the adjustment of prescribing between primary and secondary care. Currently, there is little coherence across these sectors regarding treatment guidelines and drug selection ${ }^{5}$. Lack of consistency and cooperation between primary and secondary care can lead to inefficient care and places patients at risk of poly-pharmacy ${ }^{6}$. The need for improving the integration of care provided by different physicians has been stressed by the European Working Party on Quality in Family Practice ${ }^{6}$. 
One of the recommended actions was that General Practitioners (GPs) and specialists should establish local clinical guidelines together. GPs are interested in developing personal relationships to increase their knowledge. Once they have reached a certain level of expertise, they shift their focus to another specialty ${ }^{7}$. Specialists on the other hand, are mainly interested in collaborating because the GP is the gatekeeper for access to secondary health care resources. Patients need a referral from their general practitioner to have access to specialist or hospital care ${ }^{8}$. So, both GPS and specialists have different interests in collaboration that may stimulate the integrative approach in guideline development.

Since the introduction of the analysis of GPs' volume and cost data of prescribing, GPs have become more alert of the costs of individual drugs and became more aware to which extent prescribing initiated by hospital consultants affected their overall budget. This has caused that GPs became increasingly concerned at being asked to prescribe for particular treatments if they were not involved in the decision making, particularly if clinical monitoring was only continued at the hospital ${ }^{9}$.

To improve communication on prescribing between primary and secondary care it seems desirable to integrate the GPs' and specialists' knowledge in the development of multidisciplinary guidelines. We chose to develop multidisciplinary prescribing guidelines on a local level. The aim of the project was to develop evidence based guidelines that should be used both in primary care as well as in secondary care. The prescribing guidelines were actually developed by independent multidisciplinary expert teams that included community pharmacists, specialist, GPs and hospital pharmacists and were based on national guidelines, practical experience and consensus.

\section{Characteristics of drug prescribing behaviour}

Appropriate prescribing is a major challenge for our health service. The consequences of inappropriate prescribing are major, both concerning clinical and cost implications ${ }^{10}$. A substantial amount of research has been executed, studying determinants of (inappropriate) prescribing, and methods for improvement of prescribing behaviour ${ }^{11-15}$. The quality and variation in drug prescribing can be attributed to demographic factors like growth and ageing of the (chronically ill) population, the trend towards new but usually more expensive drugs, patients' increased awareness of their decisional power in health care options, pressure from the industry and last but not least the differences in prescribing practices between primary and secondary care oriented physicians ${ }^{16,17}$. Physicians are also known to prescribe more easily as a result of today's high level of work-related stress and routines ${ }^{18}$.

The influences on prescribing behaviour can be subdivided into three categories of influences: 1) internal (personal) influences, 2) external (social) influences, and 3) drug characteristics. Key internal influences appeared to be GPs' clinical experience and routines, the level of confidence in their role, the level of expertise in specific clinical areas, and their attitudes towards cost-conscious prescribing. Important external factors were information provided by drug industry representatives; independent bulletins such as the Drugs and Therapeutics Bulletin, Formulary, peer-reviewed journals and the medical 'weeklies'; and health authority medical and pharmacy advisors ${ }^{19}$. Other professional peers, in particular 
hospital consultants, also emerged as important influences, with a significant amount of prescribing of the index drugs appearing to be hospital-initiated or hospital-led. In addition to these factors, the decisions individual GPs made were also influenced by their judgements about the drug characteristics like efficacy, safety, tolerability, cost, and pharmacological niche of the index drugs ${ }^{20}$.

In the past attempts have been made to develop models explaining GPs' prescribing behaviour. Multiple factors are involved in general practitioners' decisions to change their prescribing habits ${ }^{21}$. From the literature five main theoretical approaches can be taken to explain non-adherence to prescription guidelines in general: 1) cognitive theories and educational approaches, 2) motivational theories, 3) social influence theories, 4) marketing theories, and 5) organisational theories ${ }^{22}$.

\section{Implementation of change: a model}

One of the most consistent findings in health services research is the gap between best practice and actual clinical care. In this case: the discrepancy between the clinical guideline and the actual behaviour of $\mathrm{GPs}^{23}$. Current guideline dissemination and implementation strategies can lead to improvements in care within the context of rigorous evaluative studies. However, there is an imperfect evidence base to support decisions about which guideline dissemination and implementation strategies are likely to be efficient under different circumstances ${ }^{24}$. The central question is 'how to change GPs' prescribing behaviour'. To successfully implement guidelines a systematic approach and good planning, in which all the relevant factors are considered, is required. Also regular monitoring alongside the implementation plan is needed to see what progress is being made in achieving the goals. A one-off activity is sometimes effective, but often not. Implementation experts indicate that multistage involvement in the development of a guideline can be a positive contributor to effective implementation of guidelines ${ }^{25}$.

Two perspectives can be used to plan the implementation of change in patient care. The literature offers a variety of models for planning change ${ }^{23}$, taking either the perspective of the 'implementer' or the perspective of the target group as a starting point. In the process of formulating recommendations, implicit norms of the target users should be taken into account. Guidelines should be developed within a structured and coordinated programme by a credible central organisation. To promote their implementation, guidelines could be used as a template for local protocols, clinical pathways and interprofessional agreements ${ }^{4}$.

\section{Economic evaluations of implementation strategies}

National and regional healthcare systems are investing substantial resources in the development and introduction of clinical guidelines in the belief that they will promote effective and cost-effective healthcare ${ }^{26}$. However, the development and introduction of these guidelines are not without costs. In some circumstances, the costs of development and introduction of guidelines may outweigh their potential benefits ${ }^{26,27}$.

Implementation research determines both the positive and negative consequences of the application of implementation strategies. Therefore, it is important to consider not just the 
overall results but also the efforts required to achieve them as well ${ }^{28}$. If an implementation strategy is very expensive, the costs (use of people, time and other resources) will come at the expense of other healthcare activities. It is possible that a clinical intervention that is cost effective in the context of a clinical trial requires too many resources to implement in a routine care setting, deteriorating its cost-effectiveness. The application of an implementation strategy can therefore be considered an investment, which can be judged in an economic evaluation on its cost-effectiveness ${ }^{29}$. But, only few satisfactory economic evaluations of guideline implementation strategies have been performed yet. Current evaluations had many methodological defects and only rarely considered all relevant costs and benefits. Recent literature therefore advices that future evaluations should focus on evaluating the implementation of evidence-based guidelines taking all costs into account ${ }^{30}$.

Economic evaluations are a specific form of evaluation research that are focused on making explicit the relationship between the benefits achieved and the resources required to achieve those benefits. Therefore two criteria must be met. First, there needs to be an issue of choice. In implementation research, the choice consists of a comparison of two or more different implementation strategies or the comparison of an implementation strategy with "doing nothing" or "usual healthcare." Second, in economic evaluations, an explicit relationship is made between the inputs (use of people and resources) on the one hand and the related consequences or actual outcomes on the other hand. The use of people and resources is usually expressed in monetary units (euros or dollars), so that they can be considered expenses.

The execution of a cost analysis is the main part of each economic evaluation of an implementation strategy. Within a cost analysis a distinction is made between fixed and variable costs. Fixed costs are costs that show no link to the scale of the actual use of the specific (healthcare) provision while variable costs are dependent on the intensity. Variable costs need to be measured empirically, because they cannot be calculated through a simple division per measuring unit as can be done with fixed costs ${ }^{28}$.

In the economic evaluation of implementation, costs can be subdivided into different phases of the implementation process. Firstly, there are costs related to the task of developing new or optimal care procedures, for example guidelines. These developmental costs (fixed costs) should be part of a cost analysis regarding implementation strategies. Secondly, there are costs associated with organising a specific quality improvement or change strategy. For example, to implement clinical guidelines a strategy to enhance the implementation should be developed, like training outreach visitors to visit primary care physician. Thirdly, there are costs of the actual execution of the quality improvement strategy, like sending out guidelines to GP practices. In addition to the above mentioned cost categories, costs are sometimes associated with a change in healthcare provision as a result of application of an implementation strategy. As a result of the implementation of a clinical guideline, physicians may be able to see patients more frequently or prescriptions are more adequate $^{29}$. Short term effects will not always result in lower cost alternatives, but health care may become more cost effective if the ultimate effects on patients are taken into account ${ }^{31,32}$. 


\section{Aim and relevance of the thesis}

Health care expenditure in the Netherlands has increased for the last 30 years with about $8.5 \%{ }^{33,34}$. The government has developed a restricted policy for health care expenditure to prevent health care becoming too expensive. Drug prescribing is an important contributor to this increase in costs, and these costs are expected to continue to increase structurally in the coming years $^{35}$. The aim of this project was to improve the rationality of prescribing behaviour of physicians in primary and secondary care, and to improve the communication and collaboration between GPs and specialists.

Given the increase in costs in health care and the difficulties in improving the rationality of prescribing, the aim of this thesis was to evaluate different implementation strategies that could improve rational prescribing behaviour of physicians and executing this evaluation extensively by studying the different aspects in an effect evaluation, a process evaluation and economic evaluation.

\section{Accountability concerning the choice of implementation strategies}

Quality improvement strategies have been reported in quite a number of reviews, but there seems to be no magic bullets among the available implementation strategies ${ }^{26,36}$. Clinical guidelines on prescribing may induce small improvements, both in processes and in the

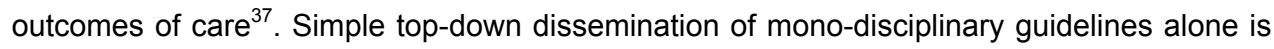
not effective ${ }^{38-41}$. More is needed for changing prescribing behaviour. Characteristics contributing to successful implementation of guidelines are: inclusion of specific recommendations, sufficient supporting evidence, a clear structure and an attractive lay out. Grol et al. extended the number of attributes that might influence the use of guidelines in practice ${ }^{4}$. Their study showed that controversial recommendations, vague and non-specific recommendations, and recommendations that demanded an alteration in existing routines and habits, were less likely to be followed.

Therefore, we chose to put much energy in the development of the multidisciplinary guidelines for professionals in primary and secondary care, in a way in which opinion leaders were involved and the professionals themselves could influence the content of the guidelines. Local consensus and involvement of opinion leaders showed to be effective in improving the adherence to guidelines ${ }^{42,43}$. Based on current expertise with decision support systems in our research group ${ }^{44}$ we additionally chose to develop a Computer Reminder System (CRS) using the multidisciplinary guidelines as input. Computerised reminders have proven to be effective in influencing doctors' behaviour in medication management ${ }^{45-47}$. A computerised system seemed appropriate for the complicated task of generating precise reminders on many drugs related to numerous different diagnoses that occur repeatedly in daily practice. In sum, we decided to evaluate the effects of our guideline implementation in a step-wise build strategy: first evaluating the effects of spreading locally developed guidelines together with opinion leaders, secondly evaluating the effectiveness of additional involvement of colleague members in the region on the adherence to guidelines and finally evaluating the effects of computer reminders on the adherence to locally developed guidelines. To evaluate the potential effects of the computerised reminder system on prescribing behaviour we chose 
for a profound evaluation of this cost consuming quality improvement strategy. We investigated the effect of the computer reminders by means of an effect evaluation, a process evaluation and a cost evaluation.

In the south of the Netherlands, the local insurance company offered a financial incentive to GPs prior to the start of our project with the objective to improve rational prescribing and to lower costs. There was a challenging opportunity to study this intervention in addition to our implementation strategy by including this in our project to influence prescribing behaviour of GPs. The effect evaluation of the financial incentive gave us the opportunity to investigate the influence of a behaviour-independent one-off financial incentive on the volume of drug prescriptions and the quality of prescribing behaviour by analysing if the guidelines were followed.

\section{Research questions}

We addressed the following questions:

a. Does a behaviour-independent financial bonus change the volume of prescribing behaviour of general practitioners in the desired direction?

b. What is the effect of the dissemination of multidisciplinary guidelines on prescribing behaviour, and is this stronger for members of the target group who were involved in the preparation and development of the guidelines?

c. What is the effect of computerised reminders based on the recommendations in the multidisciplinary guidelines on prescribing behaviour of GPs?

d. What are the costs and the effects expressed in costs of a CRS regarding prescribing behaviour differentiated to different phases: development of input (guidelines), development of the CRS, diffusion of the CRS (execution costs), and medication costs (healthcare costs)?

e. How feasible and acceptable was the implementation of the CRS for prescribing behaviour in primary care, how satisfied were the GPs, and what were the barriers and facilitators for working with the CRS?

\section{Outline of the thesis}

Chapter 2 describes the effect evaluation of a financial incentive in the south-east part of the Netherlands. In chapter 3 the research protocol related to the multi-design project in improving prescribing behaviour is presented. Chapter 4 describes the development and the results of the implementation of the multidisciplinary guidelines in an effect evaluation. The development and effects of the Computer Reminder System are presented in an effect evaluation in chapter 5. A cost analysis of the multidisciplinary guidelines and the CRS is described in chapter 6 . Finally, chapter 7 presents a process evaluation of the development and implementation of the clinical guidelines and the CRS. The results of this study are discussed in more detail in chapter 8. This chapter also considers the implications of the encompassing research for daily practice and provides recommendations for further research, in the light of implementation, prescribing and evaluation theories. A summary of the thesis is given in chapter 9 . 


\section{REFERENCES}

1. Burgers J, Grol R, Eccles M, Clinical guidelines as a tool for implementing change in patient care. In: Grol R, Wensing M, Eccles M. Improving Patient Care. The Implementation of Change in Clinical Practice. Oxford: Butterworth-Heinemann 2005:71-92.

2. Field MJ and Lohr KN (1992). Institute of Medicine. Guidelines for Clinical Practice. From Development to Use. Institute of Medicine. Washington, DC: National Academy Press.

3. Hutchinson A and Baker R (1999). Making Use of Guidelines in Clinical Practice. Abingdon: Radcliffe Medical Press.

4. Burgers JS, Grol RP, Zaat JO, Spies TH, van der Bij AK, Mokkink HG. Characteristics of effective clinical guidelines for general practice. Br J Gen Pract. 2003 Jan;53(486):15-9.

5. Fijn R, Brouwers RBJ, de Jong-van den Berg LTW. Cross-sectional pharmacotherapeutic coherence in the Netherlands. Int Pharm Pract 1999; 7: 159-166.

6. Kvamme OJ, Olesen F, Samuelsson M. Improving the interface between primary and secondary care: a statement from the European working party on quality in family practice (EQuiP). Qual Health Care 2001; 10: 33-39.

7. Berendsen AJ, Benneker WH, Schuling J, Rijkers-Koorn N, Slaets JP, Meyboom-de Jong B. Collaboration with general practitioners: preferences of medical specialists-a qualitative study. BMC Health Serv Res. 2006 Dec 4;6:155.

8. Berendsen AJ, Benneker WH, Meyboom-de Jong B, Klazinga NS, Schuling J. Motives and preferences of general practitioners for new collaboration models with medical specialists: a qualitative study. BMC Health Serv Res. 2007 Jan 5;7:4.

9. Crump BJ, Panton R, Drummond MF, Marchment M, Hawkes RA, Transferring the costs of expensive treatments. Guidelines may clarify responsibility for prescribing. BMJ 1995;310:1335.

10. Soumerai SB. Factors influencing prescribing. Aust J Hosp Pharm 1988; 18(suppl): 9-16.

11. Bradley CP. Uncomfortable prescribing decisions: a critical incident study. BMJ 1992; 304: 294296.

12. Drage $M$, Wakeford $R$, Wharton $A$. What do general practitioners think changes their clinical behaviour? Educ Gen Pract 1994; 5:48-53.

13. Allery LA, Owen PA, Robling MR. Why general practitioners and consultants change their clinical practice: a critical incident study. BMJ 1997; 314: 870-874.

14. Hartzema AG, Christensen DB. Non-medical factors associated with the prescribing volume among family practitioners. in an HMO. Med Care 1983; 21: 990-1000.

15. Jaye C, Tilyard M. A qualitative comparative investigation of variation in general practitioners' prescribing patterns. British Journal of General Practice 2002;52, 381-386.

16. Prosser H, Almond S, Walley T. Influences on GPs' decision to prescribe new drugs; the importance of who says what. Family Practice 2003;20(1):61-8.

17. Dobson R. Pharmaceutical industry is main influence in GP prescribing. BMJ 2003;326: 301.

18. Evans J, Lambert T, Goldacre M. GP recruitment and retention: a qualitative analysis of doctors' comments about training for and working in general practice. Occas Pap R Coll Gen Pract. 2002 Feb;(83):iii-vi, 1-33.

19. Muijrers PE, Knottnerus JA, Sijbrandij J, Janknegt R, Grol RP. Pharmacists in primary care. Determinants of the care-providing function of Dutch community pharmacists in primary care. Pharm World Sci. 2004 Oct;26(5):256-62.

20. Jacoby A, Smith M, Eccles M. A qualitative study to explore influences on general practitioners' decisions to prescribe new drugs. Br J Gen Pract. 2003 Feb;53(487):120-5.

21. Armstrong $D$, Reyburn $H$, Jones $R$. A study of general practitioners' reasons for changing their prescribing behaviour. BMJ. 1996 Apr 13;312(7036):949-52.

22. Grol R, Grimshaw J. From best evidence to best practice: effective implementation of change in patients' care. Lancet. 2003 Oct 11;362(9391):1225-30. Review. 
23. Grol $R$ and Wensing $M$. What drives change? Barriers to and incentive for achieving an evidencebased practice. MJA 2004;180:S57-S60.

24. Grimshaw J, Eccles M, Thomas R, MacLennan G, Ramsay C, Fraser C, Vale L. Toward evidencebased quality improvement. Evidence (and its limitations) of the effectiveness of guideline dissemination and implementation strategies 1966-1998. J Gen Intern Med. 2006 Feb;21 Suppl 2:S14-20. Review.

25. Grol R. Development of guidelines for general practice care. $\mathrm{Br} J$ Gen Pract. 1993 Apr;43(369):146-51.

26. Grimshaw JM, Thomas RE, MacLennan G, Fraser C, Ramsay CR, Vale L, Whitty P, Eccles MP, Matowe L, Shirran L, Wensing M, Dijkstra R, Donaldson C. Effectiveness and efficiency of guideline dissemination and implementation strategies. Health Technol Assess. 2004:6:iii-iv, 1-72.

27. Grimshaw JM, Russell IT. Effect of clinical guidelines on medical practice: a systematic review of rigorous evaluations. Lancet 1993;342:1317-22.

28. Severens JL. Value for money of changing healthcare services? Economic evaluation of quality improvement. Qual. Saf. Health Care 2003;12:366-71.

29. Severens JL, Martens JD, Wensing M. Economic evaluation of implementation strategies. In: Grol $\mathrm{R}$, Wensing M, Eccles M. Improving Patient Care. The Implementation of Change in Clinical Practice. Oxford: Butterworth-Heinemann 2005:273-84.

30. Vale L, Thomas R, Maclennan G, Grimshaw J. Systematic review of economic evaluations and cost analyses of guideline implementation strategies. Eur J Health Econ. 2007 Jun;8(2):111-21.

31. Mason J, Eccles M, Freemantle N, Drummond M. A framework for incorporating cost-effectiveness in evidence-based clinical practice guidelines. Health policy 1999;47(1):37-52.

32. Sculpher M. Evaluating the cost-effectiveness of interventions designed to increase the utilization of evidence-based guidelines. Fam Pract 2000;17(31):1s26-31.

33. Centraal Bureau voor de Statistiek. Statistisch jaarboek 2003+2004 (Statistical yearbook 2003+2004). Heerlen: Centraal Bureau voor de Statistiek; 2003+2004.

34. Breekveldt-Postma NS., Zwart-van Rijkom JE, Egberts AC, Leufkens HG, Herings RM. Rising costs of drugs in hospitals in the period 1996-2000 and over the next few years. Nederlands Tijdschrift voor Geneeskunde 2002;46(52):2547-51.

35. Stichting Farmaceutische Kengetallen; Data en Feiten (Foundation for Pharmaceutical Statistics; Data and Facts). The Hague/the Netherlands; 2000-2004. Homepage available at http://www.sfk.nl.

36. Grimshaw J, Eccles M, Tetroe J. Implementing clinical guidelines: current evidence and future implications. J Contin Educ Health Prof. 2004 Fall;24 Suppl 1:S31-7.

37. Grimshaw J, McAuley LM, Bero LA, Grilli R, Oxman AD, Ramsay C et. al. Systematic reviews of the effectiveness of quality improvement strategies and programmes. Qual Saf Health Care. 2003;4:298-303.

38. Kosecoff J, Kanouse DE, Rogers WH, McCloskey L, Winslow CM, Brook RH. Effects of the national Institutes of Health Consensus Development Program on physician practice. JAMA 1987;258:2708-13.

39. Grol R. Implementation of evidence and guidelines in clinical practice: a new field of research? Int J Qual Health Care 2000;6:455-6.

40. Jamtvedt G, Young JM, Kristoffersen DT, Thomson O'Brien MA, Oxman AD. Audit and feedback: effects on professional practice and health care outcomes. Cochrane Database Syst Rev. 2003;3:CD000259.

41. Bero LA, Grilli R, Grimshaw JM, Harvey E, Oxman AD, Thomson MA. Closing the gap between research and practice: an overview of systematic reviews of interventions to promote the implementation of research findings. The Cochrane Effective Practice and Organization of Care Review Group. BMJ 1998;317(7156):465-8. 
42. Greer AL. The state of the art versus the state of the science. Int. J. Technol Assess Health Care 1988; 4:5-26.

43. Grol R. Implementing guidelines in general practice care. Qual Health Care 1992;1:184-91.

44. Bindels R, Hasman A, van Wersch JW, Talmon J, Winkens RA. Evaluation of an automated test ordering and feedback system for general practitioners in daily practice. Int $\mathrm{J}$ Med Inform 2004;73(9-10):705-12.

45. Bennett JW, Glasziou PP. Computerised reminders and feedback in medication management: a systematic review of randomised controlled trials. MJA 2003;178:217-22.

46. Johnston ME, Langton KB, Haynes B, Mathieu A. Effects of computer-based clinical decision support systems on clinician performance and patient outcome: a critical appraisal of research. Ann Intern Med 1994;120:135-42.

47. Hunt DL, Haynes RB, Hanna SE, Smith K. Effects of computer-based clinical decision support systems on physician performance and patient outcomes. JAMA 1998;280:1339-46. 





Published as: JD Martens, MJ Werkhoven, JL Severens. RA Winkens. Effects of a behaviour independent financial incentive on prescribing behaviour of general practitioners. J Eval Clin Pract. 2007 Jun;13(3):369-73. 


\section{ABSTRACT}

\section{Rationale and objectives}

It is difficult to keep control over prescribing behaviour in general practice. The purpose of this study was to assess the initial effects of a behaviour independent financial incentive on the volume of drug prescribing of general practitioners.

\section{Design}

2-Year Controlled Before After study with an intervention region and a concurrent control region.

\section{Setting and participants}

General practitioners in two regions in the Netherlands $(\mathrm{N}=119$ and $\mathrm{N}=118)$.

Intervention

A financial incentive for prescribing according to local guidelines on specific drugs or drug categories. The financial incentive consisted of a non-recurrent, behaviour-independent allowance.

Main outcome measure

Change in the number of prescriptions for 10 targeted drugs or drug groups.

\section{Results}

Significant changes were seen only in three types of antibiotics and in recommended gastric medicines. In almost all cases, effects were temporary.

\section{Conclusion}

Behaviour independent financial incentives can be a help in changing prescription behaviour of GPs, but effects are small-scale and temporary. 


\section{INTRODUCTION}

As is also the case in other European countries, drug-related expenditure has increased every year in the Netherlands by about 7 to 8 percent $^{1}$. Drugs are not always prescribed appropriately: medication may be prescribed unnecessarily and cheaper alternatives are not always considered ${ }^{2}$. The problem can be attributed partially to factors such as the ageing of the population, the popularity of new drugs (which are usually more expensive), the increased awareness of patients, scientific developments and pressure from the industry ${ }^{3,4}$.

Health care provider adherence to a guideline is not a logical consequence of the guideline's dissemination ${ }^{5}$. Many implementation strategies appear to show moderate effects under certain circumstances, but no superior method has been devised ${ }^{6}$. Implementing changes is usually not a single action but involves a well-planned phased process, including a combination of interventions, linked to specific obstacles to change. Thus, all the different approaches for changing clinical practice may be valid and effective, provided that they are adapted to the specific features of the change proposal, the target group, the setting, and the obstacles to change that are encountered. The approach should be tailored to the local circumstances, taking into account any specific potential barriers ${ }^{7-9}$. The influence of guidelines on drug prescribing is often limited, and a clear gap between best-practice based on guidelines and daily practice exists ${ }^{10}$.

A recent study on the adherence of Dutch GPs revealed adherence ranging from 10.5 percent to 99.5 percent $^{11}$. So, although there is still room for improvement, the effects on implementation of practice guidelines is sometimes successful. Examples of implementation strategies include audit systems, feedback, computer reminders and peer reviews ${ }^{12,13}$. These are very time-consuming in development and execution. Financial incentives or bonus systems could also function as an implementation strategy. They are less difficult to execute, and are therefore worth considering as alternatives for the more complex implementation strategies $^{14-17}$.

In a region of a local insurance company, in the south of the Netherlands, a financial incentive was offered to General Practitioners to improve rational prescribing and to lower costs. This incentive gave us the opportunity to investigate the influence of a behaviourindependent financial incentive on the volume of drug prescriptions and the quality of prescribing behaviour by analyzing if the guidelines were followed. We addressed the following question: Does a behaviour-independent financial bonus change the volume of prescription behaviour of general practitioners in the desired direction? 


\section{Methods}

\section{Design}

We performed a controlled before-after study with a concurrent control group. Prescription data from GPs in the intervention region (receiving a financial incentive) were compared with data from GPs in a control region (no financial incentive) (figure 1).

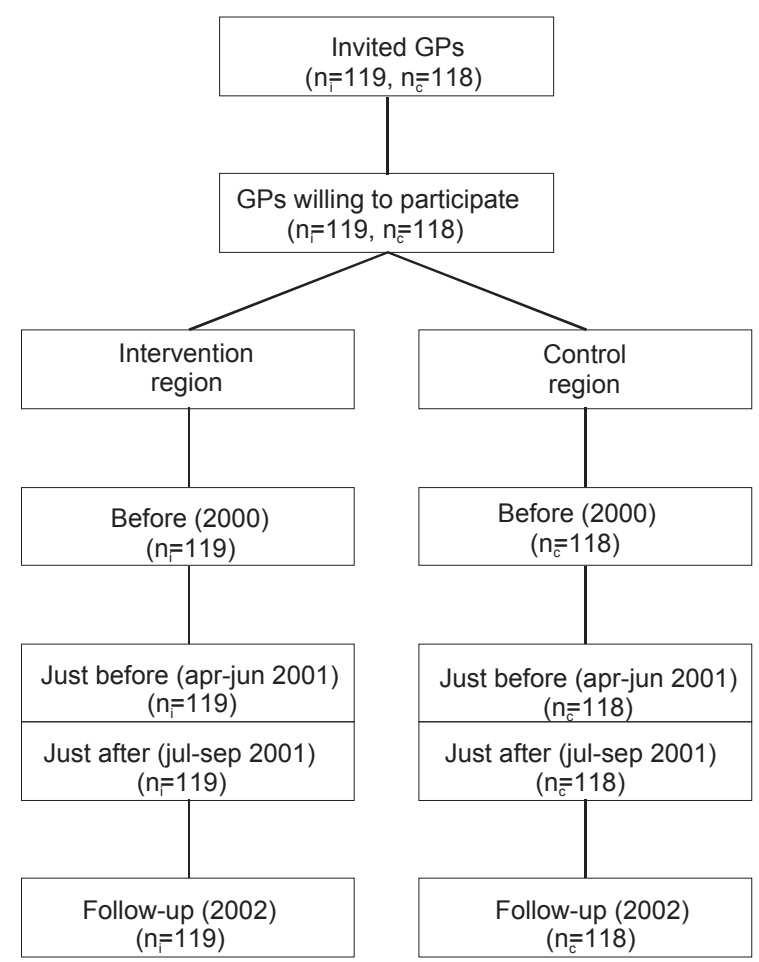

Figure 1: Overview of time and analysis in the project

Nearby 100 percent of the Dutch GPs, being a member of the Dutch Society of General Practitioners (DCGP), receives the national guidelines which are frequently discussed in national and regional Continuing Professional Development (CPD) programs. Therefore it can be assumed that both groups were equally familiar with existing national evidence-based guidelines on antibiotics and gastric drugs and equally exposed to medical education offered nationwide. The intervention group consisted of 119 GPs in a region in the south of the Netherlands. The intervention region was specifically known on overprescription of certain drug categories and new medication. We searched for a control region that was as comparable as possible. A control region with 118 GPs was selected in another part of the country. 
All members of the intervention group agreed to participate in this project and were aware that their behaviour would be evaluated. Only anonymous prescription data were collected retrospectively and therefore GPs in the control group were not informed of the intervention beforehand. The GPs in the control group were not aware of their function as a control group. The contrast between groups was then, receiving the financial incentive and awareness of the performance being checked, versus no awareness whatsoever. So, the Hawthorn effect is on purpose part of the intervention. Inclusion criteria for the GPs were: availability of complete records after April 2000 and GP practices with at least 500 patients.

\section{Intervention}

The financial incentive consisted of a one-off bonus (target payment). The bonus was performance independent, and given to all the GPs. In return to this financial incentive, GPs should adhere to relevant prescription guidelines abstracted in a one-page printed formulary that was developed by a multidisciplinary committee of GPs, pharmacists and representants of the local insurance company. The one-page formulary included recommendations on frequently prescribed drugs and a few expensive new drugs for which a cheaper alternative was available.

The reason for choosing these drugs was that improvement seemed possible and necessary. The formulary was sent to all GPs in the intervention group by post. The GPs agreed beforehand to improve prescribing according to this one-page formulary and to be more critical and efficient in their prescribing on antibiotics and gastric medicine in general. The GPs agreed by means of a democratic majority decision taken at a regional meeting where most of the regional opinion leaders were present.

\section{Data}

Prescription data were obtained from the regional health insurance company. Prescription data were collected retrospectively from each GP every month during the period 2000-2002. The data were selected according to certain volume data for drug prescribing with regard to drugs or groups of specific drugs for which clearly formulated and measurable recommendations are included in the guidelines. The following drugs were selected: 1) chinolones for urinary tract infections (decrease expected), 2) nitrofurantoin as an alternative to chinolones (increase expected), 3) trimethoprim as an alternative to chinolones (increase expected), 4) amoxicillin and clavulanic acid (decrease expected), 5) amoxicillin (decrease expected), 6) doxycyclin for sinusitis (decrease expected), 7) mupirocin for skin infections (decrease expected), 8) recommended gastric drugs (increase expected), 9) other neutrally advised gastric drugs (no significant increase), and 10) newly developed drugs (slight increase expected) (see table 1).

A marked national annual increase of 10.8 percent can be seen in the varied group of newly introduced drugs ${ }^{1}$. Because of the general agreement in the intervention group to reduce the use of these drugs in the GP practices, a less strong increase was expected. 


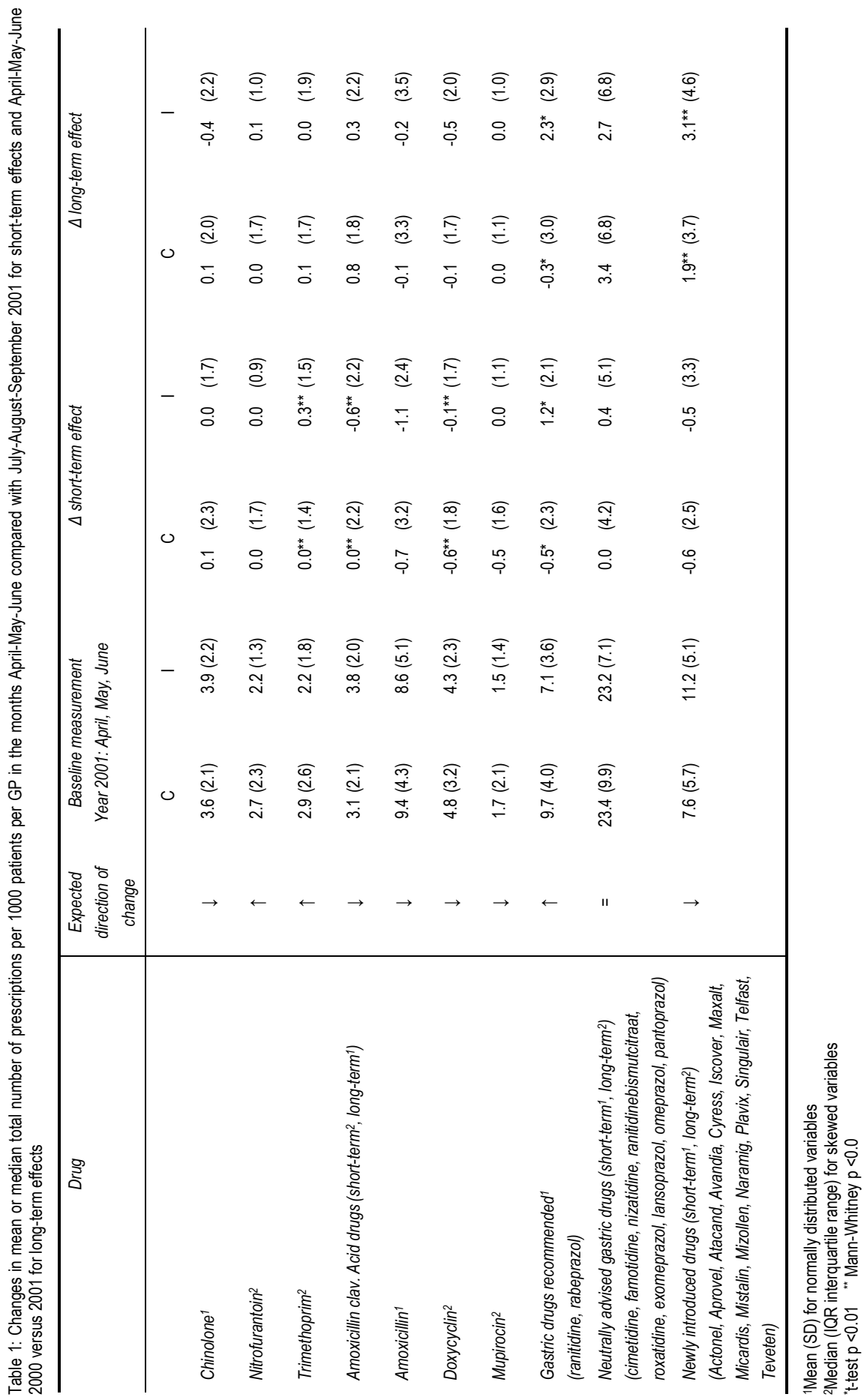




\section{Analysis}

Since practice size may differ, we indexed the prescription data by calculating the number of prescriptions per 1000 patients for the above-mentioned drugs and drug groups, based on the insurance company's data sets. Statistical tests were performed regarding the differences in change between the intervention and control groups. For this purpose, depending on the distribution of data, a t-test for independent samples or a Mann-Whitney test was used. Because of the multiple testing, we set our alpha conservatively at 0.01 .

To evaluate the immediate, short-term effect of the financial incentive, drug prescriptions before the intervention (April, May and June 2001) were compared with drug prescriptions after the start of the intervention (July, August and September 2001). Each period was compared with the same period in the year before the intervention to make sure the results were reliable and could be contributed to the financial incentive and not to seasonal effects. To assess the long-term effects of the intervention, prescription data were also analyzed over the same period in the following year, after the intervention: prescription data from April, May and June 2001 was compared with data from April, May and June 2002.

\section{RESULTS}

There were no differences in age and gender of the GPs between the regions (table 2).

Table 2: Comparison of age and gender of intervention region and control region

\begin{tabular}{l|ll}
\hline & Control group & Intervention group \\
\hline Mean age male GPS & 50.8 & 50.8 \\
Mean age female GPs & 45.1 & 45.5 \\
Mean age total & 49.9 & 49.9 \\
& & \\
Percentage male versus female GPs & $84.7 \%$ & $81.5 \%$ \\
\hline
\end{tabular}

Table 1 represents the mean total number of prescriptions per 1000 patients per GP over the second quarter of 2001 as a baseline measurement. Table 1 represents the absolute changes in the short-term and long- term per 1000 patients per GP. The intervention region showed a notable improvement directly after the financial incentive.

Significant changes in prescription behaviour were seen for three kinds of antibiotics, for recommended gastric medicine and for newly introduced drugs. The other drug groups showed no significant changes. In general, significant changes were temporary and no longer evident one year later.

\section{Antibiotics}

For two specific antibiotics (amoxicillin plus clavulan acid and trimethoprim) we found significant improvement of 17 percent $(0.6)$ in the intervention group compared to 0 percent $(0.0)$ in the control group $(p=0.008)$ and 7 percent $(0.3)$ improvement compared to 0 percent $(0.0 ; p=0.006)$ respectively. For doxycyclin, the control group performed better than the 
intervention group contrary to what we had expected. This improvement, only found in the short-term, was 14 percent $(0.6)$ in the control group compared to 2 percent $(0.1)$ in the intervention group $(p=0.01)$. In the long-term, the intervention group performed better (a decrease of 11 percent (0.5) compared to 3 percent (0.1)). However, this change was not significant. For other antibiotics, no significant effect was seen in the short-term. Effects in the long-term were not found for any of the antibiotics.

\section{Gastric medicines}

For recommended gastric medicines, significant effects in the short and long-term were found. In the short-term, an improvement of 16 percent (1.2) in the intervention group took place, compared to a downswing of 5 percent $(0.5)$ in the control group $(p=0.00)$. An increase of 27 percent (2.3) in the intervention group compared to a decrease of 4 percent $(0.3)$ in the control group was found in the long-term $(p=0.00)$. In the neutral gastric medicine group, we found no significant changes in any part of the analysis.

\section{Newly introduced drugs}

Compared to the control group, the number of prescriptions in the intervention group was higher at the start of the research period. However, the number of prescriptions decreased considerably after August 2001. In this group, we found an increase of 27 percent (3.1) in the intervention group compared to 29 percent (1.9) in the control group. This was only significant in the long-term $(p=0.01)$.

\section{Discussion}

In this study, we found a limited, temporary effect of a one-off behaviour-independent financial bonus on the prescribing behaviour of general practitioners according to existing guidelines. On a few drug indicators (amoxicillin plus clavulan acid, trimethoprim, recommended gastric medicine and newly developed drugs) a significant short-term effect in the expected direction was shown. Only the recommended gastric medicine showed a significant effect in the long-term as well. In the longer term, the modest impact of this financial incentive disappeared. This contradicts existing scientific knowledge that financial incentives may be helpful in changing the prescribing behaviour of GPs ${ }^{17}$. Possibly the recommendations underlying the incentive were not made clear enough to all participating GPs. In our point of view the GPs were not familiar with the intervention and were apparently little motivated to participate. The GPs agreed to participate by means of a democratic majority decision and were not individually approached. The behaviour-independent character was probably too much free of obligations.

Financial incentives represent a non-voluntary strategy to implement change in medical practice, and therefore an additional strategy is needed to affect the motivation of health care professionals $^{18}$. 
The strength of our study lies in the fact that the incentive was not set up as a research project but as a health care initiative and therefore was embedded in real practice. This undoubtedly improves the validity of the results for routine health care.

There are a few uncertainties in our study. Firstly, the data were not deliberately collected for research purpose, but were derived from the insurance company based on claims of all pharmacists in the region. It was assumed that the data were correct. If any of the data were incorrect, it will have been equally distributed over intervention and control group. Secondly, although we used a non-RCT-design in this pragmatic trial, it represented GPs' daily practice in a region as a whole, because all GPs participated in the study and the data stemmed from routine care.

In our study we found an effect of the intervention on prescribing behaviour of GPs. Because of the large amount of patients involved and the magnitude of the prescription data in this kind of research it is practically impossible to focus on outcome effects on individual patient level.

Although effects on patient outcome have not been assessed, we envision that a more consequent adherence to guidelines of GPs has at least no negative effects on the quality of the delivered health care and undoubtedly positive consequences on patient outcome. We did not perform an economic evaluation of this study. Overall, we calculated the financial implications of our study by correcting the economic results with the costs of the intervention. We compared an overview of total expenses of all studied drugs with the costs of the remunerated financial incentive in the region. It seemed that the intervention resulted in a cost-saving of almost $€ 1.8$ million on all drug expenses in the region. On a totally expected budget of $€ 66$ million on pharmacy expenses, this means a saving of 3 percent. The paid-out expenses to all participating GPs were more than $€ 1.4$ million, which results in a cost-saving of about $€ 300,000$ - $€ 400,000$ in one and a half years. Therefore, when is chosen for using a financial incentive as a means of changing prescribing behaviour, the costs of such an incentive need to be investigated thoroughly. Using a financial incentive can be fruitful in the short-term, but only when the proceeds of the incentive outweigh the costs of the incentive or when the quality of care is shown to be positively influenced. In that case, a full economic evaluation might be considered ${ }^{19}$. A major benefit of this group-focused intervention was that the prescribing agreements were unanimously adopted among all GPs and there was widespread public support within the region.

\section{FURTHER RESEARCH}

As expressed in literature on implementation, combined interventions are often more successful than isolated interventions ${ }^{4,5}$. In this case, additional strategies appear to be necessary to improve the long-term outcomes of this strategy ${ }^{18}$. Since guidelines on prescription are meant to both control costs and to control quality of care, it is important to take into account the quality of care when devising a system with financial incentives as a way to implement guidelines. 
Findings in the literature show that financial incentives or bonus systems might be effective as an implementation strategy and are therefore worth considering as alternatives for the more complex implementation strategies ${ }^{14-17}$. Although we already know a certain amount from implementation research regarding the effects of financial incentives aimed at the individual professional, little is known about the effects of group-focused financial incentives. In our view, more research is needed on financial bonus-based interventions in combination with supplementary, more information-based or motivational interventions to improve prescribing behaviour in order to promote the successful implementation of guidelines ${ }^{7-10,14}$.

\section{CONCLUSION}

A financial incentive seems only to have a minor and temporary effect on changes in prescriptions. Nevertheless, the intervention resulted in a cost-saving of about $€ 300,000-$ $€ 400,000$, roughly $€ 3,000$ per GP.

\section{REFERENCES}

1. Stichting Farmaceutische Kengetallen; Data en Feiten (Foundation for Pharmaceutical Statistics; Data and facts). The Hague/The Netherlands; 2000-2004.

2. Prosser $\mathrm{H}$, Almond $\mathrm{S}$, Walley $\mathrm{T}$. Influences on GPs' decision to prescribe new drugs; the importance of who says what. Family Practice 2003; 20 (1): 61-8.

3. Dobson R. Pharmaceutical industry is main influence in GP prescribing. BMJ 2003; 326: 301.

4. Grol, R, Wensing, M, Eccles M (red). (2005). Improving Patient Care; The implementation of change in clinical practice. London: Elsevier Limited.

5. Grimshaw J, McAuley LM, Bero LA, Grilli R, Oxman AD, Ramsay C, Vale L, Zwarenstein M. Systematic reviews of the effectiveness of quality improvement strategies and programmes. Qual Saf Health Care. 2003 Aug;12(4):298-303.

6. Grol R, Grimshaw J, Evidence-based implementation of evidence-based medicine. Joint Commission Journal for Quality Improvement 1999;25:503-13.

7. Lomas J, Anderson GM, Domnick-Pierre K, Vayda E, Enkin MW, Hannah WJ. Do practice guidelines guide practice? The effect of a consensus statement the practice of physicians. N.Engl. Journal Med. 1989;321:1206-11.

8. Kesecoff J, Kanouse D, Rogers W, et al. Effects of the national Institutes of Health Consensus Development Program on physician practice. JAMA 1987; 258: 2708-13.

9. Grol R, Improving the quality of medical care: building bridges among professional pride, payer profit, and patient satisfaction. JAMA. 2001 Nov 28;286(20):2578-85.

10. Grol R, Grimshaw J. From best evidence to best practice: effective implementation of change in patients' care. Lancet. 2003 Oct 11;362(9391):1225-30.

11. Braspenning JCC, Schellevis FG, Grol RPTM (redactie). Tweede Nationale Studie naar ziekten en verrichtingen in de huisartspraktijk. Kwaliteit huisartsenzorg belicht. Utrecht/Nijmegen: NIVEL/WOK, 2004.

12. Winkens RA, Pop P, Bugter-Maessen AM, Grol RP, Kester AD, Beusmans GH, Knottnerus JA. Randomised controlled trial of routine individual feedback to improve rationality and reduce numbers of test requests. Lancet. $1995 \mathrm{Feb}$ 25;345(8948):498-502.

13. Eccles M, Steen N, Grimshaw J, Thomas L, McNamee P, Soutter J, Wilsdon J, Matowe L, Needham G, Gilbert F, Bond S. Effect of audit and feedback, and reminder messages on primarycare radiology referrals: a randomised trial. Lancet. 2001 May 5;357(9266):1406-9. 
14. Hall L, Eccles M. Hall L, Case study of an inter-professional and inter-organisational programm to adapt, implement and evaluate clinical guidelines in secondary care. Clin Perform Qual Health Care. 2000;8(2):72-82.

15. Giuffrida A, Gosden T, Forland F, et al. Target payments in primary care: effects on professional practice and health care outcomes (review). The Cochrane Database of Systematic Reviews 1999, Issue 4. Art. No: CD000531. DOI: 10.1002/14651858.CD000531. 25 October 1999 in Issue 4, 1999.

16. Sonnad, SS, Foreman, SE. An incentive approach to physician implementation of medical practice guidelines, Health Economics 1997;6:467-77.

17. Shortt, SED. General practice fund holding in the United Kingdom. Do not copy. Canadian Family Physicians 2003;49:279-81.

18. Chaix-Couturier C, Durand-Zaleski I, Jolly D, Durieux P. Effects of financial incentives on medical practice: results from a systematic review of the literature and methodological issues. Int $\mathrm{J}$ Qual Health Care. 2000 Apr;12(2):133-42.

19. Severens, JL. Value for money of changing healthcare services? Economic evaluation of quality improvement. Qual Saf Health Care 2003;12:366-71. 



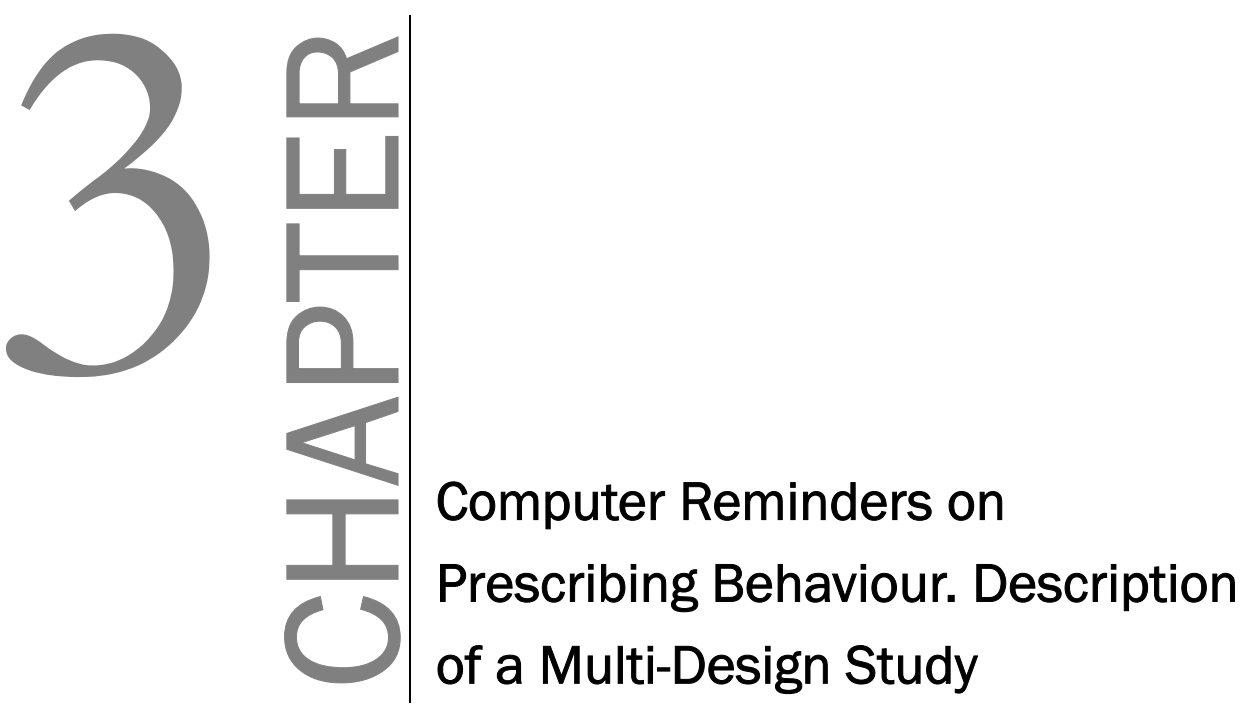

Submitted as: RAG Winkens, JD Martens, ADM Kester, T van der Weijden, JL Severens. Computer reminders on GPS' prescribing behaviour. Description of a multi-design. 


\section{ABSTRACT}

\section{Background}

It is difficult to control and -where necessary- change drug prescribing behaviour of physicians, even when guidelines on prescribing are distributed. The purpose of the study presented in this paper was to assess effects of implementing prescription guidelines through various strategies on drug prescribing behaviour: active dissemination of the guideline, with or without active involvement of the target group in guideline development, and computer reminders.

\section{Methods}

We used a combination of designs - varying from a quasi-experiment to a pragmatic clustered randomised trial following an incomplete block design - to study a pallet of implementation strategies.

Main outcome measures were satisfaction scores, application scores, performance indicators, prescription volumes and costs.

\section{Discussion}

In the preparation and execution of the study protocol we were faced with several drawbacks and practical barriers due to the complexity of the study environment. Nevertheless, all parts of the study, including the pragmatic trial could be implemented and performed as planned. Due to the comprehensive character of the study, focusing on a range of issues, the results will allow a rather complete view on what computer reminders on drug prescribing mean in daily health care. 


\section{INTRODUCTION}

As in probably all western countries healthcare expenditures increase each year in the Netherlands. Drug prescribing is an important, if not major, contributor to this increase in $\operatorname{costs}^{1-3}$. A problem that can (if not should) be tackled is that drugs are not always prescribed efficiently: drugs prescriptions are regularly unnecessary and lower-cost alternatives are not always taken into consideration.

Several factors are considered responsible for this non-rational and sometimes unbridled prescribing of drugs. Part of the increase is attributable to demographic factors (growth and ageing of the population) and to the increasing prevalence of chronic disorders. On the other hand, pressure or marketing activities from pharmaceutical industries are partially responsible too. Moreover, on personal (doctor and patient level) there is a trend towards the prescribing of new but often more expensive drugs and patients' increased awareness ${ }^{4,5}$. Physicians are also known to prescribe more readily as a result of today's high level of workrelated stress and routines ${ }^{6}$.

Clinical guidelines themselves may induce small improvements in the behaviour of clinicians, but in general, simple dissemination of guidelines alone is hardly effective ${ }^{7-12}$. Apparently, more is needed to bring about change. Involving the target group in the development of the guidelines seems an important contributor to actual behaviour change.

Computer reminders appear effective in influencing the drug prescribing behaviour of physicians $^{13}$. A computerised system seems appropriate for the complicated task of generating explicit reminders on specific drugs related to numerous different diagnoses occurring repeatedly in daily practice. Computer reminders seem especially effective when they are developed in collaboration with the users and if they are active close to the time of decision making ${ }^{14,15}$. We therefore developed reactive computerised reminders based on previously set guidelines. We envisioned that this strategy could lead to an improvement in prescribing behaviour of physicians, especially in primary care. However, more is needed for the application in routine daily health care and the broader implementation. Such an intervention will not only have to be effective, but is needs to be accepted by its users and, ideally, it is also attractive from a financial/economic point of view.

To assess all the potential effects of the computer reminders set out in daily practice on the drug prescribing behaviour we conducted a study in general practice. In the preparation of the study several questions and potential pitfalls arose. In previous studies on related topics $^{16,17}$ the project group gained much expertise with the development and conduction of trials with a block design. Additionally, in literature several trials on implementing guidelines have been reported where the block design was successfully applied. Altogether, this led to our choice for the block design as an appropriate and feasible design to perform the study. 
The study was set up to address the following research issues:

- the effects of dissemination of paper guidelines and separately the effects of involving the target group in the preparation and development of the guidelines.

- the effects of computer reminders on prescribing behaviour of certain drug groups.

- the feasibility and acceptability of the implementation of the computer reminders for prescribing behaviour in primary care, including a possible learning curve, including assessment of eventual manipulation of the system.

- the satisfaction with the Computer Reminder System and barriers and facilitators for working with the system.

- a cost evaluation in different phases: development of input (guidelines), development of the Computer Reminder System, diffusion of the system (execution costs), and medication costs (health care costs).

\section{METHODS}

To assess the effects of our intervention, including the possible first effects of distributing the guidelines, we conducted a study consisting of four parts: 1a) a pre-post study with concurrent control group on the effects of distributing guidelines, 1b) a randomised trial on the effects of distributing guidelines among GPs actively involved in guideline development versus GPs not actively involved in guideline development, 2) an effect evaluation, 3) a process evaluation on the Computer Reminder System (CRS) and 4) an extensive costanalysis of implementation of the CRS. All these parts are described consecutively.

The study as a whole was set up as a pragmatic study in routine health care. This improves the external validity of the findings, but increases the risk of situations that cause side effects.

\section{Population description}

For the pre-post study with concurrent control group (study 1a), only GPs who were not already participating in another regional intervention of similar character, were sent the guideline by post and to give comments when necessary ( $n=53$ GPs in a region of 90). No further contact was made. The GPs were not aware of the fact that they were in an evaluation study, because only anonymous volume data were collected from an existing database. Therefore, informed consent was not obtained.

From the GP data base from the insurance companies containing about 700 GPs in the centre and south of the Netherlands, we were able to set up a control group from outside the Maastricht region. The intervention group (53 GPs) in the region Maastricht was compared with a random sample of 54 GPs drawn from the remaining GPs elsewhere (control group). The inclusion criteria were: completeness of the GPs' data (no missing data per GP for more than one year) and at least 500 patients in the GPs' practice.

For the randomised trial, study $1 b$, within the intervention group in study part $1 a(n=53)$ in the intervention region in Maastricht, a random part of 27 GPs were invited for a more intense role in the development procedure and were compared with the remaining 26 GPs 
(control group). The inclusion criteria were: completeness of the GPs' data (no missing data per GP for more than one year) and at least 500 patients in the GPs' practice.

For the effects studies 2 and 4 and the process evaluation (study part 3) 77 GPs in the Maastricht region were invited to participate. There was only one inclusion criterion for inviting GPs: the use of one specific medical information system for GPs, including a computerised prescription module. All GPs were aware of the fact that they were participating in a trial, but they were blind to the fact that they only received a specific subset of all available prescribing reminders and that they were analysed on certain prescribing behaviour as controls.

\section{Description of the intervention}

\section{Guideline Development}

The prescribing guidelines were developed by independent multidisciplinary expert teams that included community pharmacists, specialists, GPs (not involved in the trial) and a hospital pharmacist, and were based on Dutch national guidelines, practical experience and consensus. Previously, guideline topics were chosen by the steering committee, existing of decision-making representatives (pharmacists, GPs, hospital staff and regional insurance company). Clinical importance in primary care (common problems) and expected health gains were the main criteria in prioritisation.

The first multidisciplinary guideline was developed for antibiotics, because non-rational attitudes towards prescriptions and an increase of resistance in micro-organisms have been observed. Over $50 \%$ of the antibiotics prescriptions for respiratory tract problems are not used appropriately ${ }^{18,19}$. Next, guidelines for asthma, COPD and cholesterol have been developed, due to the high prevalence of these diseases in the population. The concepts of the guidelines were distributed among the GPs who were planned to use them and these were invited to return comments when necessary. The guidelines were finalized by presenting the GPs comments to the multidisciplinary expert teams.

\section{Dissemination}

The Integrated Care Unit of the University Hospital of Maastricht provided both the expertise and the facilitating conditions to disseminate the guidelines within the region. All the GPs in the intervention group from the quasi experiment (see below) received the finalized paper guidelines in a ring binder by post. The antibiotics guideline was sent out in 2001 and the asthma, COPD and cholesterol guidelines in 2002.

\section{Active involvement in guideline development}

After the development, we used different methods to validate the conceptual guidelines. For the guideline on antibiotics we visited GPs in the region to get comments on the conceptual guidelines and create involvement. For the guidelines on asthma, COPD and cholesterol, the conceptual guidelines were sent by post to a random sample of GPs within the intervention group; these GPs were asked to comment and encouraged to do so. The guideline 
committee stressed the importance of knowing the GPs' comments, and that the comments would be taken very seriously in finalizing the guideline. Due to the low response rate and based on the expertise of the expert teams, a number of key individual GPs were also contacted in a more active way to generate comments.

\section{System Description}

The next step was the translation of the guidelines into the CRS. The CRS integrates prescribing guidelines into a tool that assists GPs to adhere to the guidelines and therefore to prescribe drugs more rationally. Computer reminder systems can be issued pro-actively and reactively. Pro-active systems give comments or suggestions before prescriptions are chosen. Reactive systems give comments immediately after prescriptions are chosen. We developed a real-time reactive reminder system. The automated feedback system has four parts: a Guideline Editor in which prescription-relevant guidelines were developed using a graphical user interface, a Guideline Knowledge Base that contains these guidelines, a Decision Support System (DSS) that provides reactive support (i.e. reminders), based on the guidelines developed and patient data stored in the GP Information System's database and a research database where -for each prescription- data was stored that was used to analyse the GP's behavioural changes.

\section{The Guideline Knowledge Base}

This data consisted of the patient's age and gender, prescribed drugs, diagnosis-related information and the reminders that were given by the DSS. Figure 1 shows all the parts.



Figure 1: General structure of the CRS

The guidelines were entered into a Guideline Knowledge Base using a Guideline Editor, a graphical knowledge acquisition tool that facilitates the development of prescription guidelines. These guidelines were implemented as IF-THEN rules which, based on patientspecific data, lead to a reactive reminder immediately at the moment that the GP utilized the prescription module and the corresponding guideline was not followed. 


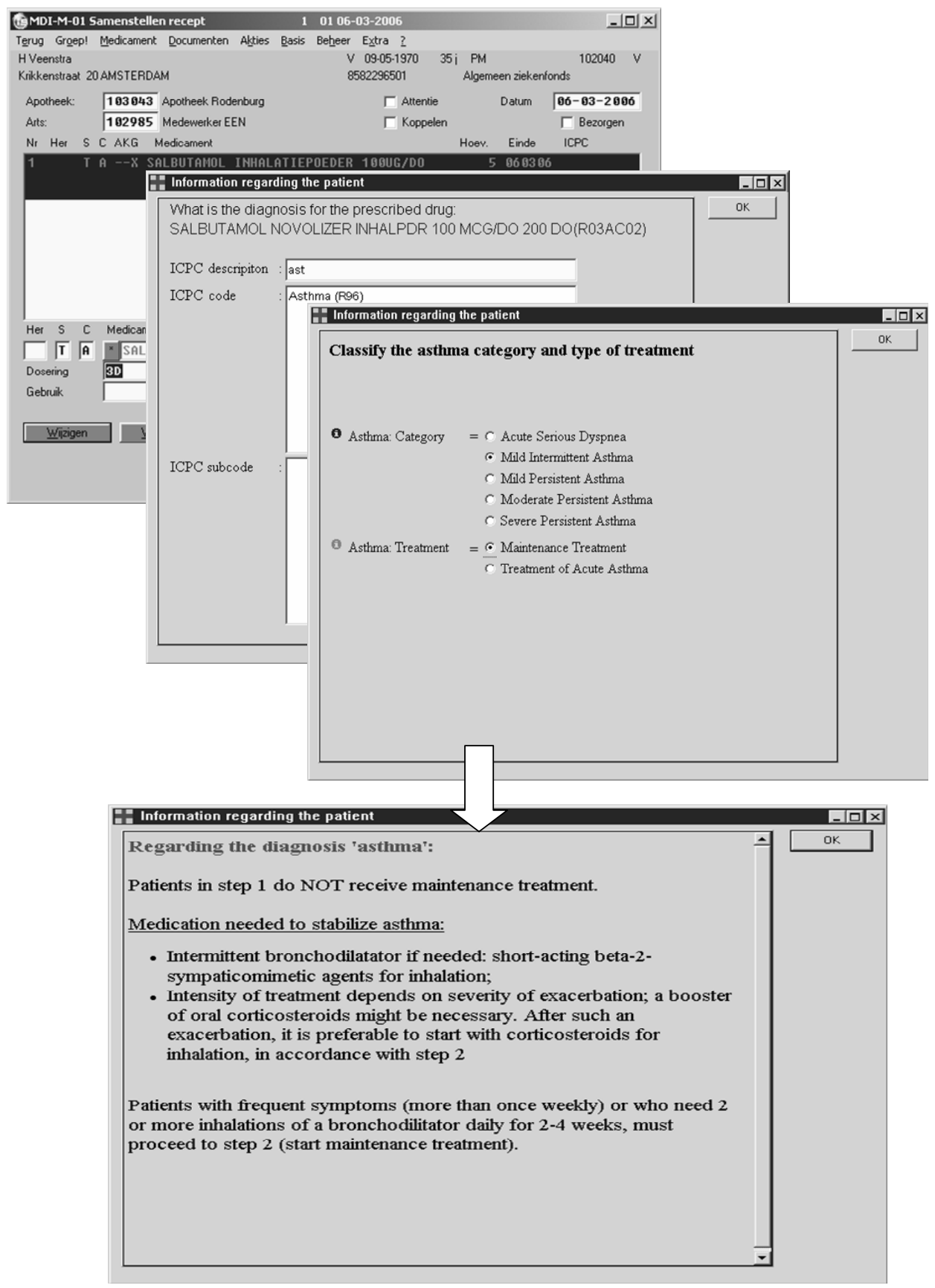

Figure 2: An example of a reminder, given by the DSS (Dutch interface) 
The Decision Support System part of the CRS was implemented on top of the existing GP. Information System that contained general patient data, medications and diagnoses. This system also contained a drug prescribing module where GPs were able to prescribe medications. When the GP prescribed a drug, the DSS was activated by the GP Information System, providing the DSS also with patient-specific information (e.g., age and sex) and the prescribed drug. For all patients with asthma/COPD, cholesterol related disease or infections for which antibiotics were prescribed, the GP was obliged to register a diagnosis in ICPC (International Classification for Primary Care) and diagnosis-related information (e.g., severity of the complaints). Based on the patient's age and sex, prescribed drugs and the above-mentioned diagnosis-related information, the DSS checked whether any of the IFTHEN rules fired. When one or more rules fired (meaning that the corresponding guideline was not followed), a reminder was given.

Figure 2 shows an example of a reminder against asthma medication for mildly intermittent asthma with a maintenance treatment. The nature of the reminders could be more or less persuasive and contained various types of reminders: alternative type of drugs, other doses, alternative drug administration, and specific indication, other duration of prescribing, not to prescribe anything, recommend an alternative (no drug prescription) approach or refer to specialist.

\section{Research data storage}

The DSS also contained a research database where -for each prescription- data was stored that was used to analyze behavioural changes of the GP. This data consisted of the patient's age and sex, prescribed drugs, diagnosis-related information and the reminders that were given by the DSS. Reactive systems give comments after prescriptions are chosen but before they are printed. The real-time automated CRS is a reactive system focusing mainly on primary care, covering a range of prescribing guidelines and containing various types of reminders: alternative type of drug, other doses, alternative drug administration, specific indication, other duration of prescribing, not to prescribe anything or recommend an alternative (no drug prescription) approach. The GPs had to register the ICPC of the prescribing diagnosis in the CRS at the moment of prescribing. The participating GPS received individual (in solo practices) or group (in group practices) instruction when the system was installed in the practice.

\section{Study part 1a}

To assess the possible effect of the dissemination of the guidelines themselves, irrespective of the implementation through the Computer Reminder System, a quasi-experimental study (a pre/post study with a concurrent control group) was executed. The Maastricht region (intervention region, $n=53 \mathrm{GPs}$ ) was compared with a random sample of 54 GPs drawn from the remaining GPs (control group). The asthma/COPD and cholesterol guidelines were disseminated in March 2002. Baseline data were gathered one year before, and follow-up measurements were made after the dissemination of each guideline. A pre trial power- 
calculation was not performed; the study concerned a pragmatic trial, where evaluation was planned alongside an intervention being executed anyway.

\section{Data collection and analysis}

Data were supplied by the two largest insurance companies in the region, which implied that about 70 percent of the total population in the region was covered. Prescription data were gathered retrospectively per GP per month during the period 2001-2004. Expected directions of change have been defined based on the detailed recommendations contained in the guidelines, in combination with estimates based on the expertise of the initially involved key regional representatives. The effect of the strategy and the differences in the pre/post changes between groups were tested with unpaired Student's t-tests and Mann Whitney tests using SPSS 12.0.1 software. Short-term effects were calculated one year after the dissemination of the guidelines, and long-term effects two years after. We set our alpha conservatively at 0.01 because of multiple testing.

\section{Study part $1 b$}

Parallel to study part 1a, a Randomised Controlled Trial (RCT) was carried out within the intervention region in Maastricht, among the intervention group in study part $1(n=53)$. A random part of 27 GPs were invited for a more intense role in the development procedure and were compared with 26 GPs in the control group.

\section{Data collection and analysis}

Except for the fact that only a control group in Maastricht is used and no control group elsewhere, the data and the data collection are similar as described for study 1a.

\section{Study part 2}

\section{Design}

A clustered Randomised Controlled Trial (RCT) with an unbalanced block design was conducted. Antibiotics, asthma/COPD and cholesterol-lowering prescriptions were chosen as topics because these are frequently prescribed while improvement was desired and seemed possible. Randomisation took place on practice level into 2 blocks. As the study was meant to improve the prescribing on several drug groups, it can be imagined that some drug groups are related, sometimes very closely. For example, blood pressure lowering drugs are frequently combined with statines. Such combinations may lead to bias when these two drug groups are not combined together in one intervention. Because of expected interactions between the reminders on antibiotics and asthma/COPD these reminders were clustered in the same block. The other block consisted of reminders about cholesterol-lowering drugs.

For the trial, GPs were split up into two groups. Each group received only some of the reminders, to enable the GPs to function as controls for each other. One group received reminders on cholesterol lowering drugs, the other group on antibiotics, asthma and COPD drugs. The reminders that should have been popping up in the control group were also 
registered in the research database. This allowed us to measure behaviour in both groups (figure 3).

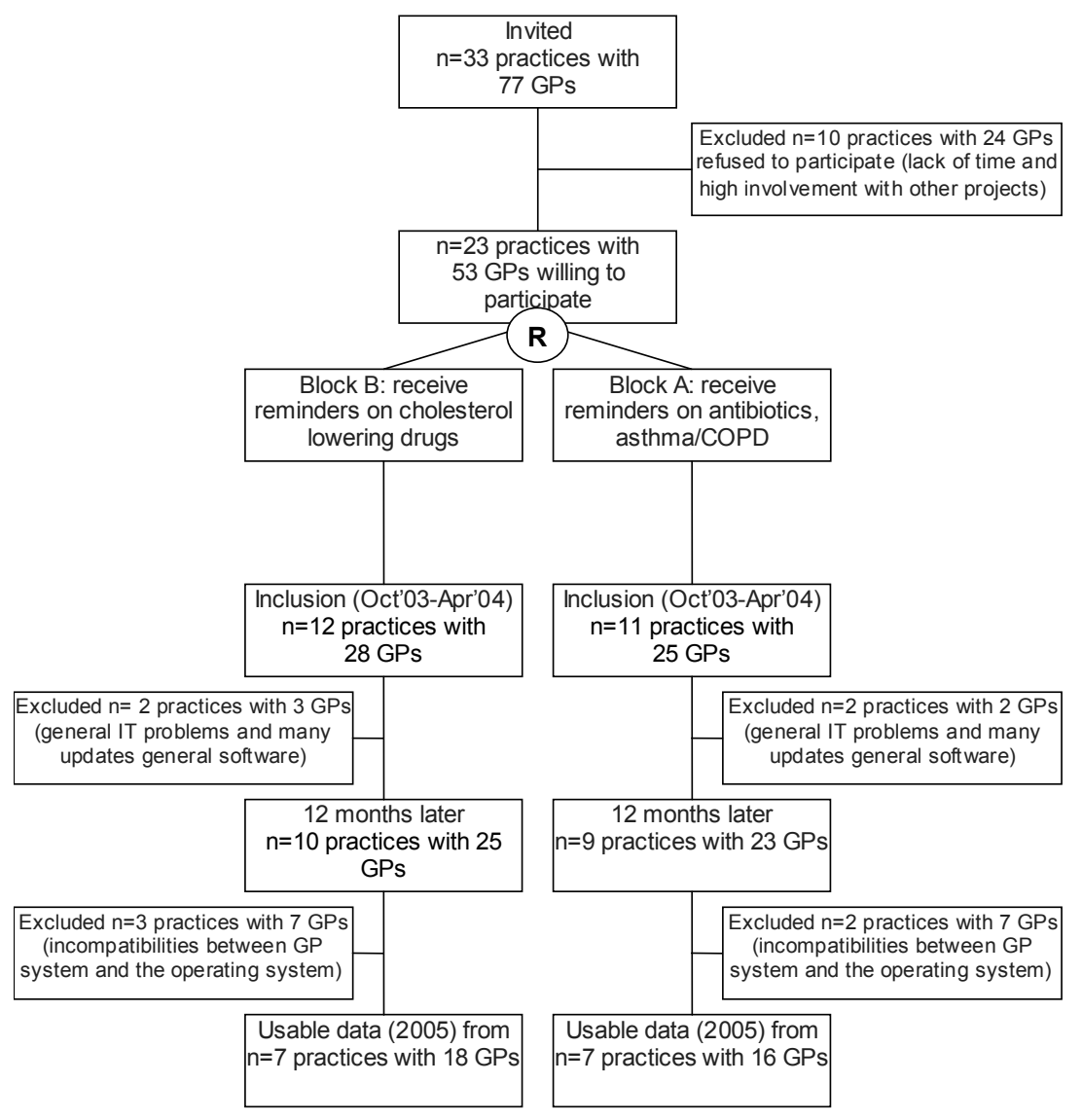

Figure 3: Flowchart overview of data inclusion (practices and GPs) and useable datasets in the project

\section{Outcome measures}

We used prescriptions according to the guideline recommendation as a percentage of total prescriptions (of the drug category involved) for the same diagnosis and absolute number of prescriptions for a specific diagnosis per GP per 1,000 patients. Prescribing indicators are expected to play a key role in evaluating strategies aimed at optimising care ${ }^{20,21}$. Measuring the quality of prescribing by means of intermediate measures such as process indicators, instead of outcome indicators, demands that the process indicators are valid ${ }^{22}$. Because the GPs had to register the prescribing diagnosis and disease related information at the moment 
of prescribing, it was possible to develop specific disease and drug-oriented prescribing indicators for which knowledge of the diagnosis and disease characteristics was necessary.

In this study, process indicators were developed based on recommendations in the guidelines on antibiotics, asthma, COPD and cholesterol-lowering drugs. The process indicators were formulated as far as possible as disease-oriented indicators or at least as drug-oriented indicators according to Haaijer-Ruskamp et al. Drug-oriented indicators include information on drugs and drug characteristics alone. On the other hand, disease-oriented indicators include information on drugs linked to the diagnosis or health problem.

An example of a drug-oriented prescribing indicator is:

$$
\frac{N_{\text {prescriptions }} \text { small spectrum antibiotics per } G P}{N_{\text {all prescriptions }} \text { antibiotics per } G P}
$$

An example of a disease-oriented prescribing indicator is:

$$
\frac{N_{\text {prescriptions }} \text { first choice asthma medication per } G P^{*}}{N_{\text {all prescriptions }} \text { total asthma medication per } G P^{*}}
$$

\footnotetext{
* medication for intermittent and mildy persistent asthma with acute complaints among patients $>7$ years
}

The guidelines contained both general and specific prescribing recommendations. Where reminders were given to quit prescribing of certain drugs for a specific diagnosis at all, the numerator should become zero and an indicator could not be calculated. In other cases specific information about disease related complaints were missing for constructing the prescribing indicator. In these cases change was only measured by volume data. An example of a volume measure is: 'Total number of prescriptions for doxycyclin and amoxicillin for acute bronchitis per GP and per 1,000 enlisted patients.

In addition to the specific prescription indicators, volume measures and sum scores we calculated an overall score for two large drug groups: all antibiotics which were expected to decline and all inhaled corticosteroids for asthma which were expected to increase.

\section{Data collection}

GPs were not motivated to register diagnoses as ICPC codes while using the drugprescribing module, without being exposed to the reminder function. Therefore, no baseline data could be collected. During the intervention data were collected about number, type and doses of prescribed drugs, patient diagnosis or severity of complaints, patient age and gender. The dataset contained prescription data for a 12-month period. 
Seasonal trends in the frequency of prescribing antibiotics and asthma-related drugs influence the comparability of prescribing data on different moments during the intervention period. Therefore, data covering one entire year were selected after starting the intervention.

\section{Analysis}

To detect a clinically relevant difference between the groups a standardised mean difference (SMD) of 0.2 on the primary outcome measure with alpha 0.05 and beta $0.2,12$ GPs were needed per group. The drop-out rate was estimated to be $20 \%$. To evaluate the effects of the randomisation, descriptive statistics were used to compare the baseline characteristics of the two groups (table 1).

Table 1: Age and gender of GPs in block A and block B with confidence intervals

\begin{tabular}{|c|c|c|}
\hline & Block A (antibiotics, asthma, COPD) & Block B (cholesterol) \\
\hline Mean age GPs & $49(\mathrm{Cl} 46-52)$ & $45(\mathrm{Cl} 41-49)$ \\
\hline Male GPs of total & $83 \%(\mathrm{Cl} 64 \%-100 \%)$ & $69 \%(\mathrm{Cl} 43 \%-94 \%)^{*}$ \\
\hline Group practice & $89 \%(\mathrm{Cl} 73 \%-100 \%)$ & $94 \%(\mathrm{Cl} 80 \%-100 \%)$ \\
\hline Mean practice size per GP & $1510(\mathrm{Cl} 1180-1840)$ & $1986(\mathrm{Cl} 1600-2373)$ \\
\hline
\end{tabular}

* significant difference: $p<0.05$

Weighted means were calculated in order to weigh each GP depending on the amount of prescriptions and the amount of enlisted patients. Confidence Intervals $(\mathrm{Cl})$ were calculated for all the indicators in block $A$ and $B$. The weighted means were tested with Mann Whitney tests. Because of the high frequency of non-normal distribution, bias-corrected accelerated bootstrap intervals were calculated in STATA ${ }^{23}$. The unit of analysis was the individual GP. Subsequently, the subgroups were analysed for each type of guideline recommendation:

- Sum scores for all guideline recommendations denouncing certain drugs.

- Sum scores for all guideline recommendations promoting first choice drugs.

\section{Study part 3}

This process evaluation was carried out as a prospective process evaluation among the 53 GPs in the south of the Netherlands who participated in the CRS trial (described in study part 2). Both quantitative and qualitative methods were applied when seeking answers to the research questions. The actions taken by the GPs working with the CRS were described through quantitative analyses of data stored in the system. Furthermore, a questionnaire was sent to the GPs with questions about technical problems and satisfaction. Also, in-depth interviews were held with a selection of the participating GPs, the project manager and the technical consultant to analyse the barriers and facilitators in a more qualitative manner. For the process evaluation, data were collected on the following outcome measures. 


\section{Objective measures}

Number of GPs who had the CRS installed and started working with the CRS (research database); number of GPs who had quit working with the CRS within one year (research database); number of reminders per GP per month per 1,000 patients (research database).

\section{Subjective measures}

GPs' user satisfaction (questionnaire): 1) GPs' experience with the technical performance of CRS (stability, speed, possibilities to manipulate the CRS), 2) GPs' experience with the content of the reminder text (content, length), and 3) GPs' experience with user friendliness and CRS layout. Barriers and facilitators to implementing and using the CRS as perceived by the different stakeholders (GPs, specialists, project leader, IT consultants) from the interviews.

\section{Data collection}

This took place from three different sources:

a. The CRS contained a research database where -for each prescription- data was stored for the purpose of analysing the type of reminders that popped up. The period from which prescription data were obtained from the research database varied depending on each GP's starting time and contained prescription data for a 12-month period. Due to seasonal influences and the comparability of the data we selected data for one year after the start of the intervention. To evaluate the learning curves, the mean number of reminders for antibiotics, asthma, COPD and cholesterol lowering drugs per month were expressed in figures with 95\% Confidence Intervals. Because of frequently evident nonnormal distributions, these and other confidence intervals were calculated as biascorrected accelerated bootstrap intervals (STATA 8.2). The trend in reminders was illustrated with linear regression lines. The effect of the strategy and the differences between the groups were tested on individual regression slopes with student's t-tests using SPSS 12.0.1 software. The unit of analysis was the individual GP.

b. About half way through the intervention year, each practice was visited by a project team member (one not known to them). The GPs were encouraged to speak freely in their response. A satisfaction questionnaire was used to explore the GPs' experiences with and opinion on the feasibility of the CRS. By means of consensus, the GPs in each practice gave one vote for each item. The quantitative data were analysed by descriptive statistics, with special attention being paid to inter-practice variation using SPSS 12.0.1 software.

c. Qualitative data were gathered among a purposely selected sample of the GPs, 2 project leaders, and one technical consultant, who were key-role players in implementing the CRS. The GPs were selected in such a way that there was a representative mix of GPS from the scale very satisfied with the CRS to not satisfied at all with the CRS (drop outs). One of the project members was instructed to perform in-depth semi-structured interviews. Each interview was audio taped, and the GPs' opinions were extracted from the text analyses performed by two other project members. 


\section{Study part 4}

\section{Design}

The design and part of the data of the previously mentioned clustered randomised trial was used for cost assessment of the effects of the computer reminders. The intervention period covered a 12-month period where prescription data of the GPs were registered. Subject of analyses was the individual GP and the prescription costs for antibiotics, and drugs for asthma and COPD, and hypercholesterolemia.

\section{Costs and measuring instruments}

We calculated total costs of the quality improvement strategy during the different phases of the implementation: 1) the development costs of the guidelines, 2) the development costs of the CRS, 3) the execution of the CRS (diffusion), and 4) the health care costs (medication costs). The implementation costs were spread over 4.3 years in which the guidelines were developed, the CRS was developed and finally the CRS was implemented in the practices. Calculations were executed on basis of retrospective data from available sources like minutes, reports, and agenda information and literature resources partly estimates and partly calculated based on the research database of the CRS.

\section{Costs of the quality improvement strategy}

Development of multidisciplinary guidelines. Preparing time and attending time for each member of the multidisciplinary guideline committee (GPs, specialists, pharmacists and insurance company) to the meetings was analysed besides salary of the project team members, project manager and secretarial time spent to organize and attend the meetings. Finally, costs of the validation of the guidelines were taken into account.

\section{Development of the Computer Reminder System}

Most important costs in this phase were costs generated by the companies that were involved in the development of the CRS and salary costs of the IT project team worker and support by the secretary.

\section{Execution of the CRS in the GP practices (diffusion)}

Most important costs were salary costs of the project worker who implemented the CRS in the GP practices and expenses of the IT consultancy company who actually installed the CRS.

Health care costs and savings of the quality improvement strategy; medication costs Individual cost prices of all drugs on which the CRS interacted were calculated on drug code level. Cost prices per drug were received via the Scientific Institute of Dutch Pharmacists, a Dutch national authority on pharmaceutical sciences. The data contained information on drug name, name of the producer, different subcoding systems, dose information, substance and cost price per entity and per pill. We selected a subset of only primary care drugs. Because it 
was impossible to report all costs of each individual drug we evaluated in detail we have chosen to show the drug costs expressed as a range of cost prices covered by a particular drug code. In the Netherlands, medication costs are reimbursed according to cost standards and standard prices. Costs were determined by assessing the mean difference in the drugcosts of GPs in block A and GPs in block B. We calculated medication costs in both block groups using existing standard tariffs per individual drug per tablet. In addition we used the analysis module of the CRS to investigate the differences in costs between the intervention and control group. Based on the advices of the guidelines the medication costs were calculated on individual drug or drug group level.

\section{Analysis}

We tested differences between the characteristics of intervention and control groups by means of student t-tests, using SPSS version 12.0.1 (SPSS inc, Chicago, III, USA). Costs of the development, the execution and health care costs were calculated per phase of the implementation strategy per GP per year. To evaluate health care costs (medication costs) the mean costs and $95 \%$ confidence intervals were calculated for all volumes of antibiotics, asthma, COPD and cholesterol lowering drugs in both blocks of the block design. For each block a sum score was constructed based on summarizing the individual health care costs (block A: antibiotics, asthma and COPD and block B: cholesterol lowering drugs). We distinguished two different kind of advises: advises NOT to prescribe a particular drug and advises to prescribe first choice drugs. Our design consisted of two blocks of GPs (block A: antibiotics, asthma, COPD and block B: cholesterol lowering drugs). So, for each block two sum scores were constructed. Because of frequently evident non-normal distributions, the differences between the GP groups were tested using a bootstrap procedure with 999 repetitions, using $R$. Using the same bootstrap technique, bias corrected accelerated confidence intervals were calculated for within-group means as well as for the difference between groups. Although randomisation was at the level of practices, data were analysed at the more meaningful level of GPs. The CRS is aimed at each individual GP and not systematically embedded in group discussions. Although it is possible that a GP discusses the content of the reminders with a colleague within a group practice and that this may have a reinforcing effect, we did not expect this to happen. During analysis, the intra-cluster correlation coefficient appeared to be low and therefore a multilevel analysis was not performed. Finally implementation costs were calculated on the individual GP level and expressed as development costs per GP, execution costs per GP, and health care costs per GP.

\section{Discussion}

The overall conclusion regarding the set up of our study following the described design is that such a design is comprehensive, but appropriate and feasible. As such, the design and preparations may be interesting for others. The combination of several study parts in one large study enabled us to assess effects of the intervention on a broad range and on various 
aspects. The effects of implementing guidelines through a reminder system is more than just the technical applicability or the effects on doctor's behaviour. The total set of data therefore allows us to get a comprehensive view of the overall effects in daily health care. In our view, this adds to existing knowledge.

Concerning the design of our study, the following needs to be considered:

- The prominent intervention in this study was the Computer Reminder System. This system was actually developed on the basis of previously set guidelines. As these guidelines were distributed among all regional GPs before the CRS was developed, the guidelines themselves could already have been active and could have (presumably at best small) effects on prescribing behaviour. This underlines the relevance of the analyses of the different steps in the implementation process as performed in our study.

- The study as a whole was set up as a pragmatic study in routine health care. This improves the external validity of the findings, but increases the risk of situations that cause side effects.

- To assess the net effects of the Computer Reminder System on drug prescribing of GPs we conducted an experiment. In the preparation of the study we were faced with several issues that influenced the choice of the design of the trial. In trials on interventions meant to change (any) behaviour of professionals there is always a certain risk that more than the intervention itself influences the behaviour. One important aspect in this perspective is the so called Hawthorne effect, meaning that people tend to change their behaviour in some way as soon as they know that their behaviour is monitored. Unfortunately, it cannot be predicted if, to what extent and in what direction, the Hawthorne effect exactly works. At best, the Hawthorne effect should be monitored. This however, is difficult and therefore, most researcher try to eliminate influence of the Hawthorne effect as much as possible. One way to do this, is to expose all participants to the Hawthorne effect, so that differences between both groups found in the analyses cannot be attributed to a Hawthorne effect. A clustered randomised controlled trial (RCT) with a block design was considered the best solution for the Hawthorne effect.

- Also, prescription data often show a highly skewed distribution of prescribing patterns. The solution was to combine related drug groups as much as possible, causing unbalanced blocks of the intervention.

Judging on the features of the different trial designs, the block design is the only design that deals with the Hawthorne effect. In a block design, the experiment is distributed in such a way that the Hawthorne effect equally occurs in all study arms, since both act as intervention group and control group. Consequently, the Hawthorne effect has no influence on the difference in effects between the intervention group and the control group. As already confirmed from other studies, the block design is probably the most suitable design to correct for a possible Hawthorne effect.

A drawback of a block design is that the intervention is split into two pieces. This is a special burden on the significance of potential effects. In some situations like ours, this could be an extra burden. 
In presumably most studies on behaviour change of professionals and their use of health care resources (think of test use, prescribing, referrals to other professionals, hospital admission etc.) there is always a chance of confounding. In daily health care, professionals may interact irrespective of their participation in one arm of a trial, resources may be combined can not be divided and separated from each other etcetera. A practical drawback in our study was the possible contamination by inter-drug relations, inter-doctor collaboration and drug group meetings. Contamination of effects through inter-drug relations can be reduced by a distribution of items over the two study groups, not combining drugs with interdrug relations in one arm. In our study, we achieved this by combining reminders on antibiotics with those on astma/COPD drugs. We consider confounding and contamination a more serious threat than a misbalance in the distribution of the intervention over the study arms.

An important drawback of the data we used, especially of the data from the health insurance companies, was that on these general and specific prescription data no data on patient outcome are available. Therefore, a complete and in-depth cost effect study could not be performed. In our study we would otherwise have had a unique opportunity to assess the full range cost effects of an implementation strategy in its different steps and phase ${ }^{24}$. This is very rarely reported in literature ${ }^{25}$.

\section{CONCLUSION}

In addition to previous studies on computer reminders on drug prescribing, our study adds the comprehensiveness of providing data on a broad range of relevant aspects. The conduction of such a comprehensive study appeared feasible even in potentially unstable daily health care conditions, despite the various drawback and practical barriers that researcher may be confronted with.

\section{REFERENCES}

1. CBS. Statistisch jaarboek 2003 (Statistical yearbook 2003), vol. 96. Heerlen; 2003.

2. Stichting Farmaceutische Kengetallen; Data en Feiten (Foundation for Pharmaceutical Statistics; Data and facts). The Hague/the Netherlands; 2000-2004.

3. Breekveldt-Postma NS, Zwart-van Rijkom JE, Egberts AC, Leufkens HG, Herings RM. Rising costs of drugs in hospitals in the period 1996-2000 and over the next few years (in Dutch). Ned Tijdschr Geneeskd. 2002; 146:2547-51.

4. Dobson R. Pharmaceutical industry is main influence in GP prescribing. BMJ 2003; 326: 301.

5. Prosser $\mathrm{H}$, Almond $\mathrm{S}$, Walley $\mathrm{T}$. Influences on GPs' decision to prescribe new drugs; the importance of who says what. Fam Pract 2003; 20: 61-8.

6. Evans J, Lambert T, Goldacre M. GP recruitment and retention: a qualitative analysis of doctors' comments about training for and working in general practice. Occas Pap R Coll Gen Pract. 2002; 83: 1-33.

7. Grimshaw J, McAuley LM, Bero LA, Grilli R, Oxman AD, Ramsay C et. al. Systematic reviews of the effectiveness of quality improvement strategies and programmes. Qual Saf Health Care. 2003;4:298-303. 
8. Kosecoff J, Kanouse DE, Rogers WH, McCloskey L, Winslow CM, Brook RH. Effects of the national Institutes of Health Consensus Development Program on physician practice. JAMA 1987; 258: 2708-13.

9. Grimshaw J, Eccles M, Tetroe J. Implementing clinical guidelines: current evidence and future implications. J Contin Educ Health Prof. 2004 Suppl 1:S31-7.

10. Grol R. Implementation of evidence and guidelines in clinical practice: a new field of research? Int J Qual Health Care 2000;6:455-56.

11. Jamtvedt G, Young JM, Kristoffersen DT, Thomson O'Brien MA, Oxman AD. Audit and feedback: effects on professional practice and health care outcomes. Cochrane Database Syst Rev. 2003;(3):CD000259.

12. Bero LA, Grilli R, Grimshaw JM, Harvey E, Oxman AD, Thomson MA. Closing the gap between research and practice: an overview of systematic reviews of interventions to promote the implementation of research findings. The Cochrane Effective Practice and Organization of Care Review Group. BMJ 1998;317:465-68.

13. Bennett JW, Glasziou PP. Computerised reminders and feedback in medication management: a systematic review of randomised controlled trials. MJA 2003;178:217-22.

14. Johnston ME, Langton KB, Haynes B, Mathieu A. Effects of computer-based clinical decision support systems on clinician performance and patient outcome: a critical appraisal of research. Ann Intern Med 1994; 120: 135-42.

15. Hunt DL, Haynes RB, Hanna SE, Smith K. Effects of computer-based clinical decision support systems on physician performance and patient outcomes. JAMA 1998; 280: 1339-46.

16. Winkens RAG Pop P, Bugter-Maessen AM, Grol RP, Kester AD, Beusmans GH et. al. Randomised controlled trial of routine individual feedback to improve rationality and reduce numbers of test requests. Lancet. 1995;345:498-502.

17. Verstappen WHJM, van der Weijden T, ter Riet G, Grimshaw J, Winkens RAG, Grol RPTM. Block design allowed for control of the Hawthorne effect in a randomised controlled trial of test ordering. J Clin Epidemiol 2004; 57: 1119-23.

18. Wise R, Haut T, Cars O. Antimicrobial resistance: is a major threat to public health. BMJ 1998; 317: 609-10.

19. Worrall G, Young B, Knight V. Inappropriate use of antibiotics for acute respiratory tract infections in a rural emergency department. Can J Rural Med. 2005;10:86-8.

20. Pringle M, Wilson T, Grol R. Measuring 'goodness' in individuals and healthcare systems. BMJ 2002;325: 704-7.

21. Nadzam DM. Development of medication-use indicators by the Joint Commission on Accreditation of Healthcare Organizations. Am J Hosp Pharm 1991; 48: 1925-30.

22. Haaijer-Ruskamp FM, Andersen M, Van der Stichele R. Prescribing Quality indicators. In: Hartzema AG, Porta M, Tilson HH. Pharmaco-epidemiology (4th edition 2005.

23. Efron B and Tibshirani RJ. An introduction to the bootstrap. New York: Chapman and Hall 1993.

24. Severens JL. Value for money of changing health care services? Economic evaluation of quality improvement. Qual Safe Health Care 2003; 12: 366-71.

25. Hoomans T, Evers SMAA, Ament A, Hubben M, Van der Weijden T, Grimshaw J, Severens JL. Methodological quality of economic evaluations of guideline dissemination and implementation strategies: systematic review of empirical studies. Value Health 2007. In press. 


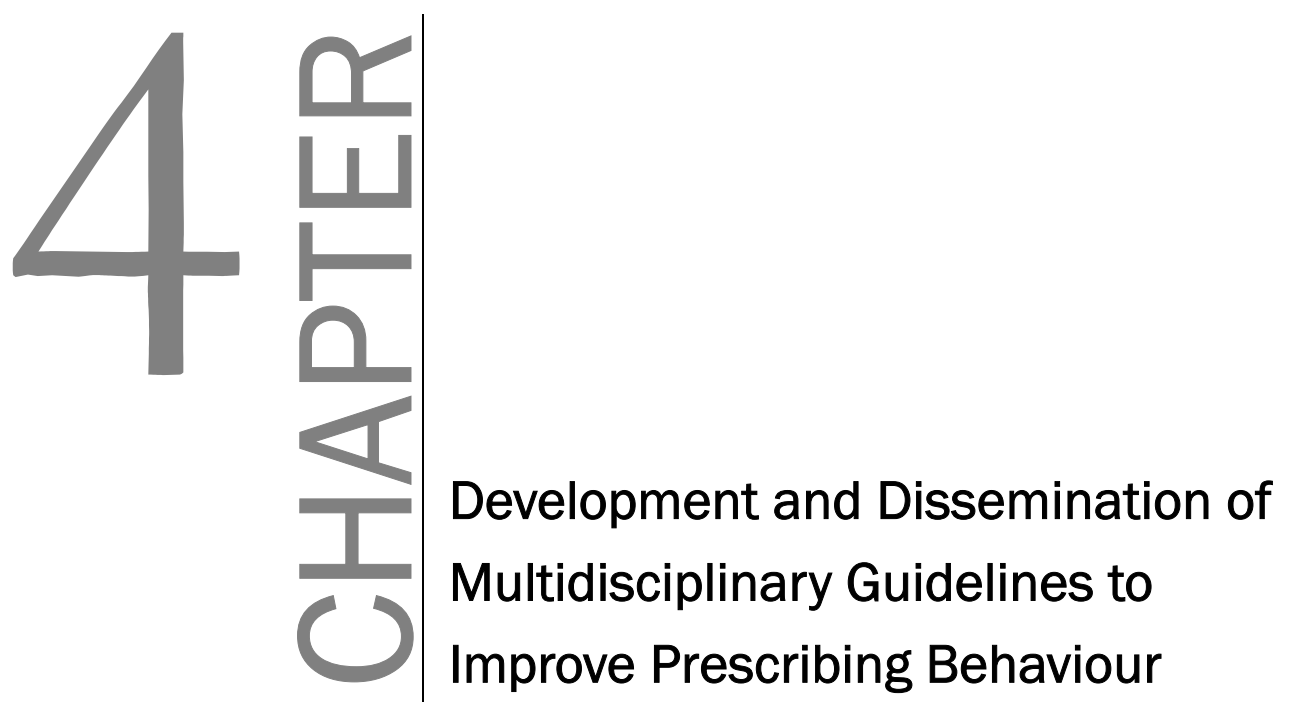

Published as: JD Martens, RA Winkens, $T$ van der Weijden, DP de Bruijn, $\mathrm{JL}$ Severens. Does a joint development and dissemination of multidisciplinary guidelines improve prescribing behaviour: a pre/post study with concurrent control group and a randomised trial. BMC Health Serv Res. 2006 Nov 2;6:145. 


\section{ABSTRACT}

\section{Background}

It is difficult to keep control over prescribing behaviour in general practices. The purpose of this study was to assess the effects of a dissemination strategy of multidisciplinary guidelines on the volume of drug prescribing.

\section{Methods}

The study included two designs, a quasi-experimental pre/post study with concurrent control group and a random sample of GPs within the intervention group. The intervention area with 53 GPs was compared with a control group of 54 randomly selected GPs in the south and centre of the Netherlands. Additionally, a randomisation was executed in the intervention group to create two arms with 27 GPs who were more intensively involved in the development of the guideline and 26 GPs in the control group.

A multidisciplinary committee developed prescription guidelines. Subsequently these guidelines were disseminated to all GPs in the intervention region. Additional effects were studied in the subgroup trial in which GPs were invited to be more intensively involved in the guideline development procedure. The guidelines contained 14 recommendations on antibiotics, asthma/COPD drugs and cholesterol drugs.

The main outcome measures were prescription data of a three-year period (one year before and 2 years after guideline dissemination) and proportion of change according to recommendations.

\section{Results}

Significant short-term improvements were seen for one recommendation: mupirocin. Long-term changes were found for cholesterol drug prescriptions. No additional changes were seen for the randomised controlled study in the subgroup. GPs did not take up the invitation for involvement.

\section{Conclusions}

Disseminating multidisciplinary guidelines that were developed within a region, has no clear effect on prescribing behaviour even though GPs and specialists were involved more intensively in their development. Apparently, more effort is needed to bring about change. 


\section{INTRODUCTION}

Health care expenditure in the Netherlands increases each year, as it does in other European countries. Drug prescribing is an important contributor to this increase in costs, and these costs are expected to continue to increase relevantly in the coming years ${ }^{1-3}$. Medication is not always prescribed effectively: drugs may be prescribed unnecessarily and lower-cost alternatives are not always taken into consideration. The problem can be attributed to demographic factors (growth and ageing of the population), the trend towards new but usually more expensive drugs, patients' increased awareness, pressure from the industry, and last but not least the differences in prescribing practices between primary and secondary care oriented physicians ${ }^{4,5}$. Physicians are also known to prescribe more easily as a result of today's high level of work-related stress and routines ${ }^{6}$.

Clinical guidelines may induce small improvements, both in processes and in the outcomes of care $^{7}$. Simple top-down dissemination of mono-disciplinary guidelines alone is not effective ${ }^{8-12}$. To bring about change, a more powerful strategy could be multidisciplinary guidelines and probably even more so if key regional representatives from primary and secondary care are involved in the development. Implementation experts indicate that multistage involvement in the development of a guideline can be a positive contributor to effective implementation of guidelines ${ }^{13,14}$. If national guidelines are involved, adjusting them to the local situation and to specified needs experienced in the target group increases commitment $^{15,16}$. We have therefore adopted an intensive guideline development procedure, involving local representatives of the relevant medical disciplines ${ }^{17,18}$. The intensity is related to the time and energy that was put into the strategy of guideline development to create support among GPs. We set up a study in which we assessed the effects of our intensive multistage guideline development. We hypothesised that this strategy could lead to a modest but relevant change of volumes of prescriptions in the desired direction. As we used two comparisons, we were able to study the effects of dissemination separately from the effects of involving the target group in the preparation and development of the guidelines.

\section{Methods}

\section{Design and population}

A quasi-experimental study (a pre/post study with a concurrent control group) was executed (figure 1). Since we had an enormous amount of data from the insurance companies at our disposal (about 700 GPs in the centre and south of the Netherlands), it was practically impossible to include them all. The Maastricht region (intervention region, $n=53$ GPs) was compared with a random sample of 54 GPs drawn from the remaining GPs (control group). First, however, a randomised controlled trial (RCT) was carried out within the intervention group; 27 GPs were invited for a more intense role in the development procedure and were compared with 26 GPs in a corresponding control group. The inclusion criteria were: 
completeness of the GPs' data (no missing data per GP for more than one year) and at least 500 patients in the GPs' practice. As the two groups in the RCT turned out to be comparable, we executed the second comparison: we compared the entire Maastricht region with an external control group, selected at random from all the available data. A pre trial powercalculation was not performed; the study concerned a pragmatic trial, where evaluation was planned alongside an intervention being executed anyway. For this study, only GPs who were not already participating in another regional intervention of similar character, were sent the guideline by post and invited to give comments ( $n=53$ GPs). The GPs in both designs were not aware of the fact that they were in an evaluation study, because only anonymous volume data were collected from an existing database. There was therefore no need for GPs or patients to give informed consent. The asthma/COPD and cholesterol guidelines were disseminated in March 2002. Baseline data were gathered one year before, and follow-up measurements were made one and two years after the dissemination of each guideline.

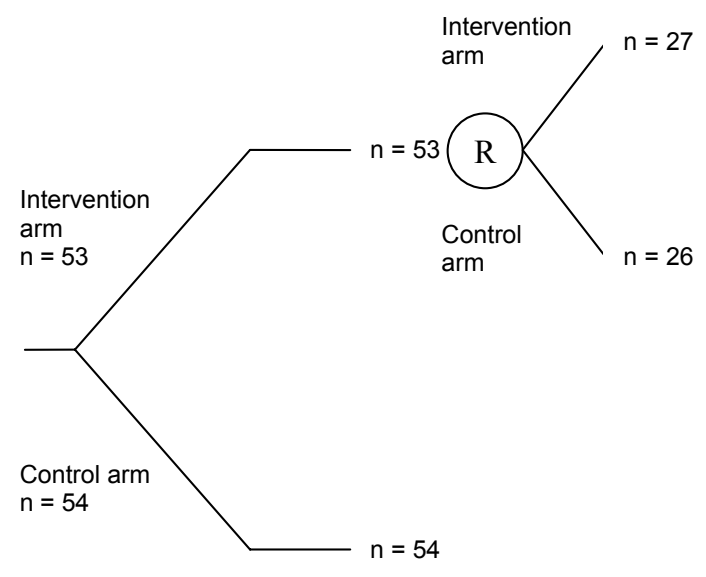

Figure 1: Flowchart of research population and randomised trial in subgroup

\section{Strategy}

The guideline topics were chosen by the steering committee, existing of decision-making representatives (pharmacists, GPs, hospital staff and regional insurance company). Clinical importance in primary care (common problems) and expected health gains were the main criteria in prioritisation. The first multidisciplinary guideline was developed for antibiotics, because non-rational attitudes towards prescriptions and an increase of resistance in microorganisms have been observed. Over $50 \%$ of the antibiotics prescriptions for respiratory tract problems are not used appropriately ${ }^{19,20}$. Guidelines for asthma, COPD and cholesterol have also been developed, due to the high prevalence of these diseases in the population and the corresponding high $\operatorname{costs}^{21}$. The guidelines were actually developed by independent multidisciplinary expert teams that included community pharmacists, specialists, GPs and a 
hospital pharmacist, and were based on Dutch national guidelines, practical experience and consensus. The participating GPs were not involved in the trial.

After the development, we used different methods to validate the conceptual guidelines. For the guideline on antibiotics we started with visiting PTAMs in the region to get comments on the conceptual guidelines and create involvement. For the guidelines on asthma, COPD and cholesterol, the conceptual guidelines were sent by post to a random sample of GPs within the intervention group, and those GPs were asked to comment and encouraged to do so. The guideline committee stressed the importance of knowing the GPs' comments, and that the comments would be taken very seriously in finalising the guideline. Due to the low response rate and based on the expertise of the expert teams, a number of key individual GPs were also contacted in a more active way to generate comments. The guidelines were finalised by presenting the GPs comments to the multidisciplinary expert teams. The Integrated Care Unit of the University Hospital of Maastricht provided both the expertise and the facilitating conditions to disseminate the guidelines within the region. All the GPs in the intervention group received the finalised paper guidelines in a ring binder by post. The antibiotics guideline was sent out in 2001 and the asthma, COPD and cholesterol guidelines were forwarded in 2002.

\section{Data collection and analysis}

Data were supplied by the two largest insurance companies in the region, which implied that about 70 percent of the total population in the region was covered. Prescription data were gathered retrospectively per GP per month during the period 2001-2004. Expected directions of change have been defined based on the detailed recommendations contained in the guidelines, in combination with estimates based on the expertise of the initially involved key regional representatives. The drugs that were selected and the desired directions of change are listed in tables 1 and 2 , in the first and second columns.

The effect of the strategy and the differences in the pre/post changes between groups were tested with unpaired Student's t-tests and Mann Whitney tests using SPSS 12.0.1 software. Short-term effects were calculated one year after the dissemination of the guidelines, and long-term effects two years after. We set our alpha conservatively at 0.01 because of the multiple testing.

\section{RESULTS}

As far as we can ascertain, the GPs in the two groups did not differ on the main characteristics. The mean age of male GPs in the intervention group was 50.0 years and 53.3 in the control group. The mean age of the female GPs in the intervention group was 48.8 years and 45.5 in the control group. Overall, the percentage of male GPs was only slightly different in both groups: in the intervention group, $85 \%(45)$ of the GPs were male, as compared with $76 \%(41)$ in the control group. 


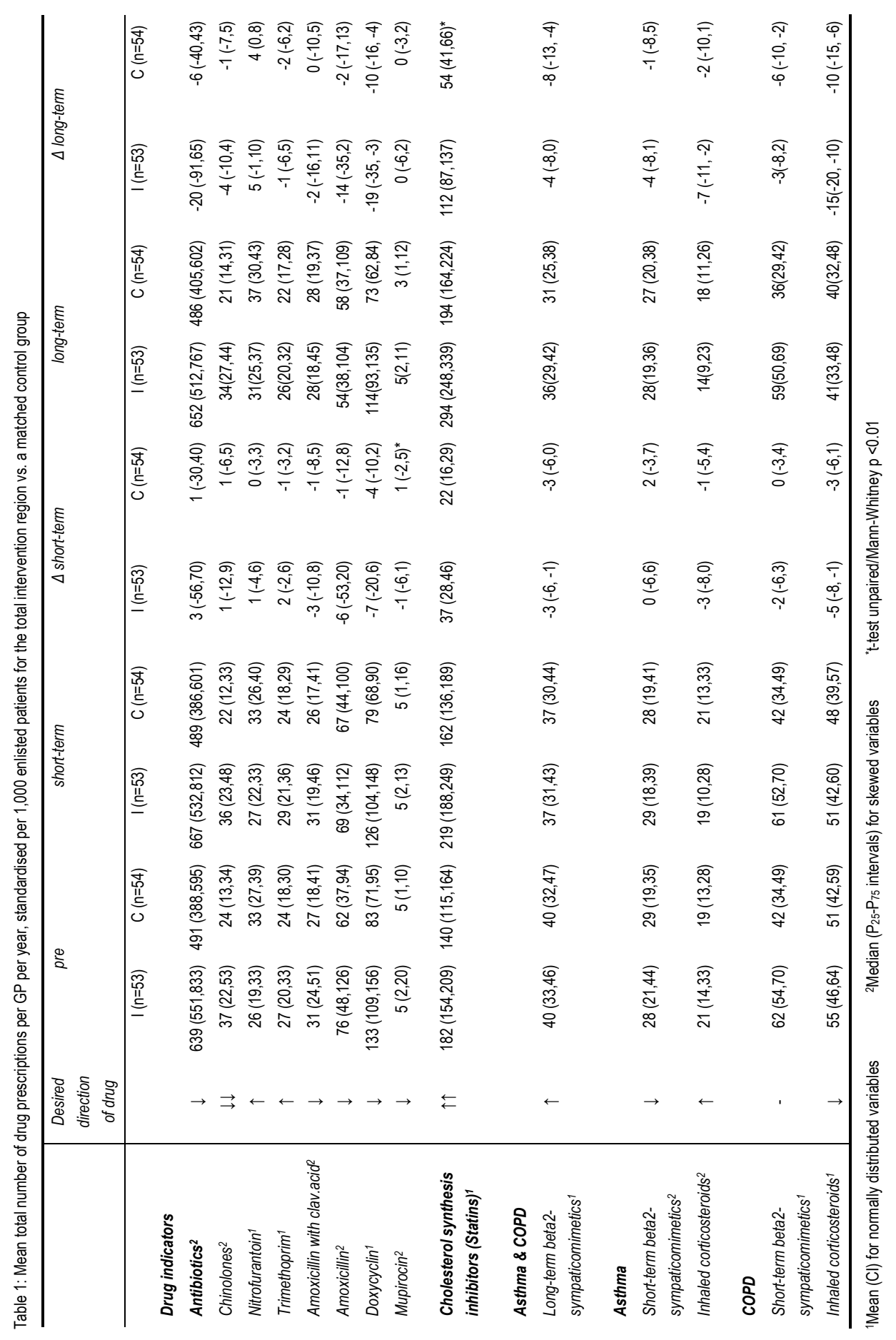




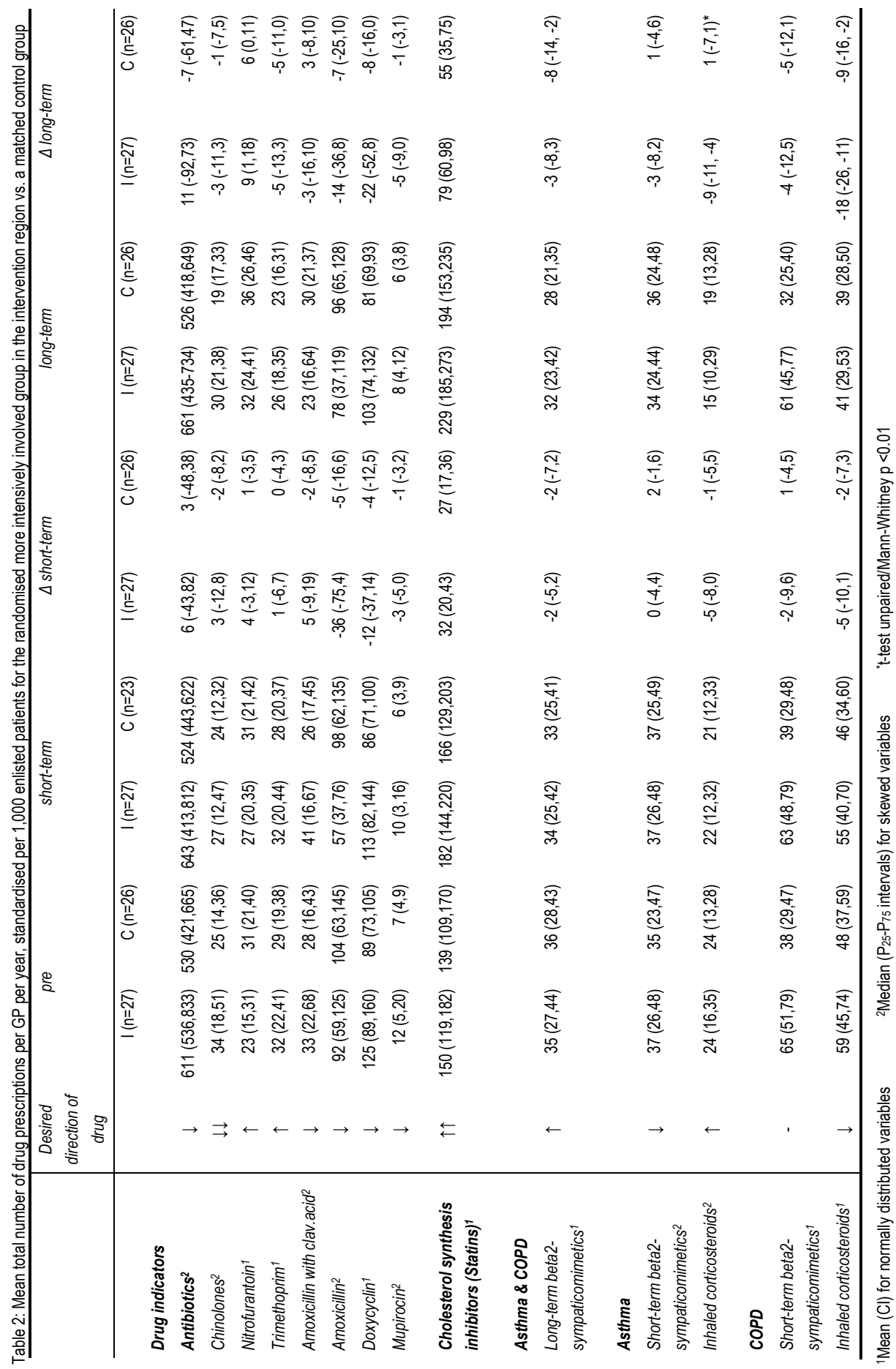


Table 1 presents the mean total number of drug prescriptions per GP per year, standardised per 1,000 enlisted patients over a baseline measurement (2001 or 2002), the short-term effects (one year) and long-term effects (two years). Table 1 also presents the absolute changes in the short term and long term per 1,000 enlisted patients per GP. Table 2 presents the same data for the random sample of GPs who were invited for a more intense role in the development procedure. Less than $10 \%$ of the GPs that were invited to play a greater role actually commented on the conceptual guidelines. The exact number varied according to the specific guideline. Most of the comments did not relate to content, but rather concerned questions about the development procedure.

For the guideline dissemination (quasi experiment), results show that a significant change in the desired direction was found for one specific antibiotic (mupirocin): a reduction of one prescription per 1,000 patients compared to an increase of one $(p=0.0014)$ in the short term. No significant effect was seen for other antibiotics, either in the short term or the long term. For cholesterol, significant long-term effects were found; an increase of 112 prescriptions per 1,000 patients in the intervention group compared to an increase of 54 in the control group $(p<0.0001)$. No significant effect was seen in the short term or long term for any asthma and COPD drugs. For antibiotics and cholesterol, no additional effects were found in the randomised study of GPs with a greater involvement (table 2). For asthma and COPD drugs, significant changes were found in the control group instead of the intervention group. Instead of the desired increase, we found a decrease of 9 prescriptions per 1,000 patients in the intervention group compared with a decrease of one prescription in the control group for inhaled corticosteroids for asthma $(p=0.0099)$.

\section{Discussion}

We found no clear impact of disseminating the rigorously developed multidisciplinary guidelines on the prescribing performance of GPs. A significant effect was found for two drugs: mupirocin and cholesterol lowering drugs. The change in mupirocin however does not seem very relevant, because it is rarely prescribed and by and large prescribed for minor ailments. The long-term effect for cholesterol lowering drugs is interesting. The standard deviation of prescribing drugs per GP turned out to be unexpectedly large. Although no significant effects were seen for the other drugs, only small changes can be seen on other indicators. The invitation for GPs to be involved in the development procedure caused no desirable effects in the subgroup.

There are some issues for consideration. First, although unlikely the quasi-experimental design cannot guarantee that the observed changes are the result of the strategy. It is possible that the effects found were caused by coincidence or by an unknown non-specific factor. Although the intervention group in both designs seems to be higher in volumes of prescription at baseline, both groups seem comparable in the exposure to quality improvement strategies that have been performed otherwise in the region. A second issue for consideration is the pragmatic base of the trial in which two regions were compared. This has caused a restriction in the number of GPs in the trial. We were not in the position to 
improve this. Together with the relatively high variation among the primary variable (volumes of prescription per GP per 1,000 patients per year) the power of the study was negatively influenced. Another power calculation executed after ending the study, based on the large standard deviations and the number of GPs, showed that this resulted in a power of $40 \%$. In this study only large differences could be detected.

We found a few significant results, although the significant effect of mupirocin is not so interesting because mupirocin is rarely prescribed and the disease is a minor ailment. Given the fact that this study was no selected sample and the participating GPs were a fine representation for the Dutch GPs other results are not expected in larger trials. Besides, when evaluating this intervention in an economic study we wonder if the changes in prescribing behaviour are in balance to such huge efforts made in investment and implementation costs.

Only volume data of prescriptions were used in this initial stage of the study. These figures are therefore not linked to any diagnosis. However, some drugs are prescribed for several different medical problems, while the guideline may contain opposing prescription recommendations. For example, amoxicillin is recommended for the treatment of bronchitis and otitis media acuta, whereas amoxicillin is discouraged in cases of acute cystitis. On the one hand, for statin use, there is a situation of overuse for patients with low risk on cardiovascular disease; on the other hand, there is a situation of underuse for high-risk patients like diabetes patients ${ }^{21}$. It is therefore possible that the results are somewhat underestimated in the sense that possible results were kept hidden. Additional information about diagnosis and cholesterol rates would be needed to make a more precise analysis.

A strong aspect of our study is that long-term effects were measured. For statinprescription, the initial non-significant effect appeared to be significant at the long run. A positive factor that may have contributed to an increased willingness to follow the cholesterol medication guideline is that our strategy concerns guidelines that have been formulated by representatives from all disciplines and was intended to improve prescription behaviour in both primary care physicians ánd medical specialists.

Overall, the implementation strategy only generated limited results. Implementation experts indicate that if guidelines are developed by the clinicians who are to use them this will be a positive contributor to the effect of guidelines. Achieving consensus on draft guidelines and creating a sense of 'ownership' through a process of development on several levels (central, local and individual) is essential for successful implementation of guidelines $^{22,23}$. We have paid specific attention to this aspect, firstly by involving representatives from all disciplines in the development of the guidelines. The term intensity is therefore related to the time and energy that was put into the guideline development strategy to create support among GPs. Secondly, we also focused specifically on the doctors' acceptance of the guidelines by including them in the validation procedure. It is not clear why the GPs did not respond to the invitation for comment. Possibly, we were successful in choosing opinion leaders to such extent that GPs did not see the need to comment on guidelines that were prepared by GPs they trusted. A second explanation lies in the assumption that the invitation by mail did not work: only a few GPs responded to the 
invitation to comment on the guideline. GPs might have had comments but did not think this would have any impact in the final guideline. In short, we did not succeed in getting GPs involved locally in the validation procedure. Apparently this way of getting GPs involved is not appropriate and possibly explains why the effect was only limited.

To create involvement in the validation procedure we searched for a successful method to achieve this. During the validation of the antibiotics guideline we started with visiting PTAMs in the region to get comments on the conceptual guidelines and create involvement. This turned out to be very time consuming and caused much delay in the dissemination of the final guideline. Therefore, during the validation of the asthma and the COPD guideline we chose for a less labour-intensive method by asking GPs to comment by mail. After finishing the analyses for this study, we subsequently started (not included in the data of the manuscript) with inviting GPs to feedback meetings. The results of this method were more convincing. We highly recommend the feedback meetings to be an effective method to create involvement among GPs during the validation procedure.

To obtain a more solid or extensive effect, an additional implementation strategy is desired. Feedback and reminders could be an necessary strategy to change GPs behaviour $^{24-26}$. For example, a computerised decision support system could give feedback to a doctor as soon as the prescription behaviour differs from the behaviour recommended in the guideline. As long as the doctor does not deviate from the guideline, the system will not interfere with the primary care physicians' information system, and the doctor giving the prescription will not be interrupted by the feedback system.

We did not perform an economic evaluation by relating the (change in) costs of prescription to the costs of the interventions (guideline development and dissemination) ${ }^{27,28}$. If we were to choose to compare the total expenses of the intensive development procedure of all guidelines with the cost savings, we would expect all the findings to be negative, because the strategy was time and energy consuming and its impact was only moderate.

Before aiming to intensify the development procedure of guidelines, the costs and savings of such a strategy need to be investigated thoroughly and executed when the proceeds of the intervention outweighs the costs of $\mathrm{it}^{29,30}$.

\section{CONCLUSION}

Disseminating multidisciplinary guidelines that were developed within a region, has no clear effect on prescribing behaviour even though GPs and specialists were involved more intensively in their development. Apparently, more effort is needed to bring about change. 


\section{REFERENCES}

1. Centraal Bureau voor de Statistiek. Statistisch jaarboek 2003 (Statistical yearbook 2003), vol. 96. Heerlen: Centraal Bureau voor de Statistiek; 2003.

2. Stichting Farmaceutische Kengetallen; Data en Feiten (Foundation for Pharmaceutical Statistics; Data and facts). The Hague/the Netherlands; 2000-2004.

3. Breekveldt-Postma NS, Zwart-van Rijkom JE, Egberts AC, Leufkens HG, Herings RM. Rising costs of drugs in hospitals in the period 1996-2000 and over the next few years (Article in Dutch). Ned Tijdschr Geneeskd. 2002 Dec 28;146(52):2547-51. Erratum in: Ned Tijdschr Geneeskd. 2003 Dec 27;247(52):2612. Ned Tijdschr Geneeskd. 2003 Jan 25;147(4):184.

4. Dobson R. Pharmaceutical industry is main influence in GP prescribing. BMJ 2003; 326: 301.

5. Prosser $\mathrm{H}$, Almond $\mathrm{S}$, Walley $\mathrm{T}$. Influences on GPs' decision to prescribe new drugs; the importance of who says what. Family Practice 2003; 20 (1): 61-8.

6. Evans J, Lambert T, Goldacre M. GP recruitment and retention: a qualitative analysis of doctors' comments about training for and working in general practice. Occas Pap R Coll Gen Pract. 2002 Feb;(83):iii-vi, 1-33.

7. Grimshaw J, McAuley LM, Bero LA, Grilli R, Oxman AD, Ramsay C, Vale L, Zwarenstein. Systematic reviews of the effectiveness of quality improvement strategies and programmes. Qual Saf Health Care. 2003 Aug;12(4):298-303.

8. Kosecoff J, Kanouse DE, Rogers WH, McCloskey L, Winslow CM, Brook RH. Effects of the national Institutes of Health Consensus Development Program on physician practice. JAMA 1987; 258: 2708-13.

9. Grimshaw J, Eccles M, Tetroe J. Implementing clinical guidelines: current evidence and future implications. J Contin Educ Health Prof. 2004 Fall;24 Suppl 1:S31-7.

10. Grol R. Implementation of evidence and guidelines in clinical practice: a new field of research? Int J Qual Health Care 2000 Dec;12(6):455-56.

11. Jamtvedt G, Young JM, Kristoffersen DT, Thomson O'Brien MA, Oxman AD. Audit and feedback: effects on professional practice and health care outcomes. Cochrane Database Syst Rev. 2003;(3):CD000259.

12. Bero LA, Grilli R, Grimshaw JM, Harvey E, Oxman AD, Thomson MA. Closing the gap between research and practice: an overview of systematic reviews of interventions to promote the implementation of research findings. The Cochrane Effective Practice and Organization of Care Review Group. BMJ 1998 Aug 15;317(7156):465-68.

13. Grol R. Development of guidelines for general practice care. $\mathrm{Br} J$ Gen Pract. 1993 Apr;43(369):146-51.

14. Grol, R, Wensing, M, Eccles M (red). Improving Patient Care; The implementation of change in clinical practice. London: Elsevier Limited, 2005.

15. Pagliari C, Grimshaw J, Eccles M. The potential influence of small group processes on guideline development. J Eval Clin Pract. 2001 May;7(2):165-73.

16. Hutchinson A, Mclntosh A, Cox S, Gilbert C. Towards efficient guidelines: how to monitor guideline use in primary care. Health Technol Assess. 2003;7(18):iii, 1-97.

17. NHS Centre for Reviews and Dissemination. Getting evidence into practice. Eff Health Care 1999;5(1):1-16

18. Grol R. Personal paper. Beliefs and evidence in changing clinical practice. BMJ 1997 Aug 16;315 (7105): 418-21.

19. Wise R, Haut T, Cars O. Antimicrobial resistance: is a major threat to public health. BMJ 1998; 317: 609-10.

20. Worrall G, Young B, Knight V. Inappropriate use of antibiotics for acute respiratory tract infections in a rural emergency department. Can J Rural Med. 2005 Spring;10(2):86-8.

21. Abookire SA, Karson AS, Fiskio J, Bates DW. Use and monitoring of "statin" lipid-lowering drugs compared with guidelines. Arch Intern Med. 2001 Jan 8;161(1):53-8. 
22. Grimshaw JM, Russell IT. Achieving health gain through clinical guidelines II: Ensuring guidelines change medical practice. Qual Health Care. 1994 Mar;3(1):45-52.

23. Grol R. Development of guidelines for general practice care. $\mathrm{Br} J$ Gen Pract. 1993 Apr;43(369):146-51.

24. Winkens RA, Pop P, Bugter-Maessen AM, Grol RP, Kester AD, Beusmans GH, Knottnerus JA. Randomised controlled trial of routine individual feedback to improve rationality and reduce numbers of test requests. Lancet. 1995 Feb 25;345(8948):498-502.

25. Weijden T van der, Wensing M, Giffel M, Winkens R, Grol R. Interventions aimed at influencing the use of diagnostic tests. Report. Maastricht University: centre for Quality of Care Research (WOK) 2000.

26. Eccles M, Steen N, Grimshaw J, Thomas L, McNamee P, Soutter J, Wilsdon J, Matowe L, Needham G, Gilbert F, Bond S. Effect of audit and feedback, and reminder messages on primarycare radiology referrals: a randomised trial. Lancet. 2001 May 5;357(9266):1406-9.

27. Mason J, Freemantle N, Nazareth I, Eccles M, Haines A, Drummond M. When is it cost-effective to change the behavior of health professionals? JAMA. 2001 Dec 19;286(23):2988-92.

28. Sculpher M. Evaluating the cost-effectiveness of interventions designed to increase the utilization of evidence-based guidelines. Fam Pract. 2000 Feb;17 Suppl 1:S26-31.

29. Severens, JL. Value for money of changing healthcare services? Economic evaluation of quality improvement. Qual Saf Health Care 2003;12:366-71.

30. Eccles M, Mason, J. How to develop cost-conscious guidelines. Health Technol Assess. 2001;5(16):1-69. 


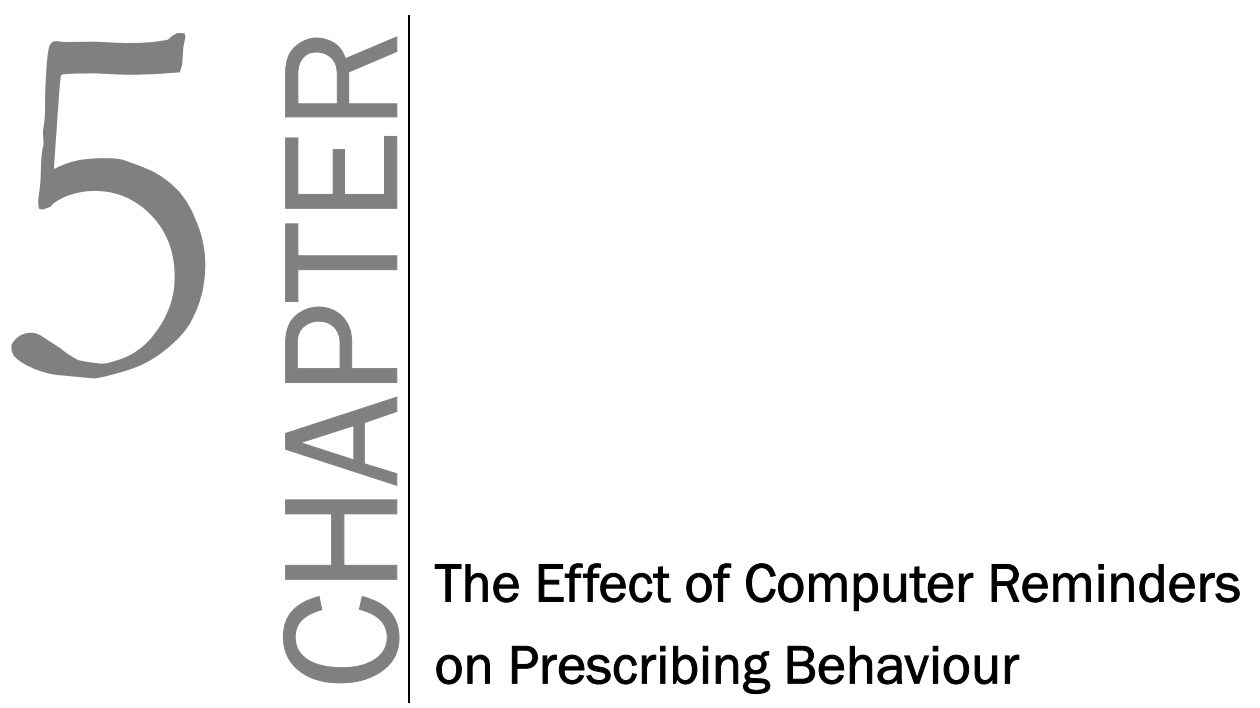

Published as: JD Martens, $T$ van der Weijden, JL Severens, PA de Clercq, DP de Bruijn, ADM Kester, RAG Winkens. The Effect Of Computer Reminders on GPS' Prescribing Behaviour: a Cluster Randomised Trial. Int J Med Inform. 2007 Jun 12; [Epub ahead of print]. 


\section{ABSTRACT}

\section{Objective}

It is difficult to control drug prescribing behaviour in general practice, despite the development and distribution of guidelines. The purpose of this study was to assess the effect on drug prescribing behaviour of implementing prescribing guidelines by means of a reactive Computer Reminder System (CRS).

\section{Design}

Cluster randomised controlled trial with an incomplete block design in the south of the Netherlands: 25 GPs (7 GP practices) received reminders about antibiotics and asthma/COPD prescriptions, 28 GPs (7 GP practices) received reminders about cholesterol prescriptions. Prescription guidelines were integrated into the computerised GP information system.

\section{Measurements}

Both performance indicators and prescription volumes were calculated as the main outcome measures. Next to individual volume measure, sum scores were constructed on the volume measures per drug group (antibiotics, asthma/COPD and cholesterol).

\section{Results}

Variation between GPs turned out to be larger and more skewed than expected. No differences between groups were found for indicators and volumes related to recommendations advocating certain drugs. Although there was a tendency towards clinically relevant results for prescription volumes that were supposed to drop, the difference in sum score between the groups was not significant. For antibiotic prescriptions that were supposed to drop, the sum score for the intervention group was 28.2 (95\% Cl: 20.8-44.5) prescriptions per 1,000 patients per GP, while this was 39.7 (95\% $\mathrm{Cl}$ : 29.7-64.1) for the control group (p: 0.2). For prescriptions asthma/COPD that were supposed to drop, the sum score for the intervention group was 1.1 (95\% Cl: 0.6-2.6) prescriptions per 1,000 patients per GP, while this was $2.2(95 \% \mathrm{Cl}: 1.4-4.3)$ for the control group $(p=0.1)$. On three specific recommendations (on quinolones for cystitis, corticosteroids for COPD, and antibiotics for acute sore throat) significant differences were found.

\section{Conclusions}

This study turned out to be underpowered due to high inter doctor variation in prescribing behaviour. Nevertheless, computerised reminders sometimes have a favourable effect on restricting certain drugs that are not or no longer indicated in general practice. 


\section{INTRODUCTION}

Healthcare expenditure in the Netherlands increases each year, as it does in other European countries. Drug prescribing is an important contributor to this increase in costs ${ }^{1-3}$. Medication is not always prescribed effectively: drugs may be prescribed unnecessarily and lower-cost alternatives are not always taken into consideration. Inappropriate drug prescription can be attributed to demographic factors (growth and ageing of the population), the trend towards new but usually more expensive drugs, increased patient awareness and pressure from the industry ${ }^{4,5}$. Physicians are also known to prescribe more readily as a result of today's high level of work-related stress and routines ${ }^{6}$.

Clinical guidelines themselves may induce small improvements, both in processes and in the outcomes of care ${ }^{7}$. Simple top-down dissemination of mono-disciplinary guidelines alone is not effective ${ }^{8-12}$. In previous research we concluded that disseminating multidisciplinary guidelines that were developed within a region had only a minor impact on prescribing behaviour $^{13}$. A financial incentive for prescribing according to national guidelines only slightly and temporarily improved prescribing behaviour ${ }^{14}$. Apparently, improving drug prescribing is not an easy task. Just disseminating guidelines using a simple dissemination strategy such as a financial incentive, is not sufficient to bring about change. So we decided to look further for more effective implementation strategies.

Computerised reminders proved to be effective in influencing doctors' behaviour in medication management ${ }^{15}$. A computerised system seems appropriate for the complicated task of generating explicit reminders on many drugs related to numerous different diagnoses that occur repeatedly in daily practice. Computer reminders seem to be especially effective if they are developed in cooperation with the users and if they appear close to the time of decision-making ${ }^{16,17}$. We therefore developed reactive computerised reminders based on the recommendations in the multidisciplinary guidelines ${ }^{13}$. Antibiotics, asthma/COPD and cholesterol-lowering prescriptions were chosen as topics because these are frequently prescribed while improvement was desired and seemed possible. We hypothesised that this strategy could lead to a relevant improvement in prescribing behaviour at the level of the GPs. Nevertheless, it was decided to deliver the intervention at practice level, because the reminder system had to be installed at the central computer of each practice, which made it technically complex to address reminders only to certain GPs within one practice.

\section{Methods}

\section{Design and participants}

A cluster-randomised controlled trial (RCT) with an incomplete block design was conducted in the very South of the Netherlands. Randomisation took place on practice level into two blocks. Clusters thus consisted of GPs per practice. Therefore, in this block design the participants were only intervened on part of the underlying guidelines (incomplete block). 
With the block design, we tried to control for the Hawthorne effect by comparing the complete intervention in both arms on either reminders on antibiotics/asthma/COPD (arm I) or cholesterol-lowering drugs (arm II); the arms acted as blind controls for each other. Because of expected interaction between the reminders on antibiotics and asthma/COPD these reminders were combined within the same arm. GPs were blind to the fact that they were controls for each other.

77 GPs in 33 practices were invited to participate. There was only one inclusion criterion for inviting GPs: the use of one specific medical information system for GPs, including a computerised prescription module. All GPs were aware of the fact that they were participating in a trial, but they were blind to the fact that they only received a specific subset of all available prescribing reminders and that they were analysed on certain prescribing behaviour as controls.

\section{Strategy}

The reminder system integrates prescribing guidelines into a tool that assists GPs to adhere to the guidelines and therefore to prescribe drugs more rationally. GPs received individual (in solo practices) or group (in group practices) instruction when the system was installed in the practice. The intervention was implemented in individual practices between October 2003 and April 2004 and had no time limit. The guidelines were set by a regional committee of multidisciplinary opinion leaders, (pharmacists, GPs, hospital staff), and based on prevailing Evidence Based Medicine (EBM).

\section{System Description}

A Computer Reminder System (CRS) with reactive reminders was developed. This real-time automated reminder system contains various types of reminders: alternative type of drug, other doses, alternative drug administration, specific indication, other duration of prescribing, not to prescribe anything, recommend an alternative (no drug prescription) approach or refer to specialist.



Figure 1: General structure of the CRS 
The automated feedback system has four parts: a Guideline Editor in which prescriptionrelevant guidelines were developed using a graphical user interface, a Guideline Knowledge Base that contains these guidelines, a Decision Support System (DSS) that provides reactive support (i.e. reminders), based on the guidelines developed and patient data stored in the GP Information System's database and a research database where -for each prescriptiondata was stored that was used to analyse the GP's behavioural changes. These data consisted of the patient's age and gender, prescribed drugs, diagnosis-related information and the reminders that were given by the $D S S^{18}$. Figure 1 shows all the parts.

\section{The Guideline Knowledge Base}

The guidelines were entered into a Guideline Knowledge Base using a Guideline Editor, a graphical knowledge acquisition tool that facilitates the development of prescription guidelines. These guidelines were implemented as IF-THEN rules which, based on patientspecific data, lead to a reactive reminder immediately at the moment that the GP was prescribing a new drug in the computerised prescription module, if the corresponding guideline was not followed.

\section{The Decision Support Module}

The Decision Support System part of the CRS was implemented on top of the existing GP Information System that contained general patient data, medications and diagnoses. This system also contained a drug prescribing module where GPs were able to prescribe medications. When the GP prescribed a drug, the DSS was activated by the GP Information System, providing the DSS also with patient-specific information (e.g., age and gender) and the prescribed drug. For all patients with asthma/COPD, cholesterol related disease or infections for which antibiotics were prescribed, the GP was obliged to register a diagnosis in terms of ICPC (International Classification of Primary Care) codes, and diagnosis-related information (e.g., severity of the complaints). Based on the patient's age and gender, prescribed drugs and the above-mentioned diagnosis-related information, the DSS checked whether any of the IF-THEN rules fired. When one or more rules fired (meaning that the corresponding guideline was not followed), a reminder was given. An example of a reminder, warning against prescribing asthma medication (salbutamol) for a patient that is suffering from mildly intermittent asthma with a maintenance treatment, is shown in figure 2.

\section{Research data storage}

The DSS also contained a research database where -for each prescription- data was stored that was used to analyze behavioural changes of the GP. These data consisted of the patient's age and gender, prescribed drugs, diagnosis-related information and the reminders that were given by the DSS. 


\section{Chapter 5}

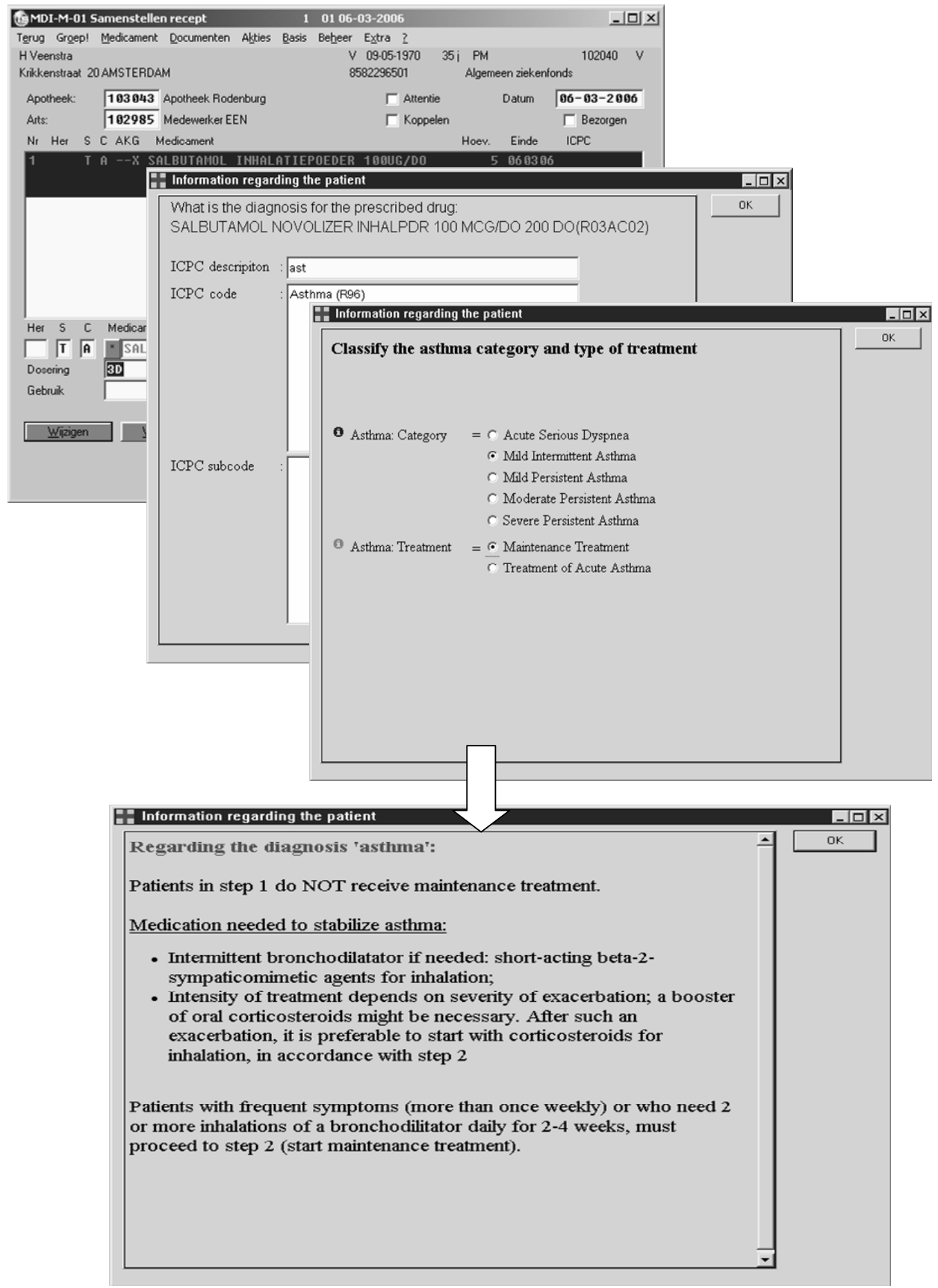

Figure 2: An example of a reminder, given by the DSS (Dutch interface) 


\section{Outcome measures and data collection}

\section{Prescribing indicators and volume data}

The primary outcome measures that were selected and the desired directions of change are listed in tables 2 and 3 :

- Prescription according to the guideline recommendation as a percentage of total prescriptions (of the drug category involved) for the same diagnosis on the individual GP level.

- Absolute number of prescriptions for a specific diagnosis per GP per 1,000 enlisted patients.

In this study, process indicators were developed based on recommendations in the guidelines on antibiotics, asthma, COPD and cholesterol-lowering drugs. The process indicators were formulated as far as possible as disease-oriented indicators or at least as drug-oriented indicators according to Haaijer-Ruskamp et al. ${ }^{19}$. Drug-oriented indicators include information on drugs and drug characteristics alone. On the other hand, diseaseoriented indicators include information on drugs linked to the diagnosis or health problem ${ }^{20}$. An example of a drug-oriented prescribing indicator is:

$$
\frac{N_{\text {prescriptions }} \text { small spectrum antibiotics per GP }}{N_{\text {all prescriptions }} \text { antibiotics per GP }}
$$

An example of a disease-oriented prescribing indicator is:

$$
\frac{N_{\text {prescriptions }} \text { first choice asthma medication per } G P^{*}}{N_{\text {all prescriptions }} \text { total asthma medication per } G P^{*}}
$$

\footnotetext{
* medication for intermittent and mildy persistent asthma with acute complaints among patients $>7$ years
}

The guidelines contained both general and specific prescribing recommendations. Where reminders were given to quit prescribing certain drugs for a specific diagnosis at all, the numerator should become zero and a ratio could not be calculated. In other cases specific information about disease related complaints were missing for constructing the prescribing indicator. In these cases change was only measured by volume data. An example of a volume measure is: 'Total number of prescriptions for doxycyclin and amoxicillin for acute bronchitis per GP and per 1,000 enlisted patients'.

In addition to the individual prescription indicators, volume measures and sum scores were calculated as an overall score for two large drug groups: all antibiotics which were 
expected to decline and all inhaled corticosteroids for asthma which were expected to increase.

\section{Data collection}

Initially, to collect baseline data, GPs had to register diagnoses as ICPC codes while using the drug-prescribing module without receiving reminders of the CRS. But GPs were not motivated to register diagnoses as ICPC codes while using the drug-prescribing module, without being exposed to the reminder function. Therefore, no baseline data could be collected. During the intervention data were collected on the individual GP level about number, type and doses of prescribed drugs, patient diagnosis or severity of complaints, patient age and gender. We used routine data collected by GPs using their GP information system and the CRS. The dataset contained prescription data for a 12-month period.

Seasonal trends in the frequency of prescribing antibiotics and asthma-related drugs influence the comparability of prescribing data on different moments during the intervention period. Therefore, data covering one entire year were selected after starting the intervention.

\section{Power analysis}

To detect a clinically relevant difference between the groups a standardised mean difference (SMD) of 0.2 on the sum score of the volume outcome with alpha 0.05 and beta $0.2,12$ GPs were needed per group. The drop-out rate was estimated to be $20 \%$.

\section{Analysis}

To evaluate the effects of the randomisation, descriptive statistics were used to compare the baseline characteristics of the two groups (table 1).

Table 1: Age and gender of GPs in block A and block B with confidence intervals

\begin{tabular}{|c|c|c|}
\hline & Block A (antibiotics, asthma, COPD) & Block B (cholesterol) \\
\hline Mean age GPs & $49(\mathrm{Cl} 46-52)$ & 45 (Cl 41-49) \\
\hline Male GPs of total & $83 \%(\mathrm{Cl} 64 \%-100 \%)$ & $69 \%(\mathrm{Cl} 43 \%-94 \%)^{*}$ \\
\hline Group practice & $89 \%(\mathrm{Cl} 73 \%-100 \%)$ & $94 \%(\mathrm{Cl} 80 \%-100 \%)$ \\
\hline Mean practice size per GP & $1510(\mathrm{Cl} 1180-1840)$ & $1986(\mathrm{Cl} 1600-2373)$ \\
\hline
\end{tabular}

* significant difference: $p<0.05$

A sum score was constructed for each block based on simply summarizing the individual volume measures of the items in each block. For example in table 2 the items 1 to 8 were summarized (block $\mathrm{A}$ : antibiotics, asthma and COPD and block $\mathrm{B}$ : cholesterol-lowering drugs). We made a distinction between two different kinds of recommendations: recommendations NOT to prescribe a particular drug and recommendations to prescribe first choice drugs.

Because of frequently evident non-normal distributions, the differences between the GP groups were tested using a bootstrap procedure with 999 repetitions, using $\mathrm{R}^{21}$. Using a bootstrap procedure with 999 repetitions, we tested whether the mean response differed 
between the experimental groups, and we generated accelerated bias-corrected intervals for the mean per group and for the difference in means. All comparisons were between two groups on separate predefined outcome measures setting our alpha at 0.05 . We used bootstrap analyses to analyse means instead of nonparametric Mann-Whitney tests, since means are more meaningful in cost-related research. The outcome of a nonparametric analysis yields less interpretable results concerning quantitative experimental effects. Although randomisation was at the level of practices, data were analysed at the more meaningful level of GPs. The CRS is meant for each individual GP and not systematically embedded in group discussions. Though it is possible that GPs discuss the content of the reminders with their colleagues within a group practice and that this may have a reinforcing effect, we did not expect such reinforcing phenomena to happen.

Subsequently, the subgroups were analysed for each type of guideline recommendation:

- Sum scores for all guideline recommendations for which it was recommended not to use certain drugs (see table 2).

- Sum scores for all guideline recommendations for which higher volumes in prescribing were desirable (first choice drugs) (see table 3).

\section{RESULTS}

53 GPs out of 77 GPs agreed to participate. 25 GPs received reminders about antibiotics and asthma/COPD prescriptions, 28 GPs received reminders about cholesterol prescriptions (figure 3). 5 GPs dropped out during the intervention period because of technical problems, leaving datasets from 48 GPs available for analysis. The reasons for dropping out were: technical problems because of general IT problems in the GP practice (2 GPs), many updates to the GP information system (2 GPs) and many updates to the operating system (1 GP). To perform the analyses on GP level, additional information was needed from the GP information system. Because of technical reasons (communication between different versions of the operating system and the analysis module of the CRS), data could not be analysed for 14 GPs. The remaining 34 GPs did not differ on GP characteristics and prescribing behaviour from the 14 GPs that could not be used for analyses. Although we found a significant difference between groups on gender (table 1), we do not expect this to affect our results.

There where it was possible to calculate performance indicators little differences can be seen between groups. More clinically meaningful effects were seen in table 2, although the sum scores were not significant. Three individual volume measures had significant outcomes. Firstly, prescriptions of quinolones were 1.5 (95\% Cl: 0.8-2.2) in the intervention group versus $4.6(95 \% \mathrm{Cl}: 2.8-8.1)$ in the control group $(p=0.03)$. Secondly, prescriptions of inhaled corticosteroids for newly diagnosed COPD patients older than 40 years dropped to 0.0 (95\% Cl: $0.0-0.1)$ in the intervention group versus $0.5(95 \% \mathrm{Cl}: 0.3-0.9)$ in the control group $(p=0.00)$. 


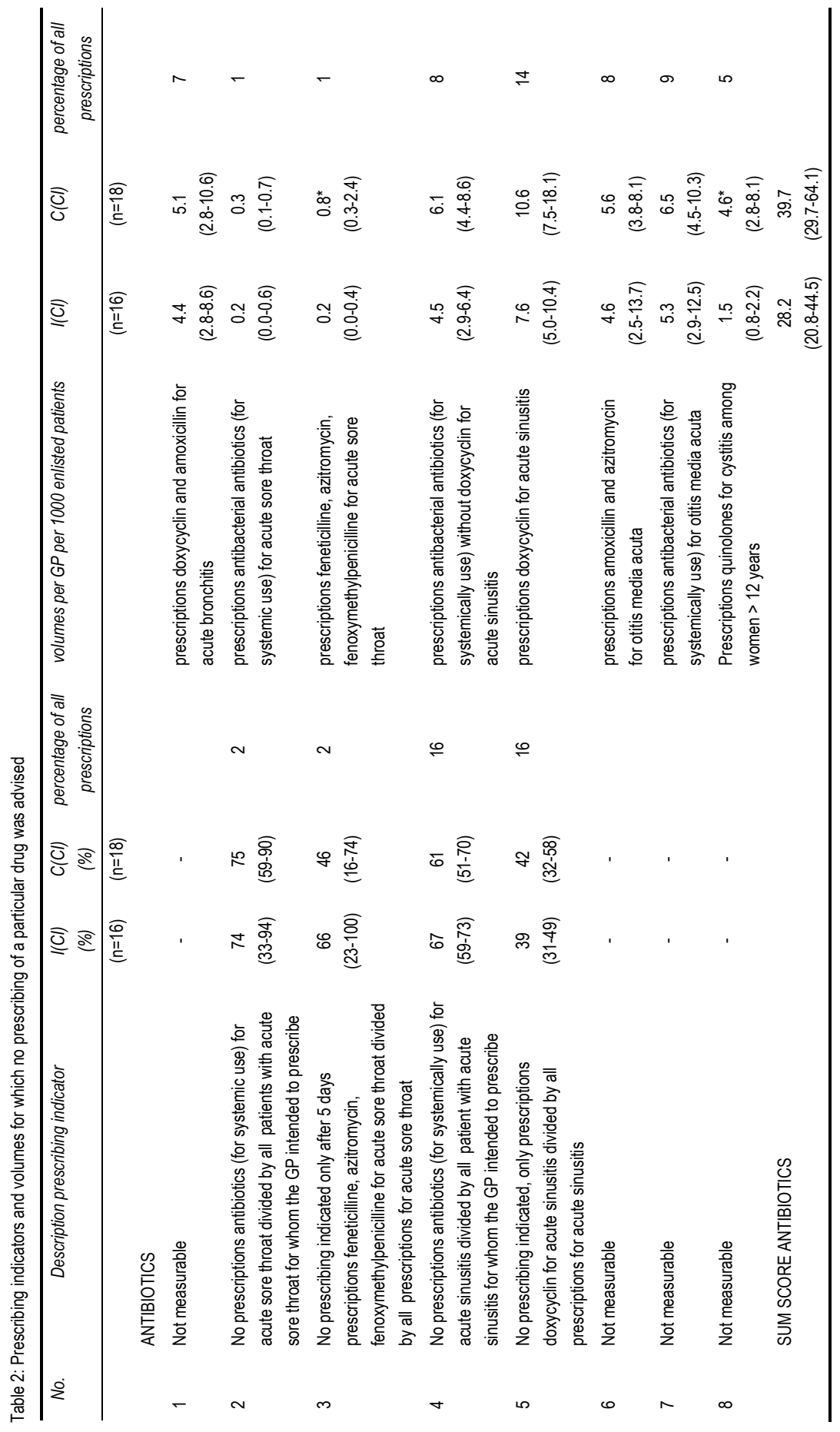









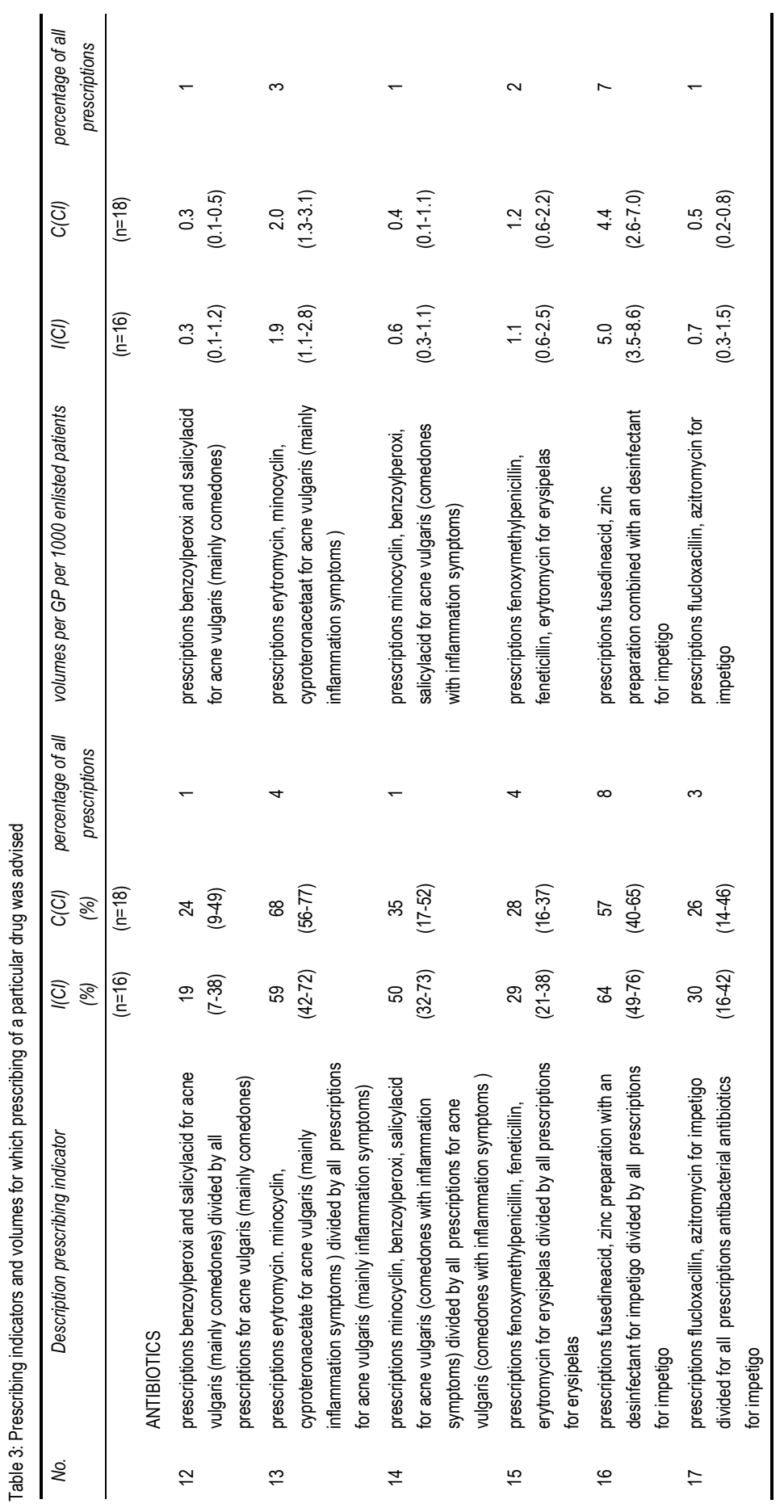




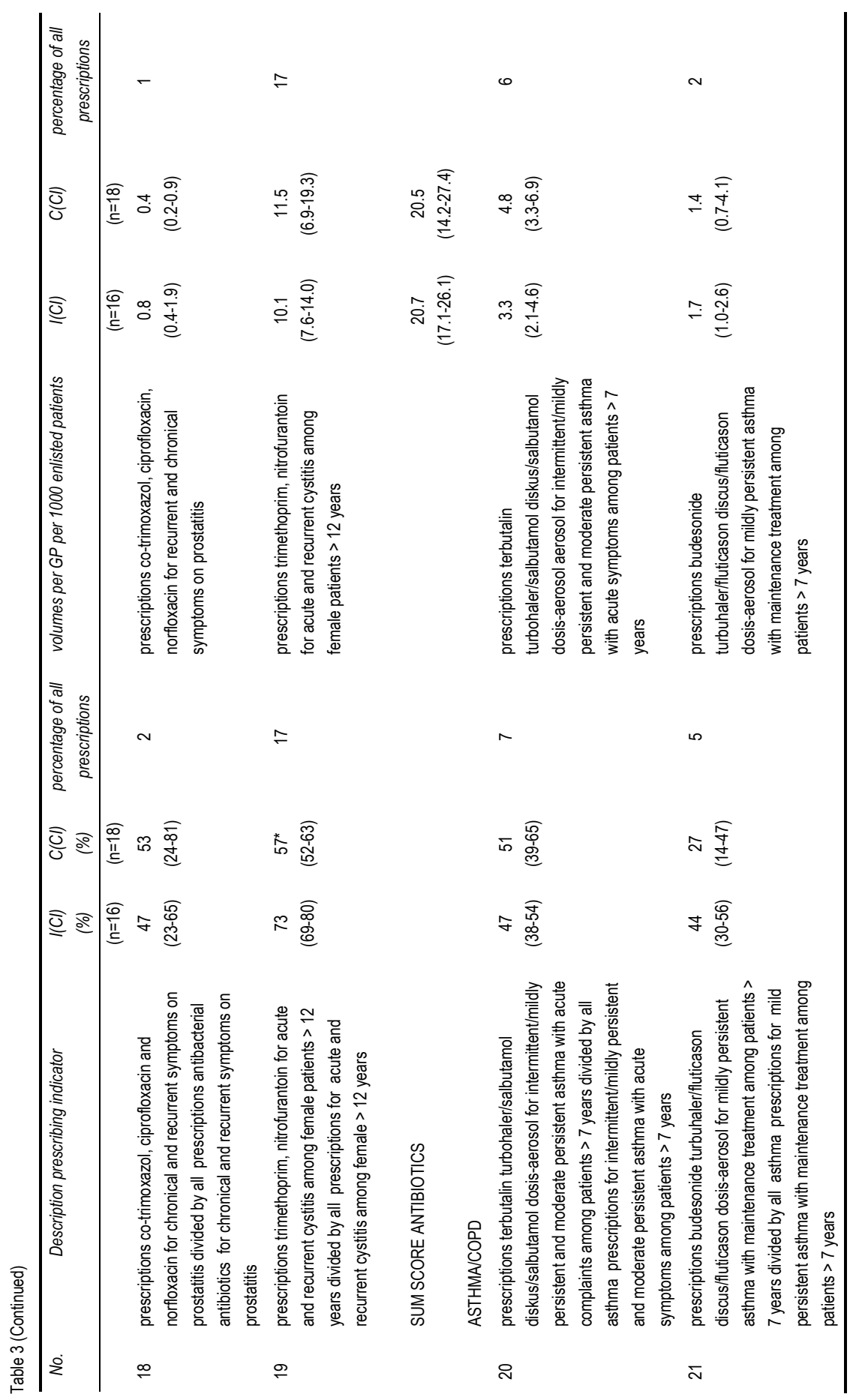




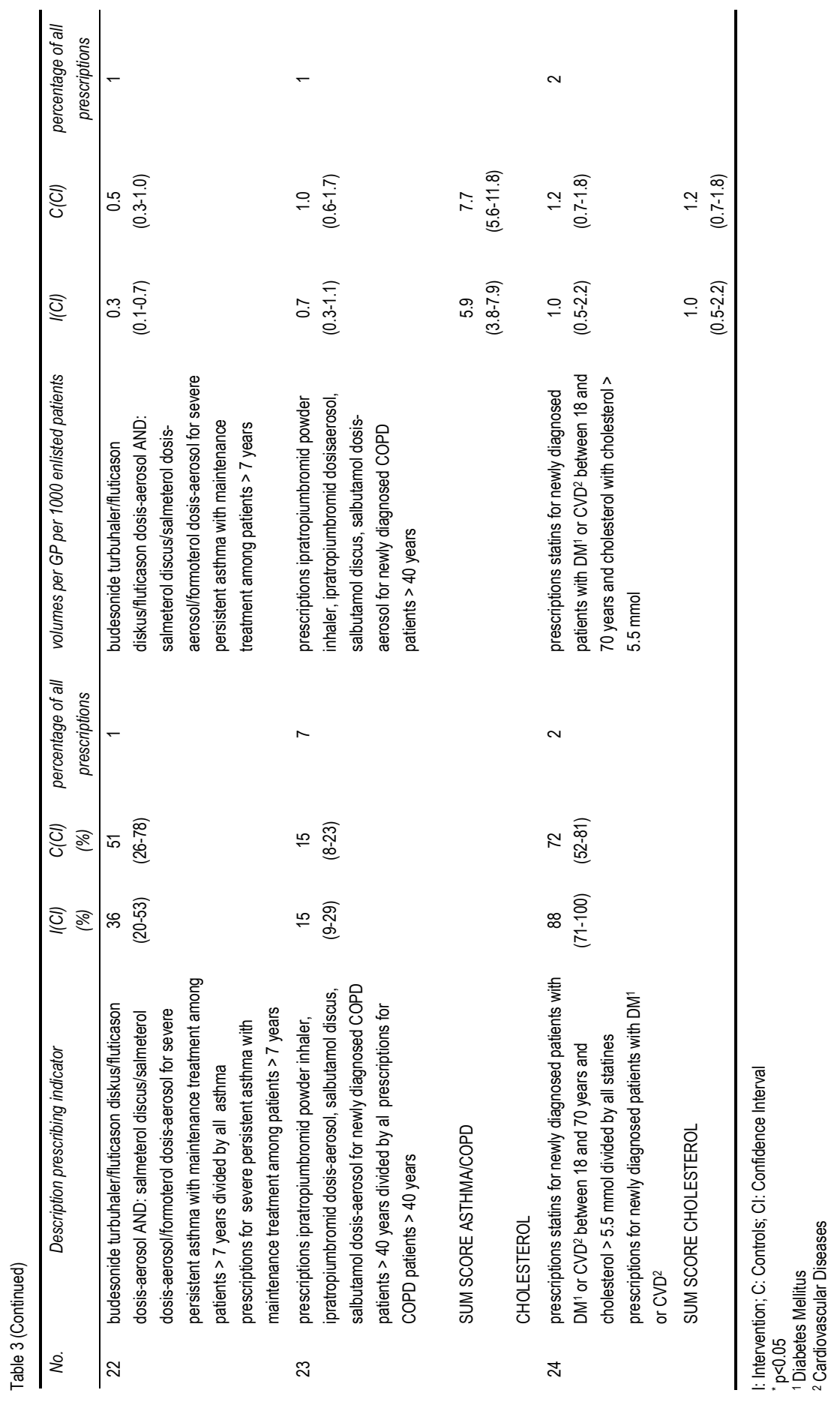


Thirdly, prescriptions of first choice drugs for acute sore throat dropped to 0.2 ( $95 \% \mathrm{Cl}$ : 0.0 $0.4)$ in the intervention group versus $0.8(95 \% \mathrm{Cl}: 0.3-2.4)$ in the control group $(p=0.03)$.

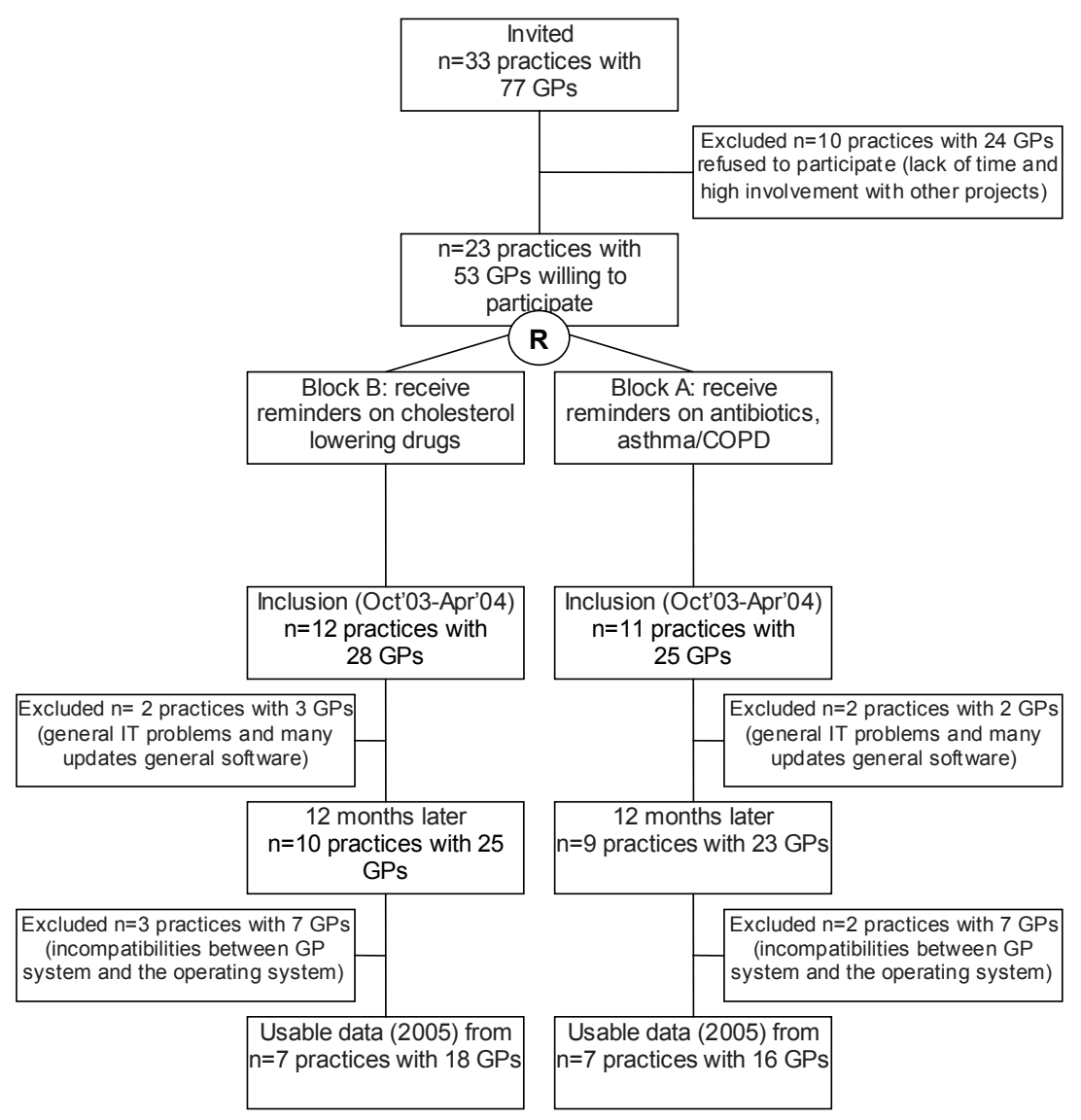

Figure 3: Flowchart overview of data inclusion (practices and GPs) and useable datasets in the project

For prescriptions that were supposed to drop, the antibiotics sum score for the intervention group was $28.2(95 \% \mathrm{Cl}: 20.8-44.5)$ prescriptions per 1,000 patients per GP while this was 39.7 (95\% Cl: 29.7-64.1) for the control group. For prescriptions asthma/COPD that were supposed to drop the sum score for the intervention group was 1.1 (95\% Cl: 0.6-2.6) prescriptions per 1,000 patients per GP while this was $2.2(95 \% \mathrm{Cl}: 1.4-4.3)$ for the control group.

Table 3 shows the prescribing and volume measures when the advice was to prescribe a specific drug according to the guidelines. The CRS had significant effect on a few of the prescribing indicators, although the more frequently occurring prescribing indicators point in 
the right direction: first choice drugs for acute and recurrent cystitis among female patients older than twelve years showed significant outcomes in the desired direction: $73 \%(95 \% \mathrm{Cl}$ : $69 \%-80 \%$ ) in the intervention group prescribed according to the recommendation and $57 \%$ (95\% Cl: $52 \%-63 \%)$ in the control group prescribed according to the recommendation $(p=0.01)$. Clinical meaningful results were seen for first choice drugs for mildly persistent asthma with maintenance treatment with $44 \%(95 \% \mathrm{Cl}: 30 \%-56 \%)$ in the intervention group versus $27 \%$ (95\% Cl: $14 \%-47 \%$ ) in the control group and first choice drugs for impetigo with $64 \%$ (95\% Cl: $49 \%-76 \%)$ in the intervention group versus $57 \%$ (95\% Cl: $40 \%-66 \%)$ in the control group. No effect of the CRS was seen on the accompanying volume measures.

Clinical meaningful results were seen for the total number of prescriptions for all antibiotics as a volume measure with 118.2 (95\% Cl: 96.7-149.7) prescriptions in the intervention group versus 140.0 (95\% Cl: 112.1-192.7) prescriptions in the control group. Secondly, clinical meaningful results were seen for the total number of prescriptions inhaled corticosteroids for all asthma patients as a prescription indicator with $33 \%$ (Cl: $29 \%-41 \%)$ in the intervention group versus $25 \%(\mathrm{Cl} 19 \%-35 \%)$ in the control group. Also the total number of prescriptions of inhaled corticosteroids for asthma patients as a volume measure showed clinical meaningful results with $6.4(\mathrm{Cl}: 4.5-8.7)$ prescriptions in the intervention group versus 5.3 (Cl: 3.4-9.3) prescriptions in the control group.

\section{Discussion}

No favourable effects were found for computerised reminders with the message to prescribe certain drugs. On the other hand, computerised reminders with the message not to prescribe certain drugs sometimes positively influence the prescribing behaviour of GPs.

Our reminders were applicable in daily practice: the CRS did not interfere with the GP information system as long as the GP did not deviate from the guideline. So, the CRS did not interrupt the GP. Furthermore, the CRS interfered at the prescribing moment only. Recent literature showed the importance of generating reminders very close to the decision moment ${ }^{22}$ and showed that reactive reminders proved to be especially effective because of their minimal disturbance to the prescribing process ${ }^{15-17}$. After all, a few stakeholder GPs were involved during the development process of the CRS. This seemed to have had a positive effect on the acceptance of the system.

A second strong aspect is that the CRS was implemented in the actual GP practices and therefore these results represent the effectiveness in daily practice. Third, the block design reduces possible Hawthorne effects, which might cause bias in implementation research. Moreover, another strong aspect of our study was that long-term effects were measured, including information about diagnosis and severity of the patient's disease. This kind of information is not often collected. Because of the availability of these data, we were able to develop diagnosis-related prescribing indicators and to perform a precise and specific evaluation $^{23}$. Finally, we developed prescribing indicators which are expected to play a key role in evaluating strategies aimed at optimising care ${ }^{24,25}$. Measuring the quality of prescribing by means of intermediate measures such as process indicators, instead of outcome 
indicators, demands that the process indicators are valid ${ }^{19,26}$. Because the GPs had to register the prescribing diagnosis and disease related information at the moment of prescribing, it was possible to develop specific disease and drug-oriented prescribing indicators for which knowledge of the diagnosis and disease characteristics was necessary.

There are some issues for consideration. Firstly, our study turned out to be underpowered. During analysis it turned out that the actual variation was larger than the estimation values we used in the power analysis. This resulted in data that were not significant, although the size of differences found between the intervention and control group seem to be clinically meaningful. Next to this, due to extreme skewness on our data we could not do a parametric multilevel analysis. Besides, there is debate in the literature on bootstrap analyses for cluster-randomised trials of our size ${ }^{27}$.

Second, we investigated the first version of the CRS in this effect evaluation. The system had a few teething troubles that might have disturbed the effectiveness of the computer reminders. For example, if the GP received a cholesterol-lowering reminder, a switch was needed between the CRS and the GP Information System to search for a recent cholesterol value. This might have caused irritation and delay for the GP, but we cannot think of any reason that this has biased the findings of the study, other than an underestimation of the true effect of a convenient reminder on cholesterol lowering drugs. New insights led to the CRS being improved. The latest update of the CRS contains shorter reminder texts and has a more attractive lay-out.

Third, the translation of the guideline recommendations by means of IF-THEN rules into reminders often results in a selection of those recommendations that are by nature more suitable for IF-THEN rules. Prescribing guidelines not only comprise recommendations that are non-complex, like prescribing of trimethoprim and nitrofurantoin for cystitis among adult women, but also more complex ones like for asthma: prescribing first choice corticosteroids in combination with first choice long-acting beta-agonists for moderately or severely persistent asthma with acute complaints or a maintenance treatment among patients older than seven years. One can question which recommendations are the most relevant ones from medical prospective. In this study we tried to translate, not just the easy-to-translate recommendations, but also the more complex ones. But we are not certain if the complex recommendations were always translated into medically meaningful reminders. In the future, it is important that GPs should be more intensively involved to improve this ${ }^{9}$.

Fourth, the results may be underestimated because a large group of the participating GPs consisted of academic GP practices, known as early innovators. This group already prescribes drugs more rationally, which makes it harder to improve their prescribing behaviour. This makes our results a conservative estimate and might have affected the generalizability of this study. The incompatibility problems and subsequent drop-out of GPs for analysis did not seem to result in selection bias.

Fifth, 14 GPs could not be analysed because of a technical problem, though this problem arose at random. In addition, the analyses on differences between the GP groups showed a difference in gender. We cannot think of any bias in our data to explain this difference, which also reflects a difference in the numbers of female versus male GPs in this region. We are 
not aware of any literature showing differences in adherence to guidelines based on gender differences.

In this study we reported on effects for two different kinds of recommendations: 'reminders NOT to prescribe drugs for a certain diagnosis' as well as 'reminders to prescribe first choice drugs for a certain diagnosis'. Surprisingly, effects were only seen by reminders NOT to prescribe drugs. Regarding the different recommendations given by the reminders we found different effects of first choice drugs and reminders NOT to prescribe drugs at all. Although many studies are published regarding effectiveness of computer reminders and important factors affecting the stated acceptance of reminders ${ }^{28}$, little evidence can be found about the specific impact of the content of the reminders on the effects. A number of reviews report effectiveness of computer reminders regarding certain subjects, like drug dosing or diagnostic testing ${ }^{17,22,29}$. But the original studies, underlying to these reviews did not report on differences in effect related to the content of the reminders. In a study of Winkens et. al. it was described that diagnostic advices giving alternatives had larger impact on behavioural change than advices not to act at all ${ }^{30}$. In a study of Teich et al. similar results were described for DO-prescribing and DO-NOT prescribing. Recommendations to change dose, frequency of administration, or medication within a class were readily accepted. Recommendations to stop prescribing without offering an equivalent action were less effective and achieved mixed results ${ }^{31}$. These findings do not match with our results. Further research on the limited effect of first choice reminders as well as the positive effect of advices not to act at all needs to be explored. Possibly, the reminders NOT to prescribe were more clinically relevant.

Overall, the literature on DSS shows different effects on outcome measures ${ }^{26}$. Numerous computerised DSS have been developed, but many failed to be taken up into actual use. There is an insistent need to shift from a technology-driven approach to one that identifies and employs the most cost-effective method to manage knowledge, regardless of the technology ${ }^{32}$. We plan to evaluate the costs of the technical development in a forthcoming economic evaluation.

\section{CONCLUSION}

The implementation of a reactive CRS is sometimes effective in improving GPs' rational drug prescribing behaviour, concerning reminders not to prescribe certain drugs. There was no effect of reminders on first choice prescriptions for certain diagnoses. 


\section{REFERENCES}

1. Centraal Bureau voor de Statistiek. Statistisch jaarboek 2003 (Statistical yearbook 2003), vol. 96. Heerlen: Centraal Bureau voor de Statistiek; 2003.

2. Stichting Farmaceutische Kengetallen; Data en Feiten (Foundation for Pharmaceutical Statistics; Data and facts). The Hague/the Netherlands; 2000-2004.

3. Breekveldt-Postma NS, Zwart-van Rijkom JE, Egberts AC, Leufkens HG, Herings RM. Rising costs of drugs in hospitals in the period 1996-2000 and over the next few years (Article in Dutch). Ned Tijdschr Geneeskd. 2002 Dec 28;146(52):2547-51. Erratum in: Ned Tijdschr Geneeskd. 2003 Dec 27;247(52):2612. Ned Tijdschr Geneeskd. 2003 Jan 25;147(4):184.

4. Dobson R. Pharmaceutical industry is main influence in GP prescribing. BMJ 2003;326: 301.

5. Prosser $\mathrm{H}$, Almond $\mathrm{S}$, Walley $\mathrm{T}$. Influences on GPs' decision to prescribe new drugs; the importance of who says what. Family Practice 2003;20(1):61-8.

6. Evans J, Lambert T, Goldacre M. GP recruitment and retention: a qualitative analysis of doctors' comments about training for and working in general practice. Occas Pap R Coll Gen Pract. 2002 Feb;(83):iii-vi, 1-33.

7. Grimshaw J, McAuley LM, Bero LA, Grilli R, Oxman AD, Ramsay C et. al. Systematic reviews of the effectiveness of quality improvement strategies and programmes. Qual Saf Health Care. 2003;4:298-303.

8. Kosecoff J, Kanouse DE, Rogers WH, McCloskey L, Winslow CM, Brook RH. Effects of the national Institutes of Health Consensus Development Program on physician practice. JAMA 1987;258:2708-13.

9 Grimshaw J, Eccles M, Tetroe J. Implementing clinical guidelines: current evidence and future implications. J Contin Educ Health Prof. 2004 Fall;24 Suppl 1:S31-7.

10 Grol R. Implementation of evidence and guidelines in clinical practice: a new field of research? Int J Qual Health Care 2000;6:455-6.

11. Jamtvedt G, Young JM, Kristoffersen DT, Thomson O'Brien MA, Oxman AD. Audit and feedback: effects on professional practice and health care outcomes. Cochrane Database Syst Rev. 2003;3:CD000259.

12. Bero LA, Grilli R, Grimshaw JM, Harvey E, Oxman AD, Thomson MA. Closing the gap between research and practice: an overview of systematic reviews of interventions to promote the implementation of research findings. The Cochrane Effective Practice and Organization of Care Review Group. BMJ 1998;317(7156):465-8.

13. Martens JD, Winkens RAG, Weijden T van der, Bruyn D de, Severens JL. Does a joint development and dissemination of multidisciplinary guidelines improve prescribing behaviour: a pre/post study with concurrent control group and a randomised subgroup. BMC Health Serv Res. 2006;6:145.

14. Martens JD, Werkhoven MJ, Severens JL, Winkens RAG. Effects of a behaviour independent financial incentive on prescribing behaviour of general practitioners. J Eval Clin Pract. 2007 Jun;13(3):369-73.

15. Bennett JW, Glasziou PP. Computerised reminders and feedback in medication management: a systematic review of randomised controlled trials. MJA 2003;178:217-22.

16. Johnston ME, Langton KB, Haynes B, Mathieu A. Effects of computer-based clinical decision support systems on clinician performance and patient outcome: a critical appraisal of research. Ann Intern Med 1994;120:135-42.

17. Hunt DL, Haynes RB, Hanna SE, Smith K. Effects of computer-based clinical decision support systems on physician performance and patient outcomes. JAMA 1998;280:1339-46.

18. de Clercq PA, Hasman A, Blom JA, Korsten HH. Design and implementation of a framework to support the development of clinical guidelines. Int J Med Inform. 2001;64 (2-3):285-318. 
19. Haaijer-Ruskamp FM, Andersen M, Vander Stichele R. Prescribing quality indicators, in: Hartzema AG, Porta M, Tilson HH. Pharmaco-epidemiology,: an introduction. 3rd ed. Cincinnati, OH: Harvey Whitney Books Company, 1998.

20. Braspenning JCC, Schellevis FG, Grol RPTM. Kwaliteit in beeld. Medisch-technisch handelen huisartsen doorgelicht. Medisch Contact (Dutch journal) 2004;59(21):853.

21. R Development Core Team (2005). R: A language and environment for statistical computing. $R$ Foundation for Statistical Computing, Vienna, Austria. ISBN 3-900051-07-0, website available at: http://www.R-project.org.

22. Kawamoto K, Houlihan CA, Balas EA, Lobach DF. Improving clinical practice using clinical decision support systems: a systematic review of trials to identify features critical to success. BMJ 2005;330:765-8.

23. Verstappen WH, van der Weijden T, ter Riet G, Grimshaw J, Winkens R, Grol RP. Block design allowed for control of the Hawthorne effect in a randomized controlled trial of test ordering. J Clin Epidemiol. 2004;57(11):1119-23.

24. Pringle M, Wilson T, Grol R. Measuring 'goodness' in individuals and healthcare systems. BMJ 2002;325:704-7.

25. Nadzam DM. Development of medication-use indicators by the Joint Commission on Accreditation of Healthcare Organizations. Am J Hosp Pharm 1991; 48(9): 1925-30.

26. Westert GP, Jabaaij L, Schellevis FG. Morbidity, performance and quality in primary care; Dutch general practice on stage. Oxon: Radcliffe Publishing, 2006.

27. Flynn TN, Peters TJ. Use of the bootstrap in analysing cost data from cluster randomised trials: some simulation results. BMC Health Serv Res. 2004;4(1):33.

28. Sittig DF, Krall MA, Dykstra RH, Russell A, Chin HL. A survey of factors affecting clinician acceptance of clinical decision support. BMC Med Inform Decis Mak. 2006;6:6.

29. Garg AX, Adhikari ND, McDonald H, Rosas-Arellano MP, Devereaux, PJ, Beyene J, Sam J, Haynes RB. Effects of Computerized Clinical Decision Support Systems on Practitioner Performance and Patient Outcomes. A Systematic Review. JAMA. 2005;293:1223-38.

30. Winkens RA, Pop P, Grol RP, Bugter-Maessen AM, Kester AD, Beusmans GH et. al. Effects of routine individual feedback over nine years on general practitioners' requests for tests. BMJ. 1996 Feb 24;312(7029):490.

31. Teich JM, Merchia PR, Schmiz JL, Kuperman GJ, Spurr CD, Bates DW. Effects of computerized physician order entry on prescribing practices. Arch Intern Med. 2000;160(18):2741-7.

32. Liu J, Wyatt JC, Altman DG. Decision tools in health care: focus on the problem, not the solution. BMC Med Inform Decis Mak. 2006;6:4. 


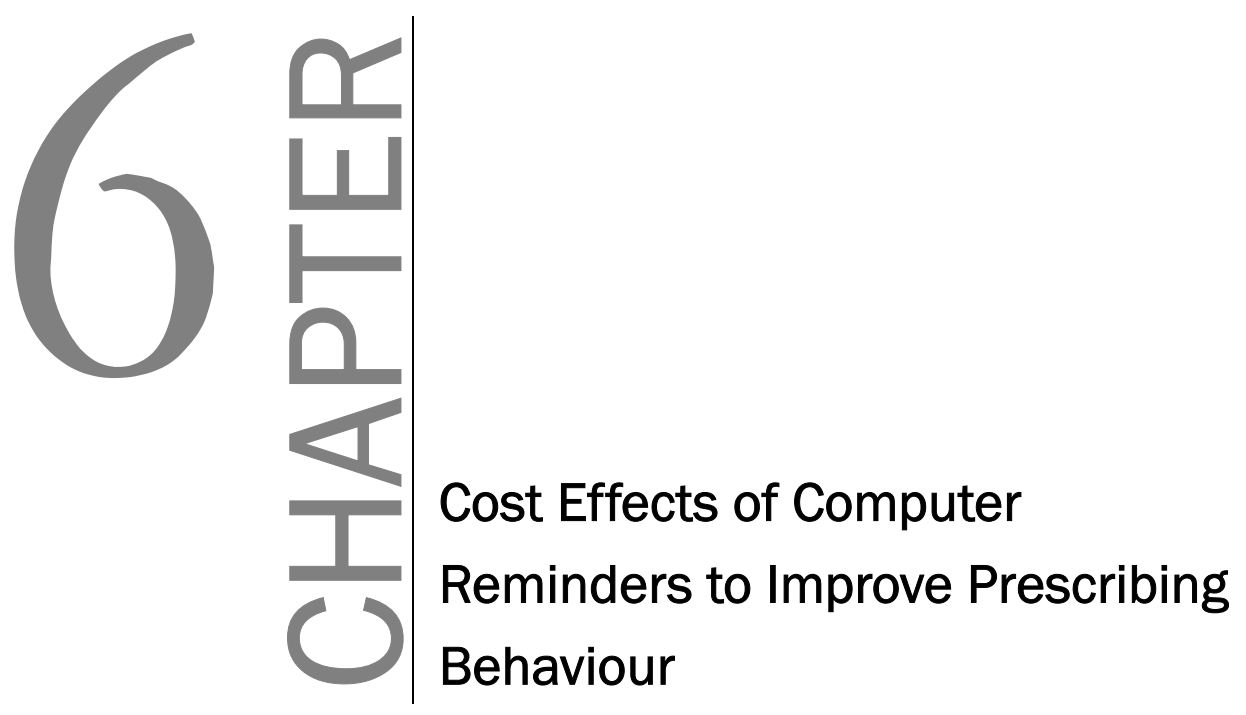

Submitted as: JD Martens, JL Severens, $T$ van der Weijden, ADM Kester, DP de Bruijn, RAG Winkens. Cost effects of computer reminders to improve prescribing behaviour among GPS. A cluster randomised trial. 


\section{ABSTRACT}

\section{Objective}

To determine the cost of implementation a Computer Reminder System (CRS) consisting of development, execution and healthcare costs, aimed at improving the drug prescribing behaviour of General Practitioners (GPs) and reducing healthcare costs.

\section{Design.}

Cluster-randomised Controlled Trial in the south of the Netherlands with an incomplete block design. GPs were randomly allocated into two groups: 25 GPs received reminders about antibiotics and asthma/COPD prescriptions, 28 GPs received reminders about cholesterol prescriptions. The prescription costs of antibiotics, asthma/COPD and cholesterol prescriptions were calculated based on volume data and multiplied by the cost prices per tablet, during a 12-month follow up.

\section{Intervention}

Multidisciplinary prescription guidelines were integrated into a CRS. This CRS was linked to the GP information system. Based on this CRS, a reminder popped up if a GP's specific drug prescription was not in line with prescribing guidelines.

\section{Main outcome measure}

Fixed and variable costs per GP per year were calculated: the development of the prescribing guidelines the development of the CRS strategy, the execution of the CRS and the prescription costs.

\section{Results}

Prescription data from 34 GP's were evaluated. The total cost of the CRS was $€ 15,239$ per GP (over 4.3 years of the project). Guideline development: $€ 7,685$ per GP; CRS development: $€ 4,130$ per GP; execution costs: $€ 3,424$ per GP. Significant results were seen for redundant prescriptions for antibiotics, asthma, and COPD: €291 per GP per year in the intervention group versus €430 per GP per year in the control group $(p=0.05)$.

\section{Conclusion}

Although we could not carry out a full economic evaluation including patient outcomes, it appeared that the improved adherence to the guideline resulted in medication cost changes in the desired direction. However, these cost changes were smaller than the input costs. Nonetheless, this strategy might still reduce costs in the long run, because the initial investments were relatively high. The development costs are once-only and will be reduced by extrapolating the strategy over time to a larger population with more guidelines, and by applying the strategy to already existing guidelines. 


\section{INTRODUCTION}

Many strategies have been developed to improve GPs' prescribing behaviour in an effort to reduce costs and to improve quality of care. Drug prescribing is an important contributor to this increase in costs, and these costs are expected to continue to increase significantly in the coming years ${ }^{1-2}$. Medication is not always prescribed effectively: drugs may be prescribed unnecessarily and lower-cost alternatives are not always taken into consideration ${ }^{3}$.

Literature shows that Computer Reminder Systems (CRS) can be effective in influencing prescribing behaviour, especially when they are developed in cooperation with the users and the reminders are presented close to the moment of decision making ${ }^{4-8}$. Because healthcare resources are limited, not only the cost-effectiveness of new treatments in patient care should be evaluated, but also the cost-effectiveness of new strategies to improve the quality of healthcare delivery.

Professionals' behaviour should also be economically analysed by weighing their expenses and the outcome ${ }^{9}$. An economic evaluation of quality improvement studies should concentrate on evaluating behavioural change and the costs of developing, disseminating and implementing the guideline $\mathrm{e}^{10-12}$. Many studies that report costs are of a poor methodological quality and do not cover all the stages of guideline introduction that may be relevant ${ }^{13}$. Only a few studies followed the basic principles of a full economic evaluation with costs and effects expressed in development costs, execution costs and healthcare costs, while the cost effects are divided into fixed and variable costs ${ }^{14}$.

In an earlier paper, we evaluated a CRS according to the volume and quality of prescribing by GPs, showing moderate effects. No effects were found for the relevant sumscores, but significant effects in the desired direction were found for a few of the volume measures ${ }^{15}$. The aim of this paper is to assess whether implementing of this innovative strategy would be worthwhile on a national scale, taking effectiveness in terms of changes in drug prescribing behaviour and costs into account. The present paper provides an example

of a method for a cost analysis of quality improvement according to Severens ${ }^{16}$. We evaluated the costs of a CRS on prescribing behaviour for antibiotics, asthma, COPD and cholesterol. The cost analysis is differentiated to different phases: development of input (guidelines), development of the CRS, diffusion of the CRS (execution costs), and medication costs (healthcare costs).

\section{Methods}

Because the Hawthorne effect might influence the outcome of this trial, a cluster-randomised controlled trial with incomplete block design was carried out ${ }^{17}$. Randomisation took place on practice level into 2 groups. Clusters thus consisted of the GPs per practice: 25 GPs received reminders about antibiotics and asthma/COPD prescriptions, 28 GPs received reminders about cholesterol prescriptions (figure 1). 


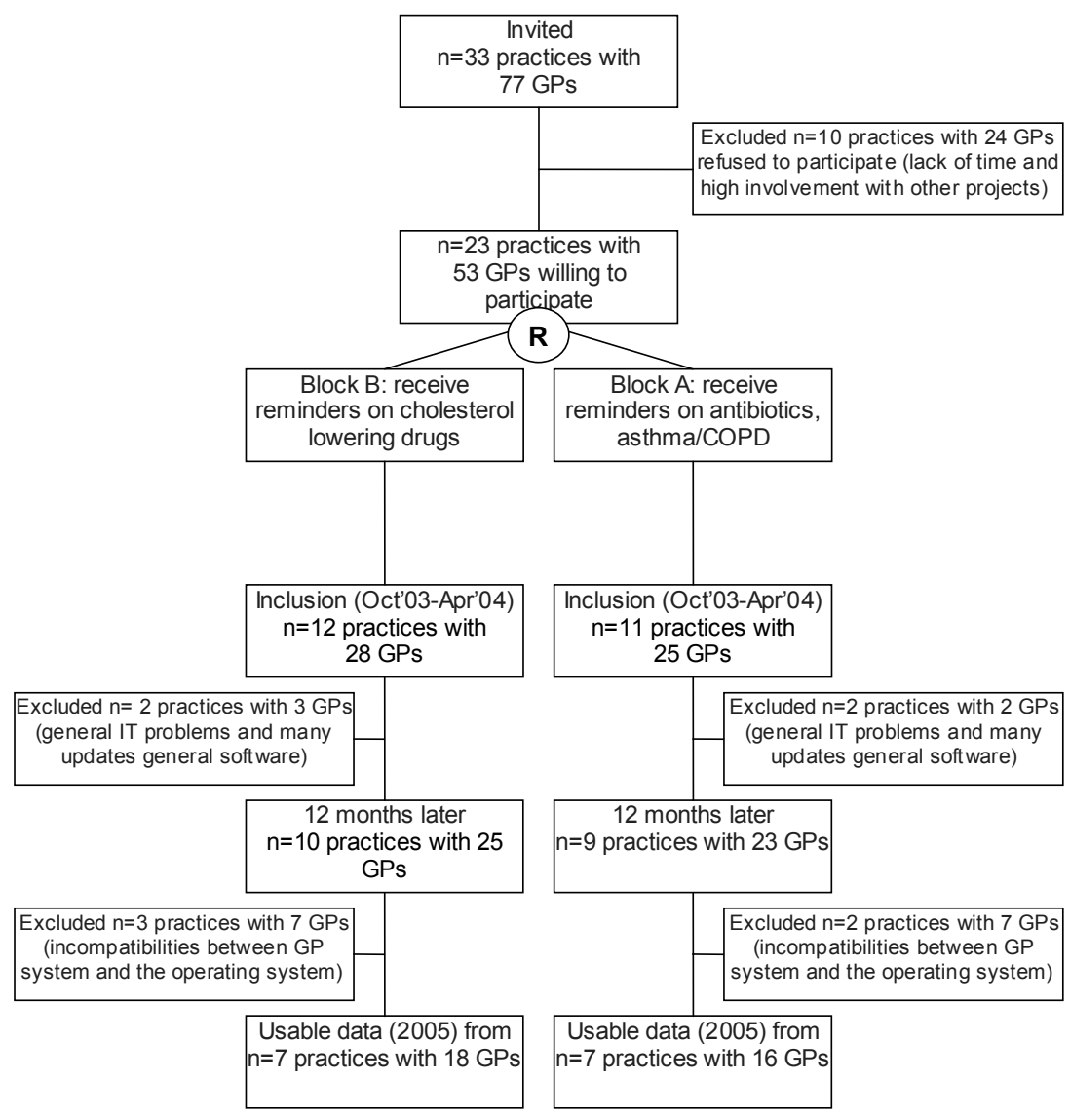

Figure 1: Flowchart overview of data inclusion (practices and GPs) and useable datasets in the project

In our block design participants were intervened on part of the underlying guidelines. Because of expected interactions between the reminders on antibiotics and asthma/COPD these reminders were combined within the same block. The other block consisted of reminders about cholesterol-lowering drugs. GPs were blind to the fact that they were controls for each other. We extracted data on all guidelines in both groups. All GPs were informed about the trial, but they were ignorant of the fact that they were only receiving some of the prescribing reminders and were regarded as a control group for the other reminders. No baseline data could be gathered, because GPs could not be motivated to register diagnoses without receiving reminders. The intervention period covered a 12-month period in which prescription data of the GPs were registered. The individual GPs and the prescription costs of the four prescribing guidelines were the subjects for analysis. 


\section{Population}

At the start 77 GPs in the south of the Netherlands were invited to take part in the intervention. The only inclusion criterion for GPs' participation in the intervention was their use of one specific GP information system, MicroHIS (ISoft BV, the Netherlands).

\section{Strategy}

Multidisciplinary expert teams developed the prescribing guidelines on which the reminders were based. The topics were selected because of the high prevalence of these health problems and contained antibiotics, asthma/COPD related drugs and cholesterol-lowering drugs. Subsequently, a CRS with reactive reminders was developed ${ }^{15}$. All relevant prescriptions were entered into a special research database.

When the GP prescribed a drug, the Decision Support System (DSS) was activated by the GP Information System, providing the DSS with patient-specific information (e.g. age and gender) and the prescribed drug. The GP was obliged to register a diagnosis in ICPC and diagnosis-related information (e.g. severity of the complaints) for all patients with asthma/COPD, cholesterol-related disease or infections for which the GP considered prescribing drugs. Based on the patient's age and gender, prescribed drugs and the abovementioned diagnosis-related information, the DSS checked whether any of the IF-THEN rules fired. When one or more rules fired (meaning that the corresponding guideline was not followed), a reminder was given. The reminders could be more or less persuasive and addressed such aspects as: alternative type of drugs, other doses, alternative drug administration, specific indication, different length of time for prescribing, not to prescribe anything or refer to specialist. The technical aspects of the system are described elsewhere $^{15}$. GPs working in a solo practice received individual instruction about its installation in the practice and those in group practices were instructed in small groups. The intervention was implemented between October 2003 and April 2004 and was not limited in time.

\section{Costs and measuring instruments}

We calculated the total costs of the quality improvement strategy during the different phases of the implementation: 1) the development costs of the guidelines, 2) the development costs of the CRS, 3) the execution of the CRS (diffusion), and 4) the healthcare costs (medication costs). The implementation costs were spread over the 4.3 years in which the guidelines were developed, the CRS was developed and was finally implemented in the practices. Calculations were performed on the basis of retrospective data from available sources like minutes, reports, and agenda information and literature resources ${ }^{18}$ partly estimated and partly calculated based on the CRS research database. 


\section{Costs of the quality improvement strategy}

\section{Development of multidisciplinary guidelines}

Preparation time and time spent attending meetings were analysed for each member of the multidisciplinary guideline committee (GPs, specialists, pharmacists and insurance company) as well as the project team members' salaries, time spent by the project manager and secretary organising and attending the meetings. Finally, the cost of validating the guidelines was taken into account.

\section{Development of the Computer Reminder System}

The most important costs in this phase were costs generated by the companies that were involved in the development of the CRS and the salary costs of the IT project team worker and support provided by the secretary.

\section{Execution of the CRS in the GP practices (diffusion).}

The most essential costs were the salary costs of the project worker who implemented the CRS in the GP practices and the expenses of the IT consultancy company who actually installed the CRS.

\section{Healthcare costs and savings of the quality improvement strategy}

Medication costs. The individual cost prices of all the drugs on which the CRS interacted were calculated at the level of the Anatomical Therapeutic Chemical (ATC) classification system. Cost prices per drug were received from the Scientific Institute of Dutch Pharmacists, a Dutch national authority on pharmaceutical sciences. The data contained information on the name of the drug, the name of the manufacturer, different sub-coding systems, dose information, substance and cost price per entity and per pill. We selected a subset of only primary care drugs. Because it was impossible to report all the costs of each individual drug we evaluated in detail, we have chosen to show the drug costs expressed as a range of cost prices covered by a particular ATC-code (table 1). In the Netherlands, medication costs are reimbursed according to cost standards and standard prices ${ }^{18,19}$. Costs were determined by assessing the mean difference in the drug-costs for GPs in block $A$ and GPs in block B. We calculated medication costs in both block groups using current standard tariffs per tablet for each individual drug. In addition, we used the CRS analysis module to investigate the differences in costs between the intervention and control group. The medication costs were calculated on individual drug or drug group level (table 4 and 5), based on the recommendations in the guidelines. More details on development costs and healthcare costs can be found in appendix 1 .

\section{Power analysis}

To detect a clinically relevant difference between the groups a standardised mean difference (SMD) of 0.2 on the sum score of the volume outcome with alpha 0.05 and beta $0.2,12 \mathrm{GPs}$ were needed per group. The drop-out rate was estimated to be $20 \%$. 


\section{Analysis}

We tested the differences between the intervention and control group characteristics by means of student t-tests, using SPSS version 12.0.1 (SPSS inc, Chicago, III, USA). The development, execution and health care costs were calculated for each phase of the implementation strategy for each GP over 4.3 years of the project. To evaluate healthcare costs (medication costs), the mean costs and 95\% confidence intervals were calculated for all volumes of antibiotics, asthma, COPD and cholesterol-lowering drugs in both blocks of the block design.

Table 1: Range of individual costs of drugs on which the CRS interacted (price per pill in $€$ )

\begin{tabular}{|c|c|c|}
\hline Drugs & ATC-code & Range of individual cost prices per pill \\
\hline \multicolumn{3}{|l|}{ Antibiotics } \\
\hline amoxicillin & J01CA04 & $0.03-0.53$ \\
\hline azitromycin & J01FA10 & $0.41-4.05$ \\
\hline benzoylperoxide & D01AE01 & $0.06-0.17$ \\
\hline ciprofloxacine, & J01MA02 & $0.20-2.87$ \\
\hline co-trimoxazol & J01EE01 & $0.02-2.24$ \\
\hline cyproteronacetaat & G03HB01 & $0.21-0.24$ \\
\hline doxycycline & J01AA02 & $0.31-0.43$ \\
\hline erytromycine & D10AF02 & $0.14-0.35$ \\
\hline feneticilline & J01CE05 & $0.03-0.15$ \\
\hline fenoxymethylpenicilline & J01CE02 & $0.03-0.30$ \\
\hline flucloxacilline & J01CF05 & $0.32-0.65$ \\
\hline fusedineacid & D06AX01 & $0.20-0.21$ \\
\hline zinc products & $\mathrm{D} 02 \mathrm{AB}$ & $0.008-0.009$ \\
\hline minocycline, & J01AA08 & $0.24-0.59$ \\
\hline nitrofurantoine & J01XE01 & $0.14-0.46$ \\
\hline norfloxacine & J01MA06 & $0.43-0.58$ \\
\hline salicylacid & $\mathrm{D} 01 \mathrm{AE} 12$ & $0.01-0.05$ \\
\hline trimethoprim & J01EA01 & $0.03-0.41$ \\
\hline \multicolumn{3}{|l|}{ Asthma/COPD } \\
\hline budesonide turbuhaler & R03BA02 & $0.02-0.04$ \\
\hline cromones & $\mathrm{R} 03 \mathrm{BC} 01 / \mathrm{R} 03 \mathrm{BC} 03$ & $0.17-0.18$ \\
\hline fluticason discus & R03BA05 & $0.14-0.33$ \\
\hline fluticason dosis-aerosol & R03BA05 & $0.11-0.71$ \\
\hline ipratropiumbromide dosisaerosol/Inhal.powder & R03BB01 & $0.21-0.58$ \\
\hline salbutamol discus/dosis-aerosol & R03AC02 & $0.02-0.09$ \\
\hline terbutaline turbohaler & $\mathrm{R} 03 \mathrm{ACO} 3$ & $0.06-0.07$ \\
\hline \multicolumn{3}{|l|}{ Cholesterol } \\
\hline antillipaemica & $\mathrm{C} 10$ & $0.20-1.71$ \\
\hline
\end{tabular}

A sum score was constructed for each block based on summarising the individual healthcare costs (block A: antibiotics, asthma and COPD and block B: cholesterol-lowering drugs). We made a distinction between two different kinds of recommendations: recommendations NOT 
to prescribe a particular drug and recommendations to prescribe first choice drugs. Our design consisted of two blocks of GPs (block A: antibiotics, asthma, COPD and block B: cholesterol-lowering drugs). Two sum scores were constructed for each block. Because of frequently evident non-normal distributions, the differences between the GP groups were tested using a bootstrap procedure with 999 repetitions, using $R^{20}$. Using the same bootstrap technique, bias-corrected accelerated confidence intervals were calculated for means withinthe groups as well as for the differences between groups. Although randomisation was at the level of practices, data were analysed at the more meaningful level of GPs. The CRS is aimed at each individual GP and not systematically embedded in group discussions. Although it is possible that GPs discuss the content of the reminders with their colleagues within a group practice and that this may have a reinforcing effect, we did not expect such reinforcing phenomena to happen.

Due to extreme skewness on our data we could not do a parametric multilevel analysis. Because of the small number of practices left over in the analysis, a bootstrap analysis at practice level was neither possible. So we used a bootstrap analysis on GP level based on earlier findings that ICC's on prescribing behaviour of GPs can be rather low ${ }^{21}$. Moreover, there is debate in the literature on bootstrap analyses for cluster-randomised trials of our size $^{22}$. Finally implementation costs were calculated on individual GP level and expressed as development costs per GP, execution costs per GP, and healthcare costs per GP.

\section{RESULTS}

A total of 77 GPs were invited to take part in this trial. Fifty-three GPs immediately expressed a willingness to participate. After randomisation, the block arms included 28 GPs in arm A and 25 GPs in arm B. Figure 1 describes the study design and shows that follow-up data were available for 48 GPs (5 GPs having dropped out). The reasons for dropping out were: technical problems because of general IT problems in the GP practice (2 GPs), multiple updates to the GP information system (2 GPs) and multiple updates to the operating system (1 GP). We found a significant difference between the groups in gender of the GPs (table 2).

Table 2: Age and gender of GPs in block A and block B with confidence intervals

\begin{tabular}{|c|c|c|}
\hline & Block A (antibiotics, asthma, COPD) & Block B (cholesterol) \\
\hline Mean age GPs & $49(\mathrm{Cl} 46-52)$ & $45(\mathrm{Cl} 41-49)$ \\
\hline Male GPs of total & $83 \%(\mathrm{Cl} 64 \%-100 \%)$ & $69 \%(\mathrm{Cl} 43 \%-94 \%)^{*}$ \\
\hline Group practice & $89 \%(\mathrm{Cl} 73 \%-100 \%)$ & $94 \%(\mathrm{Cl} 80 \%-100 \%)$ \\
\hline Mean practice size per GP & $1510(\mathrm{Cl} 1180-1840)$ & $1986(\mathrm{Cl} 1600-2373)$ \\
\hline
\end{tabular}

* significant difference: $p<0.05$

For technical reasons (communication between different versions of the operating system and the analysis module of the CRS) data could not be analysed for 14 GPs. The remaining 34 GPs did not differ on GP characteristics and prescribing behaviour from the 14 GPs that 
could not be used for analyses. Overall, the prescribing dataset contained 642 prescriptions (95\% Cl: 182; 1126) per GP per year. Each prescription could contain one or more drugs.

\section{Costs of the quality improvement strategy}

Table 3 shows that the development costs of the multidisciplinary guidelines were $€ 7,685$ per GP over 4.3 years.

Table 3: Calculation of fixed and variable costs of the CRS strategy*

\begin{tabular}{|c|c|c|c|}
\hline Type of costs & $\begin{array}{r}\text { Estimate }(\approx) \\
\text { Registrate }(\circledR)\end{array}$ & $\begin{array}{r}\text { Total } \\
\text { costs } \\
\text { (in Euro) }\end{array}$ & $\begin{array}{r}\text { Total costs } \\
\text { per } \mathrm{GP} \\
\text { (in Euro; } n=53 \text { ) }\end{array}$ \\
\hline \multicolumn{4}{|l|}{ 1. Development costs of multidisciplinary guidelines } \\
\hline \multicolumn{4}{|l|}{ Fixed costs } \\
\hline $\begin{array}{l}\text { Total costs of participation by committee members meeting } 10 \text { times and } \\
\text { preparation time (GPs, specialists, pharmacists, representative local } \\
\text { insurance company }\end{array}$ & $\approx$ & 25920 & 489 \\
\hline $\begin{array}{l}\text { Salary costs for project team members and secretary } \\
\text { (project manager, project worker and secretary) }\end{array}$ & $\approx$ & 277214 & 5230 \\
\hline Costs of consultancy during development project structure & $\approx$ & 46794 & 883 \\
\hline Material costs & $\approx$ & 39216 & 740 \\
\hline Rental costs & $\approx$ & 18200 & 343 \\
\hline Total costs phase 1 & & 407344 & 7685 \\
\hline \multicolumn{4}{|l|}{ 2. Development costs of the implementation (CRS) } \\
\hline \multicolumn{4}{|l|}{ Fixed costs } \\
\hline Salary costs for project team member (IT) and secretary & $\approx$ & 110270 & 2081 \\
\hline Material costs & $\approx$ & 39216 & 740 \\
\hline Rental costs & $\approx$ & 18200 & 343 \\
\hline \multicolumn{4}{|l|}{ Developmental costs of the CRS itself } \\
\hline Cost of connecting development software to GP information system & $\approx$ & 9627 & 182 \\
\hline Developmental costs of the CRS software & $\approx$ & 11700 & 221 \\
\hline Cost of testing and implementing the CRS at the GPs' practices & $\approx$ & 25585 & 483 \\
\hline Cost of IT-meetings to bring the parties into line with each other & $\approx$ & 4278 & 81 \\
\hline Total costs phase 2 & & 218876 & 4130 \\
\hline \multicolumn{4}{|l|}{ 3. Execution of the implementation strategy (CRS) } \\
\hline \multicolumn{4}{|l|}{ Fixed costs } \\
\hline Salary costs for project team members (implementation) and secretary & $\approx$ & 114760 & 2165 \\
\hline Material costs & $\approx$ & 19608 & 370 \\
\hline Rental costs & $\approx$ & 9100 & 172 \\
\hline \multicolumn{4}{|l|}{ Variable costs } \\
\hline Educational time for GPs (introduction to the CRS) & $\approx$ & 1193 & 23 \\
\hline Financial incentives GPs (53 GPs) & (®) & 36800 & 694 \\
\hline Total costs phase 3 & & 181461 & 3424 \\
\hline Total costs phase 1 to 3 & & 807681 & 15239 \\
\hline
\end{tabular}

${ }^{*}$ A more detailed calculation of fixed and variable costs of the CRS strategy can be found in appendix 1 


\section{Chapter 6}

Table 4: Medication costs when the recommendation was that no prescribing of a particular drug was advised meaning that the medication costs should be as low as possible

\begin{tabular}{|c|c|c|c|}
\hline Medication costs per GP per 1000 enlisted patients & $\begin{array}{c}\text { I } \\
\text { Mean } \\
(95 \% \mathrm{Cl})\end{array}$ & $\begin{array}{c}\text { C } \\
\text { Mean } \\
(95 \% \mathrm{Cl})\end{array}$ & $\begin{array}{l}\text { Percentage } \\
\text { of all costs }\end{array}$ \\
\hline & $(n=16)$ & $(n=18)$ & \\
\hline \multicolumn{4}{|l|}{ ANTIBIOTICS } \\
\hline cost of doxycyclin and amoxicillin for acute bronchitis & $\begin{array}{c}40.7 \\
(22.0,91.8)\end{array}$ & $\begin{array}{c}53.4 \\
(29.6,94.9)\end{array}$ & 13 \\
\hline $\begin{array}{l}\text { cost of antibacterial antibiotics for acute sore at the beginning of } \\
\text { the throat episode }\end{array}$ & $\begin{array}{c}1.0 \\
(0.3,2,5)\end{array}$ & $\begin{array}{c}2.9 \\
(1.0,6,3)\end{array}$ & 0.5 \\
\hline $\begin{array}{l}\text { cost of feneticilline, azitromycin, fenoxymethylpenicilline for } \\
\text { acute sore throat }\end{array}$ & $\begin{array}{c}1.3 \\
(0.1,4.0)\end{array}$ & $\begin{array}{c}5.1^{*} \\
(1.6,12.1)\end{array}$ & 1 \\
\hline $\begin{array}{l}\text { cost of antibacterial antibiotics without doxycyclin for acute } \\
\text { sinusitis at the beginning of the episode }\end{array}$ & $\begin{array}{c}49.8 \\
(32.8,80.0)\end{array}$ & $\begin{array}{c}79.1 \\
(56.9,105.1)\end{array}$ & 18 \\
\hline cost of doxycyclin for acute sinusitis & $\begin{array}{c}30.4 \\
(19.9,42.2)\end{array}$ & $\begin{array}{c}42.3 \\
(28.7,67.3)\end{array}$ & 10 \\
\hline cost of amoxicillin and azitromycin for otitis media acuta & $\begin{array}{c}24.6 \\
(15.8,37.9)\end{array}$ & $\begin{array}{c}32.1 \\
(20.5,51.7)\end{array}$ & 8 \\
\hline cost of antibiotics for otitis media acuta & $\begin{array}{c}32.6 \\
(22.0,50.5)\end{array}$ & $\begin{array}{c}42.4 \\
(28.0,68.4)\end{array}$ & 10 \\
\hline cost of quinolones for cystitis among women $>12$ years & $\begin{array}{c}28.7 \\
(13.8,53.9)\end{array}$ & $\begin{array}{c}39.3 \\
(22.9,59.7)\end{array}$ & 9 \\
\hline \multicolumn{4}{|l|}{ ASTHMA/COPD } \\
\hline $\begin{array}{l}\text { all asthma costs for intermittent asthma and maintenance } \\
\text { treatment }\end{array}$ & $\begin{array}{c}77.0 \\
(32.1,170.8)\end{array}$ & $\begin{array}{c}96.9 \\
(40.7,241.6)\end{array}$ & 24 \\
\hline $\begin{array}{l}\text { cost of cromones for mildly persistent asthma with maintenance } \\
\text { treatment }\end{array}$ & $\begin{array}{c}1.5 \\
(0,3.8)\end{array}$ & 0 & 1 \\
\hline $\begin{array}{l}\text { cost of inhaled corticosteroids for newly diagnosed COPD } \\
\text { patients }>40 \text { years }\end{array}$ & $\begin{array}{c}2.6 \\
(0,11.8)\end{array}$ & $\begin{array}{c}37.2^{\star} \\
(20.6,58.2)\end{array}$ & 5 \\
\hline total costs of antibiotics/asthma/COPD block & $\begin{array}{c}290.9 \\
(221.9,384.0)\end{array}$ & $\begin{array}{c}430.0^{*} \\
(336.4,616,0)\end{array}$ & \\
\hline \multicolumn{4}{|l|}{ CHOLESTEROL } \\
\hline $\begin{array}{l}\text { cost of statins for newly diagnosed patients with } \mathrm{DM}^{1} \text { or } \mathrm{CVD}^{2} \\
\text { aged } 18-70 \text { years with cholesterol }<3.5 \mathrm{mmol}\end{array}$ & 0 & $\begin{array}{c}5.7 \\
(0,17.1)\end{array}$ & 1 \\
\hline total costs of cholesterol block & 0 & $\begin{array}{c}5.7 \\
(0,17.1)\end{array}$ & \\
\hline
\end{tabular}

${ }^{*} \mathrm{p}<0.05$

${ }^{1}$ Diabetes Mellitus

${ }^{2}$ Cardiovascular Diseases 
Table 5: Medication costs when the recommendation was that prescribing of a particular drug was advised meaning that the medication costs should be as high as possible

\begin{tabular}{lccc}
\hline Medication costs per GP per 1000 enlisted patients & $\begin{array}{c}l \\
\text { Mean }(95 \% \mathrm{Cl})\end{array}$ & $\begin{array}{c}\text { Mean }(95 \% \mathrm{Cl}) \\
\text { of all costs }\end{array}$ \\
\hline & $(\mathrm{n}=16)$ & $(\mathrm{n}=18)$ &
\end{tabular}

\section{ANTIBIOTICS}

cost of benzoylperoxi and salicylacid for acne vulgaris (mainly

comedones)

cost of erytromycin, minocyclin, cyproteronacetaat for acne

vulgaris (mainly inflammation — symptoms )

cost of minocyclin, benzoylperoxi, salicylacid for acne vulgaris

(comedones with inflammation - symptoms)

cost of fenoxymethylpenicillin, feneticillin, erytromycin for

erysipelas

cost of fusedine acid, zinc preparation combined with a

disinfectant for impetigo

cost of flucloxacillin, azitromycin for impetigo

cost of co-trimoxazol, ciprofloxacin, norfloxacin for recurrent and chronic symptoms of prostatitis

cost of trimethoprim, nitrofurantoine for acute and recurrent

cystitis among female patients $>12$ years

\section{ASTHMA/COPD}

cost of first choice short-acting beta-agonist ${ }^{1}$ for

intermittent/mildly persistent and moderately persistent asthma

with acute symptoms among patients $>7$ years

cost of first choice corticosteroids ${ }^{2}$ for mildly persistent asthma

with maintenance treatment among patients $>7$ years

cost of long-acting beta-agonist ${ }^{3}$ AND: costs of first choice

corticosteroids ${ }^{2}$ for moderately persistent asthma with

maintenance treatment among patients $>7$ years

cost of long-acting beta-agonist ${ }^{3}$ AND: costs of first choice

corticosteroids ${ }^{2}$ for severely persistent asthma with acute

symptoms or maintenance treatment among patients $>7$ years

cost of ipratropiumbromid powder inhaler, ipratropiumbromid

dose aerosol, salbutamol disk, salbutamol dose-aerosol for

newly diagnosed COPD patients $>40$ years

total costs of antibiotics/asthma/COPD block

\section{CHOLESTEROL}

cost of statins for newly diagnosed patients with $\mathrm{DM}^{4}$ or $\mathrm{CVD}^{5}$ age 18-70 years and cholesterol with cholesterol $>5.5 \mathrm{mmol}$ total costs of cholesterol block
0.8

$(0.1,3.0)$

1.2

0

20.6

$(0.4,2.3)$

$(11.3,42.2)$

6.7

$(2.1,24.4)$

8.8

27.2

5

(16.5,38.0)

5.8

$(2.1,14.2)$

8.8

9.8

$(4.7,20,4)$

21.9

18.4

4

$(14.3,38.1)$

$(10.0,29.8)$

10.6

5.5

$(4.6,22.5)$

$(2.3,10.3)$

12.4

5.4

$(1.8,15.1)$

$(5.2,28.0)$

26.9

(16.4, 40.8)

(12.4, 43.8)

93.7

19

90.8

$(62.1,146.3)$

$(51.5,173.3)$

156.0

39

234.1

$(80.8,349.0)$

$(115.8,460.0)$

11.9

0

1

$(0,35.8)$

22.5

12.7

4

$(0.4,124.3$

$(0.4,78.0)$

29.7

31.1

6

$(14.9,53.5)$

$(11.0,73.8)$

501.0

394.0

(307.1, 764.7)

(268.2, 645.6)

55.4

34.8

9

\section{8}

$(13.7,81.8)$

* $p<0.05$

1 terbutalin turbohaler/salbutamol disk/salbutamol dose-aerosol

2 budesonide turbuhaler/fluticasone disk/fluticasone dose-aerosol

${ }^{3}$ salmeterol disk/salmeterol dose-aerosol/formoterol dose-aerosol

${ }^{4}$ Diabetes Mellitus

${ }^{5}$ Cardiovascular Diseases 
The cost of developing the CRS was $€ 4,130$ per GP for 4.3 years. With respect to the diffusion of the CRS among GPs in the region execution costs were $€ 3,424$ per GP over 4.3 years. The total implementation costs of the CRS were therefore $€ 15,239$ per GP over 4.3 years.

\section{Healthcare costs and savings of the quality improvement strategy}

Tables 4 and 5 show the healthcare costs (medication costs) on which the CRS interacted. Table 4 shows the medication costs of drugs that were discouraged in the intervention group. Table 5 shows the medication costs of drugs that were recommended in the intervention group. Clinically meaningful trends were seen in both tables, but only table 4 showed significant results. Two specific medication costs had significant outcomes. Firstly, costs for feneticilline, azitromycin, fenoxymethylpenicilline for acute sore throats were $€ 1.3(95 \% \mathrm{Cl}$ : $0.1-4.0)$ in the intervention group versus $€ 5.1(95 \% \mathrm{Cl}: 1.6-12.1)$ in the control group $(p=0.05)$. Secondly, the costs of inhaled corticosteroids for newly diagnosed COPD patients older than 40 years were $€ 2.6$ (95\% Cl: $0-11.8)$ in the intervention group versus $€ 37.2(95 \%$ Cl: 20.6-58.2) in the control group $(p=0.01)$. Significant results were seen for the total medication costs for all the antibiotics, asthma and COPD drugs that were discouraged, being $€ 291$ per GP per year in the intervention group versus $€ 430$ per GP per year in the control group $(p=0.05)$. The total medication costs of cholesterol-lowering drugs that were discouraged were $€ 0$ per GP per year in the intervention group versus $€ 5$ per GP per year in the control group ( $p>0.2)$.

Medication costs of antibiotics, asthma and COPD for recommended drugs were $€ 501$ per GP per year in the intervention group versus €394 per GP per year in the control group $(p>0.2)$. For cholesterol-lowering drugs that were recommended for patients with an indication for these drugs, medication costs were $€ 55$ per GP per year in the intervention group versus $€ 35$ per GP per year in the control group $(p>0.2)$.

\section{Discussion}

\section{Main results}

It proved possible to gather the data of the remaining GPs (90\%) to evaluate the costs and cost reductions of the CRS to improve GPs' prescribing behaviour. Due to technical problems such as communicational problems between different versions of the operating system and the analysis module of the CRS, evaluation could only be executed on $65 \%$ of all GP databases.

Strategy and healthcare costs are summarised in table 6. The costs of developing the guidelines and of developing and executing the CRS were $€ 15,239$ per GP over 4.3 years. The major costs were the development of the multidisciplinary guidelines ( $€ 7,685$ per GP) and the development of the CRS (€4,130 per GP). There was a significant decrease when prescribing of a particular drug was not advised, meaning medication costs were intended to 
become as low as possible according to guidelines that recommended restricting certain drugs. At the same time, a positive trend, although not significant, was seen when prescribing of a particular drug was advised, meaning medication costs were expected to become as high as possible for guidelines that recommended prescribing certain drugs.

There was a significant decrease when prescribing of a particular drug was not advised, meaning medication costs were intended to become as low as possible according to guidelines that recommended restricting certain drugs. At the same time, a positive trend, although not significant, was seen when prescribing of a particular drug was advised, meaning medication costs were expected to become as high as possible for guidelines that recommended prescribing certain drugs.

Table 6: Costs of the strategy and healthcare costs per GP

\begin{tabular}{|c|c|c|}
\hline \multirow[t]{2}{*}{ Type of costs } & \multicolumn{2}{|c|}{$\begin{array}{l}\text { Total costs per GP } \\
\text { (in Euro; } n=53 \text { ) }\end{array}$} \\
\hline & $\begin{array}{r}\text { Intervention } \\
\text { group }\end{array}$ & $\begin{array}{r}\text { Control } \\
\text { group }\end{array}$ \\
\hline \multicolumn{3}{|l|}{ Costs of the quality improvement strategy (over 4.3 years) } \\
\hline 1. Developmental costs of multidisciplinary guidelines & 7685 & - \\
\hline 2. Developmental costs of the innovation (CRS) & 4130 & - \\
\hline 3. Execution of the implementation strategy & 3424 & - \\
\hline Total costs of phase 1 to 3 & 15239 & - \\
\hline \multicolumn{3}{|l|}{ Healthcare costs and savings of the quality improvement strategy (1 year follow-up) } \\
\hline $\begin{array}{l}\text { Medication costs of prescriptions antibiotics, asthma and COPD when the recommendation } \\
\text { was NOT to prescribe }\end{array}$ & 291 & $430^{*}$ \\
\hline $\begin{array}{l}\text { Medication costs of prescriptions cholesterol-lowering drugs when the recommendation was } \\
\text { NOT to prescribe }\end{array}$ & 0 & 6 \\
\hline $\begin{array}{l}\text { Medication costs of prescriptions antibiotics, asthma and COPD when the recommendation } \\
\text { was to prescribe a particular drug }\end{array}$ & 501 & 394 \\
\hline $\begin{array}{l}\text { Medication cost of prescription cholesterol-lowering drugs when the recommendation was to } \\
\text { prescribe a particular drug }\end{array}$ & 55 & 35 \\
\hline
\end{tabular}

${ }^{*} p<0.05$

\section{Strengths and weaknesses of the economic evaluation}

A strong aspect of our study is that we were able to calculate the fixed and variable costs of the different phases of a quality improvement strategy: development costs of the prescribing guidelines, development costs of the CRS and execution costs of the CRS among GPs in the region. These costs were calculated per phase and expressed in costs per GP over 4.3 years. Medication costs were also expressed as cost indicators and were based on drug information stored in the CRS data warehouse. This gave us a unique opportunity to make a rather precise estimation of the change in medication costs per GP due to the CRS strategy.

There are also some issues for consideration. Firstly, no data on health benefits were available in this evaluation so our study can not be considered to be a full economic evaluation. Given the complexity of our study, including health benefits might not be 
practicable because for this purpose patient characteristics should be connected to each prescription.

Secondly, this cost evaluation was limited because we used retrospective data for the cost calculations per phase and some of the calculations were based on estimates. Because we used retrospective data, some costs could not be expressed because registration was missing or during registration some expected costs turned out to be negligible. For example the time GPs took to read and validate the guidelines could not be calculated in terms of costs because it turned out that GPs hardly ever read the draft guidelines. To be able to evaluate the cost of quality improvement strategies in the future, prospective data should be collected during the development and execution of the strategy to improve the quality of the calculations. Due to the fact that GPs in the Netherlands are only registering a diagnosis as a text field for the problem list of their GP information system we could not distract the coded diagnosis data (as ICPC codes) for our study. Therefore, we needed additional data. GPs could not be motivated to enter additional information for our study (diagnosis and disease related information) without being rewarded with feedback by the reminders. So, in this study we had no baseline measurement. It is possible that some of the GPs were already prescribing quite well (ceiling effect), so there was not much room for improvement. This would be problematic if this well behaving would be unbalanced over the groups. Our GPs can be looked upon as the innovators, and were all participating during the complete trial period. So we do not expect an unbalanced distribution of already well prescribing GPs in one of the blocks

Thirdly, due to technical problems and incompatibilities between the GP system and the operating system, data could not be analysed for $14 \mathrm{GPs}$, which had a negative effect on the power of this study, although this problem arose at random. Furthermore, our analyses on differences between the GP groups revealed a difference in gender. We cannot think of any bias in our data to account for this difference, which reflects a difference in the numbers of female versus male GPs in this region. We are not aware of any literature showing differences in adherence to guidelines based on gender differences.

At last, as was explained in the methods section we did not execute multilevel analysis due to the severe skewness of the data. We do not expect within practice clustering of the adapted behaviour, because there were no signs that individual GPs discussed the CRS among each other within one practice. Moreover, Intra Cluster Correlations (ICC's) in comparable studies are commonly too low to be meaningful (ICC $0.01-0.06^{23}$ ).

Economic evaluation in quality improvement strategies might not be neglected and might be an important factor when making decisions about the implementation of CRS on a national scale. In this study simple sensitivity analyses using prices of medication and other prices were not performed because these prices are exact for the Netherlands (prices for medication) or are based on Dutch reference prices.

We found an effect of the intervention on prescribing costs. Because of the large amount of patients involved and the magnitude of the prescription data in this kind of research it is practically impossible to focus on outcome effects on individual patient level. Although effect 
on patient outcome have not been assessed, we envision that a more consequent adherence to guidelines of GPs has at least no negative effects on the quality of the delivered health care and undoubtedly positive consequences on health outcomes. The health outcomes envisioned depend on the studied recommendations per guideline:

a. Antibiotics: Shortened episodes of infections.

b. Asthma and COPD: Improved control of asthmatic episodes.

c. Cholesterol: A reduction of events related to cardiovascular diseases.

The participating GPs in the project could be considered as computerisation innovators. This might make the results less representative. On the other hand, there might be more room for improvement among those who lag behind. Only by extending the number of guidelines and the number of GPs the balance between costs and savings might become positive. The costs of developing the guidelines and the CRS were largely once-only. When introducing the CRS to all GPs in the Netherlands, with 8000 practicing GPs, the impact of the development costs for the guidelines and the CRS will decrease. Expanding the number of guidelines in the CRS will enlarge the savings on medication costs. Applying the CRS to already existing national guidelines will also improve the balance between costs and effects. The CRS can easily be used in all the available medical information systems in the Netherlands.

\section{CONCLUSION}

We did not perform a full economic evaluation taking the benefits of better adherence into account. This study turned out to be underpowered due to high inter doctor variation in prescribing behaviour. Nevertheless, improved adherence to the guidelines restricting certain drugs that are not or no longer indicated in general practices resulted in medication cost changes in the desired direction. This cost evaluation shows that implementation of the CRS costs $€ 15,239$ per GP over 4.3 years. The cost changes were smaller than the development and execution costs. However, development costs are once-only and will be reduced by extrapolating the strategy over time, to a larger population with more guidelines, and applying the strategy to already existing national guidelines. Implementing this intervention all over the country, would mean that we could distribute the fixed costs of the CRS intervention ( $€ 769,666$ in total) over all Dutch GPs, being about 8000 GPs. Expecting a participation rate of $90 \%$ would mean that the fixed costs would be hugely reduced to $€ 107$ per GP. Given the savings generated by the CRS and the possibility of reducing the development costs we recommend further extension of the number of guidelines in the CRS and further expansion of the CRS among GP practices in the Netherlands. Although initial investments were high, we expect this strategy to reduce costs in the long run. 


\section{REFERENCES}

1. Centraal Bureau voor de Statistiek. Statistisch jaarboek 2003 (Statistical yearbook 2003), vol. 96. Heerlen: Centraal Bureau voor de Statistiek; 2003.

2. Stichting Farmaceutische Kengetallen; Data en Feiten (Foundation for Pharmaceutical Statistics; Data and facts). The Hague/the Netherlands; 2000-2004.

3. Breekveldt-Postma NS, Zwart-van Rijkom JE, Egberts AC, Leufkens HG, Herings RM. Rising costs of drugs in hospitals in the period 1996-2000 and over the next few years (Ned Tijdschr Geneeskd 2002;146(52):2547-51.

4. Kawamoto K, Houlihan CA, Balas EA, Lobach DF. Improving clinical practice using clinical decision support systems: a systematic review of trials to identify features critical to success. BMJ 2005;330:765-8.

5. Sittig DF, Krall MA, Dykstra RH, Russell A, Chin HL. A survey of factors affecting clinician acceptance of clinical decision support. BMC Med Inform Decis Mak. 2006;6:6.

6. Garg AX, Adhikari ND, McDonald H, Rosas-Arellano MP, Devereaux, PJ, Beyene J, Sam J, Haynes RB. Effects of Computerized Clinical Decision Support Systems on Practitioner Performance and Patient Outcomes. A Systematic Review. JAMA. 2005;293:1223-38.

7. Hunt DL, Haynes RB, Hanna SE, Smith K. Effects of computer-based clinical decision support systems on physician performance and patient outcomes. JAMA 1998;280:339-46.

8. Bennett JW, Glasziou PP. Computerised reminders and feedback in medication management: a systematic review of randomised controlled trials. MJA 2003;178:217-22.

9. Mason J, Freemantle N, Nazereth I, Eccles M, Haines A, Drummond M. When is it cost effective to change the behaviour of health professionals? JAMA 2001;286:2988-92.

10. Severens JL. Value for money of changing healthcare services? Economic evaluation of quality improvement. Qual. Saf. Health Care 2003;12:366-71.

11. Mason J, Eccles M, Freemantle N, Drummond M. A framework for incorporating cost-effectiveness in evidence-based clinical practice guidelines. Health policy 1999;47(1):37-52.

12. Sculpher M. Evaluating the cost-effectiveness of interventions designed to increase the utilization of evidence-based guidelines. Fam Pract 2000;17(31):1s26-31.

13. Jefferson TO, Demicheli V, Vale L. Methodological reviews of economic evaluations in health care. JAMA 2002;287:2809-12.

14. Grimshaw JM, Thomas RE, MacLennan G, Fraser C, Ramsay CR, Vale L, Whitty P, Eccles MP, Matowe L, Shirran L, Wensing M, Dijkstra R, Donaldson C. Effectiveness and efficiency of guideline dissemination and implementation strategies. Health Technol Assess. 2004:6:iii-iv, 1-72.

15. J.D. Martens, T. van der Weijden, J.L. Severens, P.A. de Clercq, D. de Bruyn, A.D. Kester, R.A.G. Winkens The effect of computer reminders on GPs' prescribing behaviour. Int J Med Inform. 2007 Jun 12; [Epub ahead of print].

16. Severens JL, Martens JD, Wensing M. Economic evaluation of implementation strategies. In: Grol $\mathrm{R}$, Wensing M, Eccles M. Improving Patient Care. The Implementation of Change in Clinical Practice. Oxford: Butterworth-Heinemann 2005:273-84.

17. Verstappen WH, van der Weijden T, ter Riet G, Grimshaw J, Winkens R, Grol RP. Block design allowed for control of the Hawthorne effect in a randomized controlled trial of test ordering. J Clin Epidemiol. 2004;57(11):1119-23.

18. Oostenbrink JB, Bouwmans CAM, Koopmanschap MA, Rutten FFH. Handleiding voor kostenonderzoek. Methoden en standaard kostprijzen voor economische evaluaties in de gezondheidszorg. Diemen: CVZ 2005. Website available at http://cvz.nl

19. Z-index: Wetenschappelijk Instituut Nederlandse Apothekers (WINAp) Geneesmiddelinformatie. Website available at: http://z-index.nl.

20. R Development Core Team (2005). R: A language and environment for statistical computing. $R$ Foundation for Statistical Computing, Vienna, Austria. ISBN 3-900051-07-0. Website available at: http://www.R-project.org. 
21. Eccles $M$ et. al. Experimental evaluations of change and improvement strategies. In: Grol R, Wensing M, Eccles M. Improving Patient Care. The Implementation of Change in Clinical Practice. Oxford: Butterworth-Heinemann 2005:273-84.

22. Flynn TN, Peters TJ. Use of the bootstrap in analysing cost data from cluster randomised trials: some simulation results. BMC Health Serv Res. 2004;4(1):33.

23. Eccles M, Grimshaw J, Campbell M, Ramsay C. Research designs for studies evaluating the effectiveness of change and improvement strategies. Qual Saf Health Care. 2003;12(1):47-52. 



\section{Appendix 1: DeVelopment costs, healthcare costs and savings of the QUALITY IMPROVEMENT STRATEGY}

\section{Development costs of the quality improvement strategy}

\section{Development of multidisciplinary guidelines}

Preparation times for each member of the multidisciplinary guideline committee (GPs, specialists, pharmacists and insurance company) and time spend by the committee member during the meetings. Secretarial time spent organising the meetings was calculated per meeting. Since each meeting lasted 1.5 hours, and we assumed half an hour for preparation and travelling, one meeting took 2 hours of the professionals' time. Fees were derived from the Dutch Government's annual care review. A percentage of the project team members' salary (project manager, project team members) was calculated for each phase. Other costs were: Cost of validating the guidelines: time spent by GPs reading the conceptual guidelines in order to comment and response time if comments were made.

\section{Development of the Computer Reminder System}

The most important costs in this phase were costs generated by the meetings when the parties to met to develop the CRS, costs generated by the company that developed the Computer Reminder System and the company that developed the interface between the reminder system and the GP information system and the cost of testing the CRS. Salary costs of the project team worker involved and the secretary.

\section{Healthcare costs of the quality improvement strategy}

\section{Medication costs}

The individual cost prices of all drugs on which the CRS interacted were calculated on ATCcode level. The ATC system for classifying drugs is widely used in European countries and is a specific classification, although different doses or trademarks of one manufacturer are classified on the same ATC-code. ATC classifications are available online, and are updated and published once a year by the World Health Organization Collaborating Centre for Drug Statistics Methodology. Cost prices per drug were received via the Scientific Institute of Dutch Pharmacists, a Dutch national authority on pharmaceutical sciences. The data contained information on the name of the drug, the name of the manufacturer, different subcoding systems, dose information, substance and cost price per entity and per pill. We selected a subset of only primary care drugs.

To prevent our having to work with an extensive number of cost prices, we chose to calculate a cost price on ATC-code level by means of bulk prices. Table 1 shows the individual drug costs expressed in a range of individual cost prices of all drugs covered by a particular ATC-code. In addition, we used the analysis module of the CRS to investigate the differences in costs between the intervention and control group (table 4 and 5). 


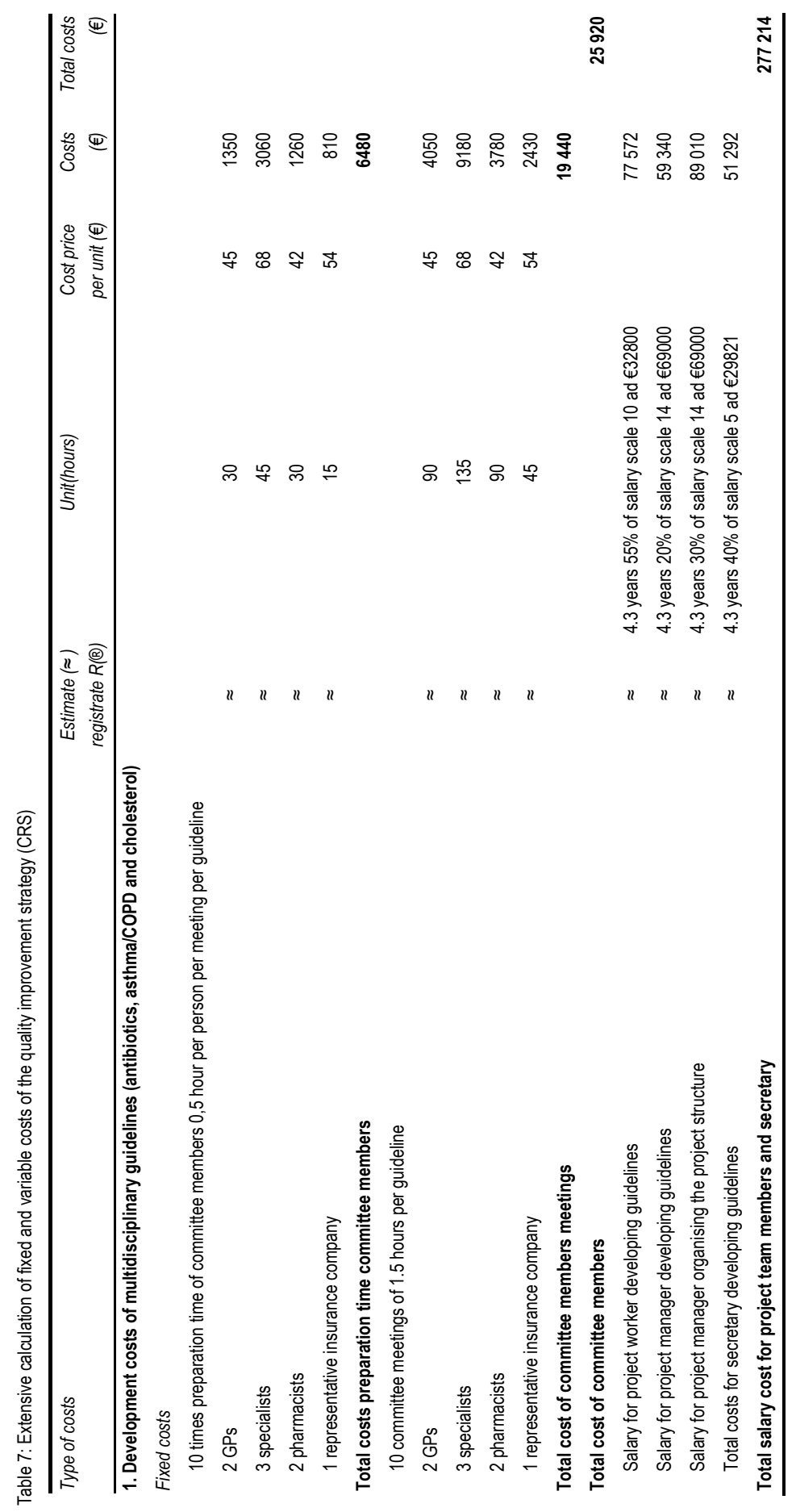









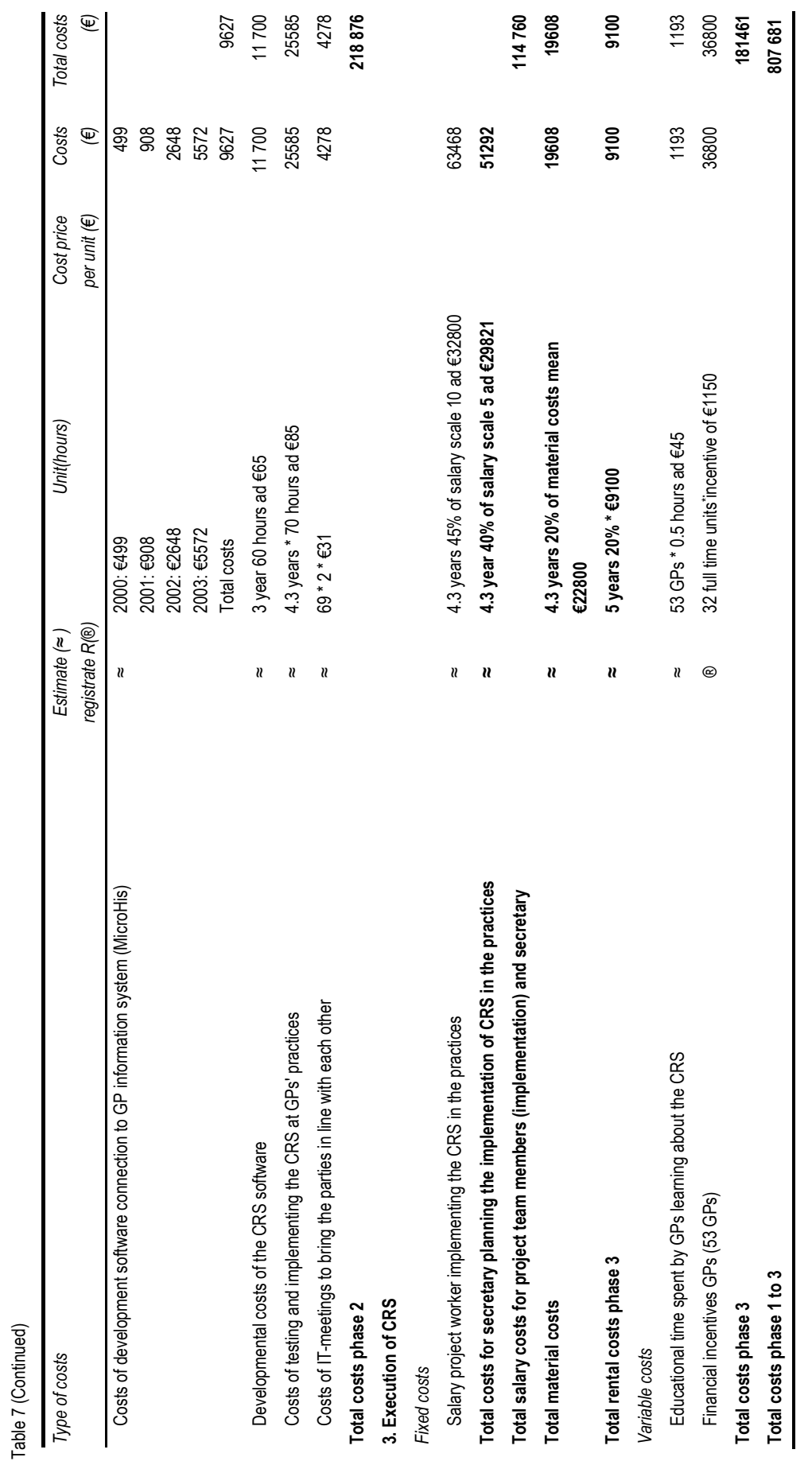




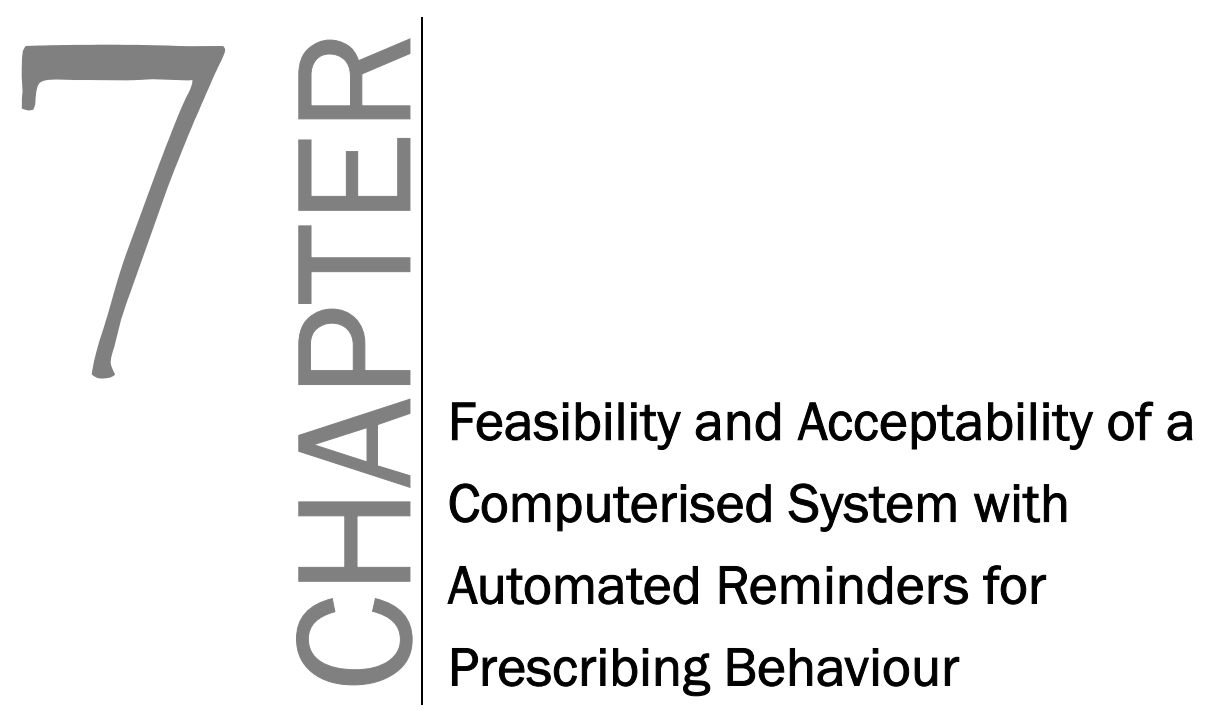

Published as: JD Martens, $T$ van der Weijden, RAG Winkens, AD Kester, PJH Geerts, SMAA Evers, JL Severens Feasibility And Acceptability Of A Computerised System With Automated Reminders For Prescribing Behaviour In Primary Care. Int J Med Inform. 2007 Jul 13; [Epub ahead of print]. 


\section{ABSTRACT}

\section{Objective}

To evaluate the feasibility and acceptability of a Computer Reminder System (CRS) to improve prescribing behaviour in general practice and to explore the strengths and weaknesses of a reminder system. One group of GPs received reminders on cholesterol lowering drugs, the other group on antibiotics, asthma and COPD drugs.

\section{Methods}

Process evaluation of the computer reminder system being used by 53 GPs in 20 practices, by means of an analysis of the research database of the CRS. In addition, a questionnaire and semi-structured face-to-face interview were conducted with all GP practices, 2 project leaders, and one technical consultant.

\section{Results}

The strategy was largely carried out as planned, although the development period for the CRS had to be extended. $9 \%$ of the GPs dropped out. We found a significant learning curve without extinguishing effect $(p=0.03)$ for the antibiotics reminders. The questionnaire showed that, in general, GPs were satisfied with the user-friendliness and the content of the different types of reminders, but less satisfied with certain specific technical performance issues of the system. The GPs reported mixed feelings towards the CRS in the interviews. In general, they were positive about the guidelines themselves, but negative regarding to the organisational context and the method of implementing the CRS. GPS stated that they sometimes manipulated the system to bypass reminders. Interviews with the project leaders and technical consultant revealed barriers to cooperation and miscommunication between the different parties, and technical problems with multiple updates of the GP information system and the operating system.

\section{Conclusions}

This process evaluation demonstrated that the implementation of the CRS was mainly carried out as planned, but the subjective experience of working with the CRS was not only positive. Participating GPs had mixed feelings, and quite a number of barriers need to be addressed to facilitate large-scale implementation of the CRS. Costs cannot be neglected, so it is important to analyse the balance between costs and effects. 


\section{INTRODUCTION}

Health care expenditure in the Netherlands increases every year, as is the case in other European countries. Drug prescribing is an important contributor to the escalation of these costs, and these costs will continue to increase considerably in the next few years ${ }^{1}$. Medication is not always prescribed efficiently; lower-cost alternatives are not always taken into consideration ${ }^{2}$.

Quality improvement strategies are used to improve prescribing behaviour. A Computer Reminder System (CRS) was developed for a local quality improvement project. It was based on prescribing recommendations from regionally adapted evidence-based multidisciplinary guidelines. From previous studies we know that computerised reminders can be effective in improving practitioners' performance and have sometimes even proved to be cost-effective in influencing prescribing behaviour ${ }^{3-9}$.

We therefore carried out a randomised trial to evaluate the effects of a CRS on prescribing behaviour among GPs in our region, which resulted in mixed effects ${ }^{10}$. There were significant and clinically meaningful changes in the desired direction with regard to recommendations NOT to prescribe, while there were hardly any changes regarding the recommendations to change the type of drug or the dose. To shed light on these findings it may be of relevance to document the reasons for the system's success or failure and to disentangle the system in search of its effective components ${ }^{11,12}$. Findings on the feasibility of the CRS under consideration can be used as input for other CRS being developed and improve progressive understanding of why CRS sometimes work and sometimes do not.

The purpose of this study was to assess the actual dissemination and implementation of the CRS for changing prescribing behaviour in the participating practices in our trial. Was the CRS strategy implemented according to plan, and which barriers and facilitators have to be taken into account for large-scale implementation of the CRS?

Research questions:

a. How feasible and acceptable was the implementation of the CRS for prescribing behaviour in primary care (proportion of GPs that actually started working with the CRS and continued working with it after one year, course of the reminder frequency per GP per month, the learning curve, and course of manipulating the system)?

b. How satisfied were the GPs and what were the barriers and facilitators for working with the CRS? 


\section{Methods}

\section{Design and population}

The study was carried out as a prospective process evaluation among 53 GPs in the south of the Netherlands who were participating in the CRS trial. The trial protocol is described elsewhere ${ }^{13}$. In a process evaluation the adherence to the intervention protocol is assessed in the intervention arm of an experiment. As we have chosen for a block design ${ }^{10}$, both arms of the experiment were exposed to the intervention. In Figure 1 this block design is shown. In a block design all participants are exposed to the intervention, but only to one part ("block") of the underlying guidelines. One group received reminders on cholesterol lowering drugs and the other group received reminders on antibiotics/asthma/COPD. The topics on antibiotics/asthma-/COPD-drugs were combined into one group because the underlying clinical problems may occur together for some patients with therefore a risk that reminders may interact. GPs were blind with regard to being controls for each other. A block design has advantages in implementation studies; because of the blinding of the professionals to a certain extend and meeting the participants' wish to be exposed to the intervention ${ }^{14}$.

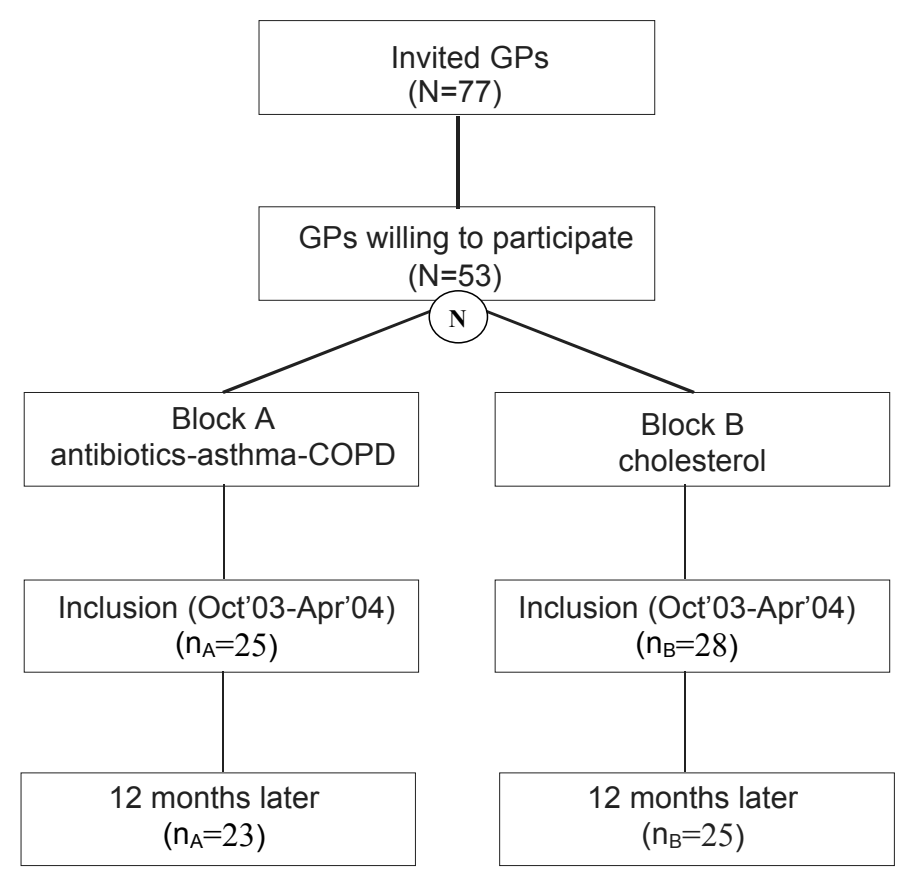

Figure 1: Flowchart overview of GP inclusion 
In our block design participants were intervened on part of the underlying guidelines. We chose for one group receiving reminders on antibiotics, asthma and COPD and another group receiving reminders on cholesterol lowering drugs. GPs were blind with regard to being controls for each other. We extracted data on both groups being control groups for each other ${ }^{10}$. Although randomisation was at the level of practices, data were analysed at the more meaningful level of GPs. But the CRS is aimed at each individual GP and not systematically embedded in group discussions. Although it is possible that a GP discusses the content of the reminders with his or her colleague within a group practice, which may have a reinforcing effect, we did not expect this to happen. Intra-cluster correlation coefficients for prescribing were low (ICC's: 0.01-0.07) according to Eccles et. $\mathrm{al}^{15}$.

Both quantitative and qualitative methods were applied in seeking the answers to the research questions ${ }^{13}$. The actions taken by the GPs working with the CRS were described through quantitative analyses of data stored in the system (question 1). Furthermore, a questionnaire was conducted among the GPs with questions about technical problems and user satisfaction. Besides this, in-depth interviews were held with a selection of the participating GPs, the project manager and the technical consultant, in order to analyse the barriers and facilitators in a more qualitative manner (question 2).

\section{Strategy}

Prescribing guidelines were set by a regional multidisciplinary committee of opinion leaders, (pharmacists, GPs, hospital staff), and based on the prevailing insights of Evidence Based Medicine (EBM). The topics were selected because of the high prevalence of these health problems, and included antibiotics, asthma/COPD-related drugs and cholesterol-lowering drugs $^{16}$.

The CRS integrates these prescribing guidelines into a tool that assists GPs to adhere to the guidelines and therefore to prescribe drugs more rationally. CRS can be issued proactively and reactively. Proactive systems give comments or suggestions before a drug is chosen. Reactive systems give comments after a drug is chosen but before the prescription is actually printed. The real-time automated CRS is a reactive system focusing mainly on primary care, covering a range of prescribing guidelines and containing various types of reminders, recommending: alternative type of drug; other doses; alternative drug administration; only prescribe for a specific indication; other length of treatment; not to prescribe anything; an alternative (no drug prescription) approach; refer to specialist. The GPs had to register the diagnosis for which they prescribed the medication, using the diagnoses listed in the ICPC (International Classification of Primary Care ${ }^{17,18}$, available in their GP Information System.

The automated feedback system has four parts: 1). a guideline editor in which prescriptionrelevant guidelines were developed using a graphical user interface; 2). a guideline knowledge base that contains these guidelines, 3) a decision support system (DSS) that provides reactive support (i.e. reminders) based on the guidelines developed and patient data stored in the GP Information System's database, and finally 4) a research database 
where -for each prescription- data was stored that was used to analyse the GP's behavioural changes (figure 2). This data consisted of the patient's age and gender, prescribed drugs, diagnosis-related information and the reminders that were given by the $\mathrm{DSS}^{19}$.

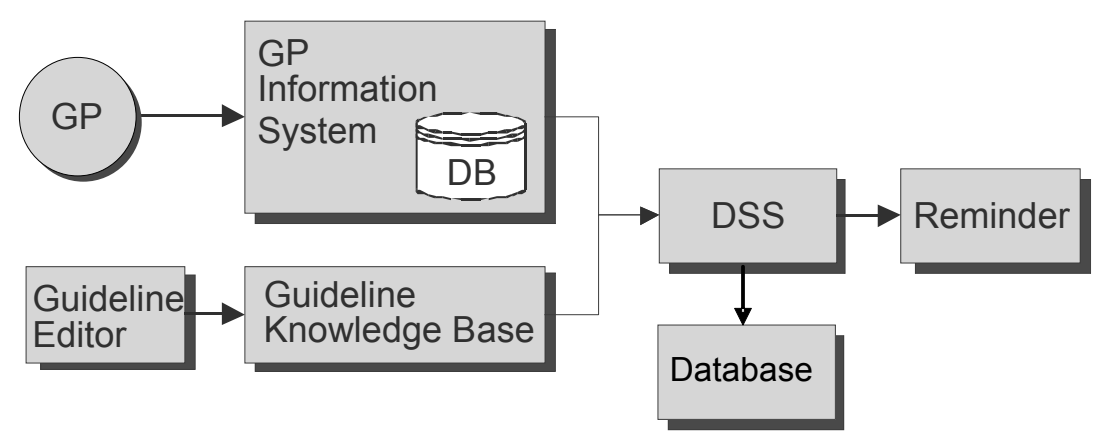

Figure 2: General structure of the CRS

The Decision Support System part of the CRS was implemented on top of the existing GP Information System that contained general patient data and the patient's medications and diagnoses. The GP Information System also provides a drugs prescribing module. When the GP prescribed a drug, the DSS was activated by the GP Information System, providing the DSS with patient-specific information (e.g. age and gender) and the prescribed drug. The GP was obliged to register a diagnosis, using the ICPC-code, and diagnosis-related information (e.g. severity of the complaints) for all patients with asthma/COPD, cholesterol-related disease or infections, for which drugs were prescribed. Based on the patient's age and gender, prescribed drug and the above-mentioned diagnosis-related information, the DSS checked whether any of the IF-THEN rules fired. When one or more rules fired (meaning that the corresponding guideline was not followed), a reminder was given. An example of a reminder, disrecommending prescribing asthma medication (Salbutamol) for a patient suffering from mildly intermittent asthma with maintenance treatment, is shown in figure 3 . The character of the reminders could be more or less persuasive and contained various types of reminders, recommending: alternative type of drug; other doses; alternative drug administration; only prescribe for a specific indication; other length of treatment; not to prescribe anything; an alternative (no drug prescription) approach; refer to specialist.

The participating GPs received individual (in solo practices) or group (in group practices) instruction when the system was installed in the practice. The intervention was implemented in individual practices between October 2003 and April 2004 and had no time limit. The GPs were split up into two groups for the sake of the trial. Each group received only some of the reminders, to enable the GPs to function as controls for each other. One group received reminders on cholesterol lowering drugs, the other group on antibiotics, asthma and COPD drugs. The reminders that would have popped up in the control group were also registered in the research database. In this way it was possible to measure behaviour in both groups. 


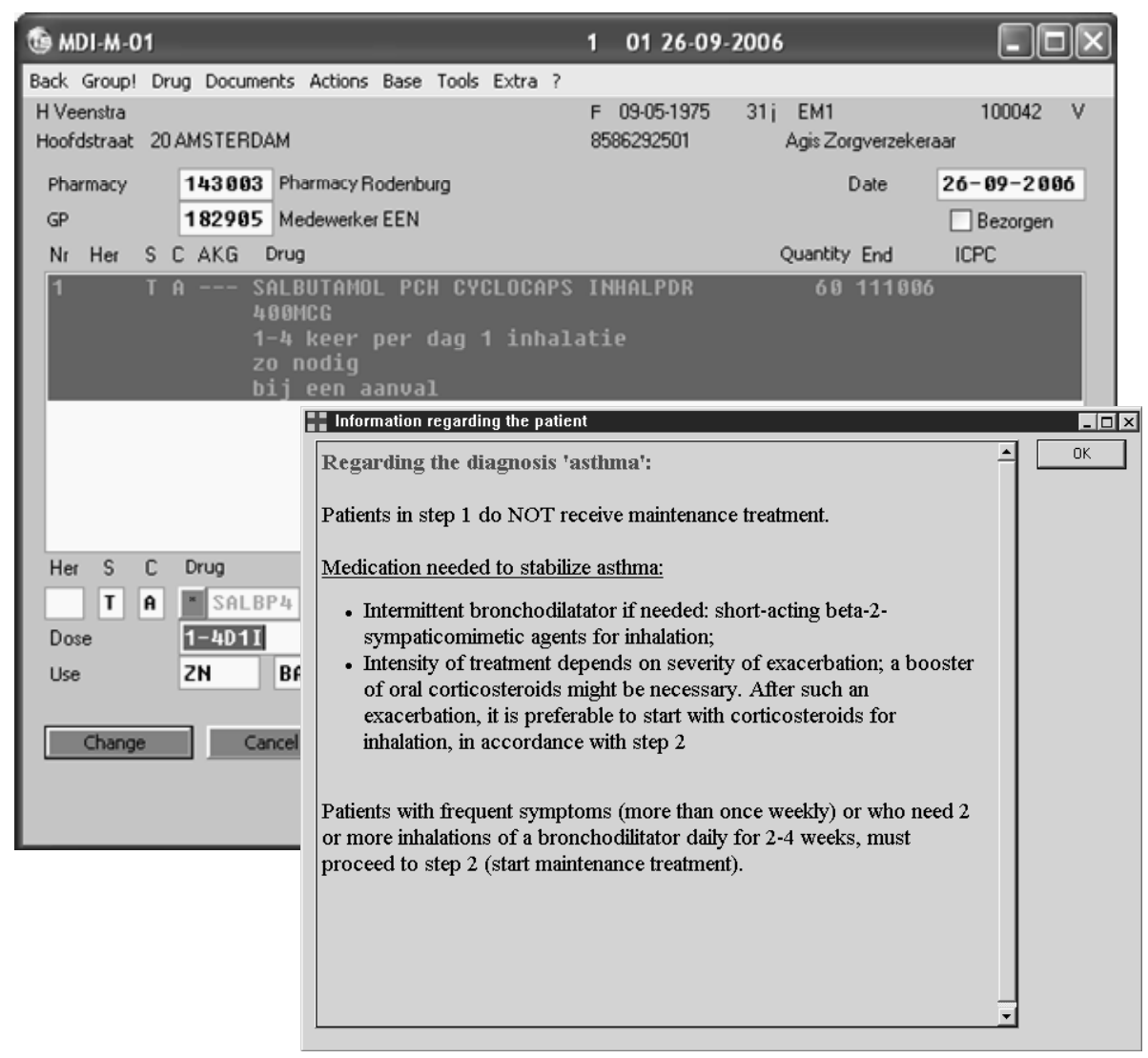

Figure 3: An example of a reminder, given by the DSS (Dutch interface). Only the relevant words in the figure have been translated from Dutch into English

\section{Outcome measures}

Data were collected on the following outcome measures.

\section{Objective measures (question 1)}

- Number of GPs on whose computer the CRS was installed, who were competent and willing to work with the CRS and where the CRS was still functioning one year after installation, without a period of interruption (research database).

- Number of GPs on whose computer the CRS was installed, but was made inactive by the IT consultant, due to technical problems or the GP's unwillingness to start or continue working with the CRS (research database).

- Number of reminders per GP per month per 1,000 enlisted patients (research database). The GP will probably learn from reminders and it is therefore expected that reminders will decrease during the trial period. 


\section{Subjective measures}

- The GPs' user satisfaction (satisfaction questionnaire):

a. The GPs' experience with the technical performance of the CRS (stability, speed, and possibilities of manipulating the CRS).

b. The GPs' experience with the content of the reminder texts (content, extensiveness of the reminders).

c. The GPs' experience with the user friendliness and layout of the CRS.

- Barriers and facilitators to implementing and using the CRS, as perceived by the different stakeholders (GPs, project leader, IT consultants) who were interviewed (semi structured interviews).

\section{Data collection and analysis}

Data collection took place from three different sources. First, the CRS contained a research database where -for each prescription- data was stored for the purpose of analysing the type of reminders that popped up. The period during which prescription data were obtained from the research database, varied depending on each GP's starting time and contained prescription data for a 12-month period. Due to seasonal influences and the comparability of the data we selected data for one year after the start of the intervention. To evaluate the learning curves, the mean number of reminders for antibiotics, asthma, COPD and cholesterol lowering drugs per month were expressed in figures with $95 \%$ Confidence Intervals (figures $4 a$ and $4 b$ ).

Because of frequently evident non-normal distributions, these and other confidence intervals were calculated as bias-corrected accelerated bootstrap intervals (STATA 8.2) ${ }^{20}$. The trend in reminders was illustrated with linear regression lines. The dotted lines show that there is a lot of inter-doctor variation in mean number of reminders per month. To facilitate interpretation we have also provided the regression lines that summarize those fluctuating lines. The effect of the strategy and the differences between the groups were tested on individual regression slopes with student's t-tests using SPSS 12.0.1 software. The unit of analysis was the individual GP.

Secondly, about half way through the intervention year, each practice was visited by an uninvolved project team member, who was at some distance from the GPs and from the project team, so the GPs could speak out freely. The questionnaire was filled in in the presence of and together with the GPs. The GPs were encouraged to speak freely in their response. A satisfaction questionnaire was used to explore the GPs' experiences with and opinion on the feasibility of working with the CRS (see table 1 for the questions). By means of consensus, the GPs in each practice gave one vote for each item. The quantitative data were analysed by descriptive statistics, with special attention being paid to inter-practice variation using SPSS 12.0.1 software.

Thirdly, qualitative data were gathered among a purposely selected sample of the GPs, 2 project leaders, and one technical consultant, who were key-role players in the organisation of the implementation of the CRS. The GPs were selected in such a way that there was a 
representative mix of GPs from the scale very satisfied with the CRS to not satisfied at all with the CRS (drop outs).
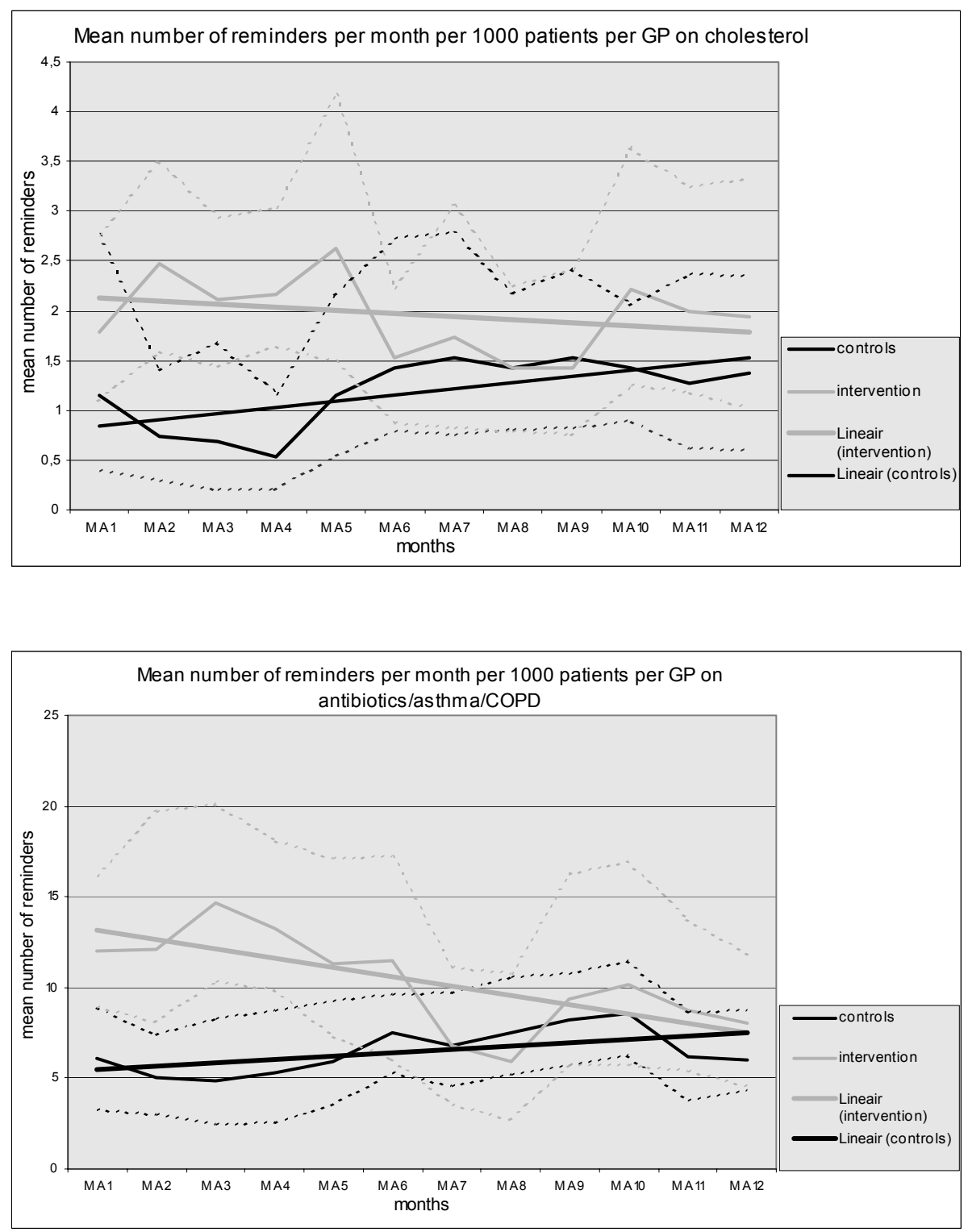

Figure 4a+b: Mean number of reminders per GP per month per 1,000 enlisted patients for cholesterol reminders (a) and antibiotics/asthma/COPD reminders (b) during first year of CRS Implementation (95\% C.I. is shown by mean of dotted lines).

NB. No seasonable influences are expected. The month number corresponds to the 12 months after recruitment and the recruitment per GP was spread over six months 
One of the co-authors $[P G]$ was instructed to perform in-depth semi-structured interviews. The interviewer was trained to stimulate the interviewee to talk freely about the barriers and facilitators by open questions, without steering the interview in a certain direction. Each interview was fully audio taped and transcribed, and after that the GPs' opinions were extracted from the text analyses performed by two of the authors [PG, SE]. The transcribed text was independently coded by two of the authors, and subsequently consensus meetings were held to solve discrepancies. There was a question route, which is available in Dutch, consisting of 23 questions for GPs, 16 items for the IT consultant, and 16 items for the project managers. The question route of the GPs consisted of 5 dimensions: 1) the underlying guideline, 2) characteristics of the GPs (target group) 3) the social context, 4) the organisational context of the project and communication, 5) the method of implementing (the CRS itself) and technical problems.

\section{RESULTS}

In a region in the very south of the Netherlands with 120 practising GPs, 77 GPs met the inclusion criterion for the compatible GP information system and were invited to participate in the trial. Fifty-three GPs in 23 practices (mostly computer-minded) agreed to participate and actually started working with the CRS, 28 GPs receiving cholesterol reminders and 25 GPs receiving antibiotics/asthma/COPD reminders (see figure 1 for the block design). The participating GPs appeared to be the GPs with the highest level of computerisation or with the most positive attitude towards information technology.

\section{Feasibility and acceptability of the CRS (Research database)}

Of the participating GPs, 48 GPs (19 practices) were still continuing to work with the CRS after one year (figure 1). The drop out rate one year after starting the intervention was therefore $9 \%$. The reasons for discontinuation among the GPs were: technical problems because of general IT problems in the GP practice (2), multiple updates to the GP information system (2) and multiple updates to the operating system (1). During 1 year follow up, there were no GPs interrupting the use of the CRS.

The mean number of reminders per GP per month for the cholesterol reminders (a) and the antibiotics/asthma/COPD reminders (b) are listed in figure $4 \mathrm{a}$ and $4 \mathrm{~b}$. The figures show the mean numbers per month per 1,000 enlisted patients and the $95 \% \mathrm{Cl}$ during the first year of implementation of the CRS. The regression lines for the cholesterol reminders show a slight decrease in the number of reminders for the intervention group while the control group shows an increase in mean number of reminders (although these reminders did not pop-up) over time, but this difference between the groups was not significant. A significant learning curve was found $(p=0.03)$ for the reminders on antibiotics, asthma and COPD compared to the control group. The greatest effect was seen in the first months after activation of the CRS.

When one looks more closely at the regression slopes, reminders appear to have more than just a direct effect. If reminders would only work instantly at the moment they appear, and the GP would not remember anything of the content of the reminder in following 
consultations, we expected the number of reminders to be stable over time. The decline in the number of reminders over time suggests that doctors learn from the reminders considering the negative relation between the frequency of reminders popping up and the level of adherence to the guideline. For example: a GP was reminded to prescribe trimethoprim instead of quinolones for cystitis among women older than 12 years. During the next consultation with a woman complaining of cystitis, the GP remembers that he has been reminded on antibiotics for cystitis and will therefore adapt his prescription. Consequently, future actions are more often in the desired direction and reminders appear less frequently.

\section{GPs' satisfaction (questionnaire)}

All GPs in the 20 practices using the CRS, participated in filling in the questionnaire together with an uninvolved project team member. Among these GPs, $85 \%$ stated that the reminders occurred daily on their computer screen. Table 1 shows that $80 \%$ of the GPs indicated that the CRS showed several technical problems, like e.g. inappropriately popping up when a prescription was stopped (question 1a), asking for non-available patient information (question 1c), and GPs sometimes or often deliberately fed wrong information to the system in response to the CRS question so as to get through the system (question 2). Regarding to the speed of the system, the GPs appeared to be rather satisfied (question 5). With regard to the content of the reminders, the GPs generally displayed a positive attitude, although there seemed to be some hesitation in following reminders NOT to prescribe (30\%) (question 9D). The GPs seemed moderately satisfied about the user-friendliness of the CRS (95\%) (question 12). We also evaluated satisfaction with the helpdesk. Because of a different rating scale we did not include these results in table 1 . Only $30 \%$ of the GPs were aware that they could contact a helpdesk for problems. The GPs that did contact the helpdesk (39\%) were very satisfied about the way the problems were solved (rating with 8.2 on scale 1 to 10).

\section{Barriers and facilitators}

Nine interviews were held with six GPs, the two people who consecutively led the project, and the technical consultant who implemented the CRS in the practices. The mean duration of the interviews was about 45 minutes. The GPs did not mention specific barriers or facilitators, other than covered by the five themes.

Firstly, the GPs felt that they had ownership of the underlying guidelines, and that the guidelines had been developed carefully. They were willing to follow reminders about the guideline topics (antibiotics, asthma, COPD and cholesterol). The project managers mentioned both GPs as well as specialists did sometimes not show up for the guideline development meetings. The frequency with which the reminders popped up on their screen was not evaluated negatively, although GPs admitted that they did not always read the reminder text or clicked them away without reading the reminder at all. From the interviews with the project managers it turned out that they expected a better social basis for attending to guidelines among GPs as for specialists.

Besides this, the demand to enter ICPC diagnosis codes did not hamper the GPs during prescribing in daily practice. Regarding the social context, only a few GPs were aware of 


\section{Chapter 7}

their colleagues' opinion of the CRS. They only knew about the experiences of their colleagues in a small subgroup, and it emerged that these colleagues were not always that positive.

Table 1: GPs' user satisfaction $(n=20)$ about the CRS regarding its technical performance, speed, reminder text, layout, user friendliness and help desk function in absolute numbers (\%)

\begin{tabular}{|c|c|c|c|c|}
\hline & No, never & $\begin{array}{l}\text { Sometimes/ } \\
\text { little }\end{array}$ & $\begin{array}{l}\text { Often/ } \\
\text { always }\end{array}$ & Don't know \\
\hline \multicolumn{5}{|l|}{ Technical performance } \\
\hline \multicolumn{5}{|l|}{$\begin{array}{l}\text { 1. The CRS causes serious obstructions during drug } \\
\text { prescribing ... }\end{array}$} \\
\hline $\begin{array}{l}\text { by starting up incorrectly while drugs are being } \\
\text { stopped? }\end{array}$ & $3(15)$ & $6(30)$ & $10(50)$ & $1(5)$ \\
\hline $\begin{array}{l}\text { by starting up incorrectly for cases where no } \\
\text { guideline has yet been formulated? }\end{array}$ & $11(55)$ & $8(40)$ & $1(5)$ & 0 \\
\hline $\begin{array}{l}\text { because patient information is asked for that is not } \\
\text { available? }\end{array}$ & $3(15)$ & $6(30)$ & $10(50)$ & $1(5)$ \\
\hline $\begin{array}{l}\text { 2. Do you give wrong answers to get through the } \\
\text { system? }\end{array}$ & $3(15)$ & $9(45)$ & $7(35)$ & $1(5)$ \\
\hline $\begin{array}{l}\text { 3. Do you give wrong answers to circumvent the } \\
\text { system? }\end{array}$ & $11(55)$ & $6(30)$ & $3(15)$ & 0 \\
\hline $\begin{array}{l}\text { 4. Is your GP information system slow since the CRS } \\
\text { installation? }\end{array}$ & $11(55)$ & $5(25)$ & 0 & $3(15)$ \\
\hline $\begin{array}{l}\text { 5. Can you progress through the CRS module fast } \\
\text { enough during prescribing? }\end{array}$ & $1(5)$ & $1(5)$ & $17(85)$ & $1(5)$ \\
\hline \multicolumn{5}{|l|}{ Content of the reminder text } \\
\hline 6. Do you always read the complete reminder texts? & $1(5)$ & $13(65)$ & $5(25)$ & 0 \\
\hline 7. Do you regard the reminder texts as too long? & $9(45)$ & $7(35)$ & $3(15)$ & $1(5)$ \\
\hline $\begin{array}{l}\text { 8. Do you ever check the paper version of the } \\
\text { guidelines after receiving a reminder? }\end{array}$ & $16(80)$ & $4(20)$ & 0 & 0 \\
\hline $\begin{array}{l}\text { 9. Are you willing to follow the recommendation on the } \\
\text { reminder if ... }\end{array}$ & - & - & - & - \\
\hline the CRS advises another drug? & 0 & $8(40)$ & $12(60)$ & 0 \\
\hline the CRS advises about the drug dose? & 0 & $16(20)$ & $4(80)$ & 0 \\
\hline the CRS advises about the course of treatment? & 0 & $1(5)$ & 19(95) & 0 \\
\hline the CRS advises NOT to prescribe drugs? & $6(30)$ & $8(40)$ & $5(25)$ & $1(5)$ \\
\hline the CRS advises a non-pharmaceutical treatment? & $2(10)$ & $4(20)$ & $14(70)$ & 0 \\
\hline the CRS offers advice concerning diagnosing? & $1(5)$ & $4(20)$ & 13(65) & 0 \\
\hline User friendliness & No & A little & Yes & Don't know \\
\hline 10. Do you like the layout of the CRS module? & $1(5)$ & $5(25)$ & $12(60)$ & $2(10)$ \\
\hline 11. Is the CRS module user-friendly to work with? & $1(5)$ & $13(65)$ & $6(30)$ & - \\
\hline $\begin{array}{l}\text { 12. Is the ICPC-screen to fill in the diagnosis user- } \\
\text { friendly to work with? }\end{array}$ & $1(5)$ & $12(60)$ & $7(35)$ & - \\
\hline 13.Are the diagnoses easy to find in the search term? & $9(45)$ & - & $9(45)$ & $1(5)$ \\
\hline
\end{tabular}


The practical support from the CRS project team was evaluated as positive by all of the GPs. With regard to organisational aspects, the finances of the project were sufficient, so the implementation of the strategy encountered no financial barriers. GPs valued the financial compensation for hardware as positive but did not feel that the compensation made the difference between participating in the project or not. From all parties was heard that miscommunication and lack of cooperation between the different parties about information technology hampered prioritising what needed to be done first, sometimes resulting in severe delays in problem solving and dissemination of the CRS. After all, according the project managers and IT consultant, multiple updates to the GP information system and the operating system in a short period of time hampered the implementation of the CRS. GPS had to wait longer before they could start working with the CRS and had to wait before installing updates to the operating system because the CRS was not ready for them. Eventually, the implementation of the CRS had to be extended by more than one year. This caused irritation among GPs.

\section{Discussion}

\section{Main results}

Firstly, a significant learning curve was found in terms of GPs' behaviour as a result of the antibiotics reminders from the CRS. The largest effects were seen in the first months after installation. This finding is probably a confirmation of the learning effect of reminders.

Secondly, the GPs turned out to be satisfied about the CRS on the following subjects: stability and speed of the CRS, the instructiveness and shortness of the reminders, the userfriendliness, layout, and support from the help desk. GPs were not satisfied with some technical problems that caused delay during prescribing. The sensitivity to new updates and their delay also caused irritation among GPs. Moreover they sometimes or often manipulated the CRS to get through the system faster.

Thirdly, the interviews made it clear that the implementation of the CRS was hampered as a result of different types of problems related to the organisational context and the method of implementing the strategy, like software problems with updates, hardware problems and interactions between the program and the user. In the development phase, the CRS was seriously hampered by a diversity of non-specific technical problems. Although the system was successfully disseminated in the end there were some compatibility problems with various versions of the operating system and the GP information system. For participation in the trial and to improve compliance, GPs were financially compensated in part if there was a need for new hardware (max. $€ 1,100$ ). However, the problems described above could not prohibit a drop out rate of $9 \%$ during the project.

\section{Strengths and weaknesses of the process evaluation}

The strength of the study is the extensive research database that contains unique data such as the number of prescriptions and number of reminders, popped-up or not. Besides this, a 
combination of quantitative and qualitative methods was used in the study in a complementary way.

There are also some issues for consideration. Firstly, the fact that the participating GPs in the project were known as computerisation innovators could be pointed out as a weakness of the study. This also influences the external validity of the study. Secondly, surprisingly the groups differed in the number of reminders at baseline despite the random allocation design. This is possibly due to the low number and to coincidence.

Why did the CRS result in changes for some behaviour? Recent literature provides more insight into the conditions under which decision support can be a successful instrument for changing behaviour. Firstly, automatically generated support results in better delivery of care than user-initiated decision support: the reminder was automatically provided as part of the clinician's workflow (the reminders are presented close to the time of decision making) ${ }^{8}$. Secondly, possible explanations for our positive findings might be found in the development phase of the guideline because the guidelines were developed in close relation with the $\mathrm{GPs}^{21,22}$. Finally, the CRS offered reminders that were easy to ignore rather than being compelling: the CRS provided recommendations rather than strict compelling orders ${ }^{21}$.

According to the results of the questionnaire, GPs seem more willing to follow "to do" recommendation reminders instead of recommendation reminders "to refrain from prescribing" ("NOT to do"). Strangely enough these findings are not in line with the conclusions in our effect evaluation of the $\mathrm{CRS}^{10}$. In that study we found the opposite effect: GPs tended to adhere more to reminders "NOT to do" instead of reminders "to do". We cannot explain this discrepancy. Perhaps the GPs intuitively responded with resistance to reminders NOT to prescribe, based on their belief that a good GP should not withhold therapy from his/her patients, while in practice reminders "NOT to do" are usually shorter and clearer and therefore might be easier to follow than the reminders about recommendations "to do".

Why did the reminders not work for the "to do" reminders? Firstly, we experienced difficulty in creating reminders that fit into GP's daily practice, instead of reminders that are used in a robot-like way. The project team members possibly should have paid more attention to involving GPs during the translation phase of the guidelines into the reminder texts ${ }^{11,12}$. We did have a working group that was composed of both IT experts and practising GPs to develop the CRS. But apart from paying attention to translating the recommendations into IF-THEN rules, more attention should have been paid to prioritising the relevant guideline recommendations. Secondly, to engage IT experts in reminder use and improvement, a CRS should provide a feedback mechanism for GPs to increase user acceptance $^{23}$. Our CRS did not provide for a feedback mechanism in the system itself. Thirdly, the technical problems described and lack of flexibility of the CRS might have put up additional barriers to the effectiveness of the reminders ${ }^{23}$.

Besides this, it is important to consider whether the use of the CRS is the most preferred way of supporting a GP during daily care ${ }^{22}$. Depending on the problem area and technical possibilities consideration should be given to whether other forms of decision support might 
be more suitable than using reminders. At the starting point of improving behavioural change, it should be reconsidered whether the use of CRS is suitable for initiating the desired change in behaviour ${ }^{22}$.

Finally, cost considerations need to be looked at as another important aspect of feasibility. Developing a computerised system to control prescribing behaviour in GPs' practices is time and cost-consuming and only a few studies report on the value for money invested in implementing a computerised decision support system. A forthcoming economic evaluation will report the costs and benefits of the CRS in detail.

\section{CONCLUSION}

This process evaluation demonstrated that the implementation of the CRS was mainly carried out as planned, although the subjective experience of working with the CRS was not only positive. Participating GPs had mixed feelings, and quite some barriers need to be addressed to facilitate large-scale implementation of the CRS. If the decision is taken to use CRS, based on good arguments, the GPs' needs for reminders have to be critically assessed before translating guideline recommendations into computerised reminders. Costs cannot be neglected, it is important to analyse the balance between costs and effects in a costeffectiveness-analysis.

\section{REFERENCES}

1. Stichting Farmaceutische Kengetallen; Data en Feiten (Foundation for Pharmaceutical Statistics; Data and Facts). The Hague/the Netherlands; 2000-2004. Homepage available at http://www.sfk.nl/

2. Breekveldt-Postma NS, Zwart-van Rijkom JE, Egberts AC, Leufkens HG, Herings RM. Rising costs of drugs in hospitals in the period 1996-2000 and over the next few years. Nederlands Tijdschrift voor Geneeskunde 2002;46(52):2547-51.

3. Johnston ME, Langton KB, Haynes B, Mathieu A. Effects of computer-based clinical decision support systems on clinician performance and patient outcome: a critical appraisal of research. Ann Intern Med 1994;120:135-42.

4. Hunt DL, Haynes RB, Hanna SE, Smith K. Effects of computer-based clinical decision support systems on physician performance and patient outcomes. JAMA 1998;280:1339-46.

5. Eccles M, Steen N, Grimshaw J, Thomas L, McNamee P, Soutter J, Wilsdon J, Matowe L, Needham G, Gilbert F, Bond S. Effect of audit and feedback, and reminder messages on primarycare radiology referrals: a randomised trial. Lancet 1994;357(9266):1406-9.

6. Bennett JW, Glasziou PP. Computerised reminders and feedback in medication management: a systematic review of randomised controlled trials. MJA 2003;178:217-2.

7. Teich JM, Merchia PR, Schmiz JL, Kuperman GJ, Spurr CD, Bates DW. Effects of computerized physician order entry on prescribing practices. Arch Intern Med 2000;160(18):2741-7.

8. Garg AX, Adhikari ND, McDonald H, Rosas-Arellano MP, Devereaux PJ, Beyene J, Sam J, Haynes RB. Effects of Computerized Clinical Decision Support Systems on Practitioner Performance and Patient Outcomes. A Systematic Review. JAMA 2005;293:1223-38.

9. Bindels R, Hasman A, Van Wersch JW, Talmon J, Winkens RA. Evaluation of an automated test ordering and feedback system for general practitioners in daily practice. Int $\mathrm{J}$ Med Inform 2004;73(9-10):705-12. 
10. Martens JD, Van der Weijden T, Severens JL, De Clercq PA, De Bruyn D, Kester AD, Winkens RAG The effect of computer reminders on GPs' prescribing behaviour. Int J Med Inform. 2007 Jun 12; [Epub ahead of print].

11. Hulscher ME, Laurant MG, Grol RP. Process evaluation on quality improvement interventions. Qual Saf Health Care 2003;12(1):40-6.

12. Grol R, Wensing W. Determinants of effective change. in: R. Grol, M. Wensing, Eccles M ed. Improving patient care. The implementation of change in clinical practice. Elsevier, Oxford, 2004.

13. Winkens RAG, Martens JD, Kester ADM, Van der Weijden T. De Bruijn DP. Severens JL. Computer reminders on GPs' prescribing behaviour. Description of a multi-design study. Submitted.

14. Verstappen WH, Van der Weijden T, Ter Riet G, Grimshaw J, Winkens R, Grol RP. Block design allowed for control of the Hawthorne effect in a randomized controlled trial of test ordering. Journal of Clinical Epidemiology 2004;57:1119-23.

15. Eccles M, Grimshaw J, Campbell M, Ramsay C. Experimental evaluations of change and improvement strategies. In: Improving Patient Care. The implementation of change in clinical practice. Elsevier. Oxford. 2004.

16. Martens JD, Winkens RAG, Van der Weijden T, De Bruyn D, Severens JL. Does a joint development and dissemination of multidisciplinary guidelines improve prescribing behaviour: a pre/post study with concurrent control group and a randomised subgroup. BMC Health Serv Res 2006;6:145.

17. WONCA International Classification Committee. ICPC-2. International Classification of Primary Care, 2nd edn. Oxford: Oxford University Press, 1998.

18. Okkes IM, Jamoulle M, Lamberts H, Bentzen N. ICPC-2-E. The electronic version of ICPC-2. Differences from the printed version and the consequences. Fam Pract 2000;17:101-6.

19. De Clercq PA, Hasman A, Blom JA, Korsten HH. Design and implementation of a framework to support the development of clinical guidelines. Int J Med Inform 2001;64(2-3):285-318.

20. Efron B, Tibshirani RJ. An introduction to the bootstrap. Chapman and Hall, New York (1993) 312.

21. Kawamoto K, Houlihan CA, Balas EA, Lobach DF. Improving clinical practice using clinical decision support systems: a systematic review of trials to identify features critical to success. BMJ 2005;330:765-8.

22. Liu J, Wyatt JC, Altman DG. Decision tools in health care: focus on the problem, not the solution. BMC Med Inform Decis Mak 2006; 6:4.

23. Saleem J, Patterson ES, Militello L, Render ML, Orshansky G, Asch SM. Exploring barriers and facilitators to the use of computerized clinical reminders. J Am Med Inform Assoc 2005;12:438-47. 


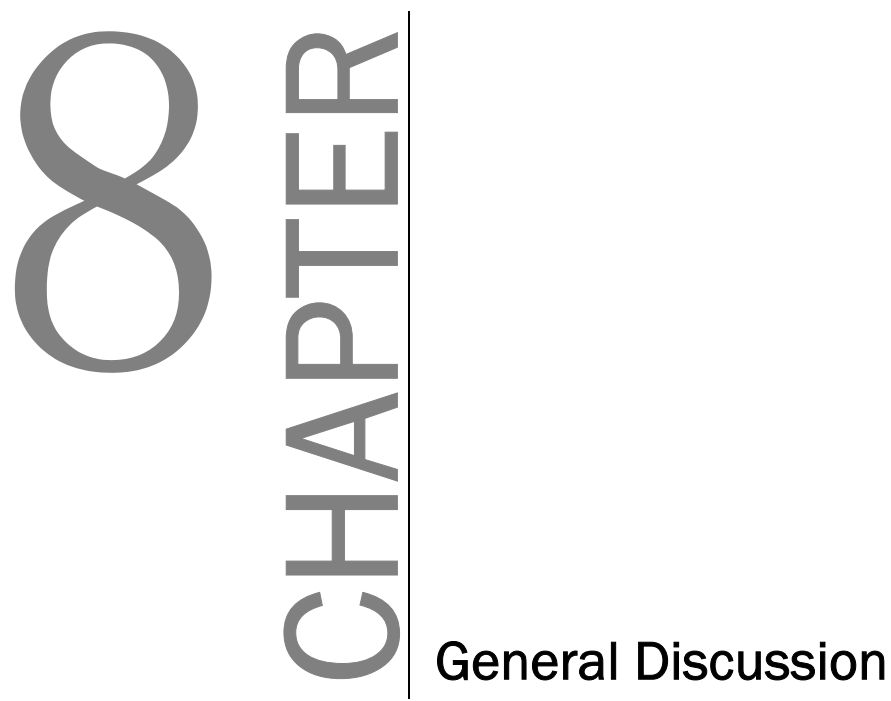





\section{GENERAL DISCUSSION}

Medication is not always prescribed efficiently and has often been subject of guideline development. Up till now, no magic bullets have been found on which a guideline implementation strategy turned out to be most effective. This thesis presents the evaluation of the development, and the implementation of a series of guideline strategies, and explores their impact on prescribing behaviour of General Practitioners (GPs). It focuses on different implementation strategies with the potential to improve the adherence to prescription guidelines among GPs. The thesis concentrates on three implementation strategies: a financial incentive, the dissemination of intensively developed paper guidelines and a Computer Reminder System (CRS). The latter was evaluated extensively by using an effect evaluation on GP's drug prescribing, a process evaluation and a cost analysis. The choice for the implementation strategies was partially pragmatic, but mostly based on insights from literature and our experience with the organisation of integrated care and with decision support systems ${ }^{1,2}$.

In this chapter the main findings of a financial incentive, the dissemination of multidisciplinary guidelines and of computerised reminders will be presented. Methodological issues including strengths and limitations will be discussed. Subsequently, the results of the studies will be discussed in relation to implementation theories, prescribing theories and evaluation theories. This chapter will conclude with implications for health care practice and further research.

\section{MAIN FINDINGS}

\section{Financial incentive}

The effect evaluation of the financial incentive strategy revealed a limited, temporary effect on prescribing behaviour of GPs in line with existing guidelines. A significant short-term difference in the expected direction was shown just for a few drug indicators. Nevertheless, a cost-saving of almost $€ 1.8$ million on all drug expenses in the intervention region was seen. The paid-out reimbursements to all participating GPs were more than $€ 1.4$ million, which resulted in a cost-saving of about $€ 300,000$ - $€ 400,000$ in one and a half year, meaning a cost-saving of $€ 2,000$ per GP per year. In the longer term, the modest impact of this financial incentive disappeared, except for one group of recommended drugs, recommended gastric medicine (ranitidine, rabeprazol), that showed a significant effect in the long-term as well. Given the non-randomised design these findings have to be cautiously interpreted.

\section{Multidisciplinary guidelines}

Disseminating rigorously developed multidisciplinary guidelines had no obvious direct impact on the prescribing performance of GPs. A significant effect in the desired direction was found for one specific antibiotic (mupirocin) in the short-term only. No significant effect was seen for 
other antibiotics, either in the short-term or the long-term. Significant long-term effects were found for another drug group, the cholesterol lowering drugs. The variation of prescribing drugs between GPs turned out to be larger than expected. The effort to get a subgroup of GPs involved in the guideline development procedure did not result in meaningful involvement, and no desirable effects in the subgroup were seen.

\section{Computerised reminders}

Computer reminders with the message not to prescribe certain drugs seemed to influence the prescribing behaviour of GPs in the desired direction. Clinically relevant results were found, both for the sum scores and for individual indicators and volume measures, but most of them were not significant. An overall improvement of 30 percent was found for the largest group of recommendations, recommendations on antibiotics, although the sumscores were not significantly different between intervention and control groups. In general, numbers of prescriptions dropped where there were guidelines that recommended restricting certain drugs for certain diagnoses.

The costs of developing the guidelines and of developing and executing the CRS amounted to $€ 15,239$ per GP over 4.3 years. The major costs were the development of the multidisciplinary guidelines ( $€ 7,685$ per GP) and the development of the CRS $(€ 4,130$ per GP). A significant decrease of 32 percent in antibiotics and asthma/COPD medication costs was found, when the recommendation was not to prescribe particular drugs. At the same time, a positive trend in prescribing according to guidelines, although not significant, was seen for the medication costs where the recommendation was that prescribing a certain drug was advised.

In the process evaluation a significant learning curve has been found, leading to a significant decrease in the number of reminders per GP per month. This finding is probably a confirmation of the learning effect of reminders. Secondly, the GPs turned out to be only partially satisfied with the CRS: they were quite satisfied on stability and speed, the instructiveness and content and length of the reminders, the user-friendliness, layout, and support from the help desk. GPs were not satisfied with some technical problems that caused delay during prescribing and the procedure for installation of new updates. The implementation of the CRS was hampered as a result of different types of problems related to the organisational context and the method of implementing the strategy, such as software problems with updates, hardware problems and undesirable interactions between the program and the user. Moreover, GPs at times ignored and manipulated the CRS to get through the system faster. Overall, 9 percent of the GPs dropped out during the project.

In summary, in applying different implementation strategies it appeared that a financial incentive had little and only short-term impact on prescribing behaviour. Disseminating the multidisciplinary guidelines had also little impact on prescribing behaviour, despite the participation of the GP's during the intensive development procedure and given the fact that developing these multidisciplinary guidelines was very time- and cost-consuming. The CRS strategy showed influence on prescribing behaviour for recommendations not to prescribe, 
although effects were limited. Working with the CRS turned out to be more complex than expected due to technological shortcomings, incompatibilities, etc. ICT-applications in general practice needed careful tailoring to practice and professionals' needs. These efforts incurred high cost and therefore the CRS can only be expected to become cost reducing by extending these costs by means of extending the CRS with more (existing) guidelines, over more time, and with a larger population.

\section{METHODOLOGICAL CONSIDERATIONS: STRENGTHS AND LIMITATIONS}

\section{Implementation methods}

One of the regional insurance companies offered the challenging opportunity to evaluate an implementation strategy on prescribing behaviour: a financial incentive. This intervention that was executed before the dissemination of the multidisciplinary guidelines focussed on influencing prescribing behaviour among GPs in the same region, so it fitted well to the research objectives. In this convenience study, only marginal and short-term effects were found. A true experiment, with randomised allocation of the strategy was not possible, so the causality of effects has to be cautiously interpreted. Possibly, the recommendations underlying the financial incentive were not clear enough to the participating GPs. In our point of view not all GPs were familiar enough with the intervention goals and were possibly little motivated to participate and change their prescribing behaviour due to the financial incentive. The behaviour-independent character of the intervention seemed too much free of any obligations and during the study, the participating GPs were not informed in any way nor reminded about their participation in the trial.

The choice for using a local multidisciplinary guideline development procedure in the second implementation strategy, based on insights from literature ${ }^{3,4}$ was a strength of the project: we used a development procedure in which all stakeholders were closely involved during the development phase of the guidelines. The multidisciplinary paper guidelines were formulated by key persons from all disciplines and were developed for GPs and specialists.

Fewer thoughts were given to the choice of the dissemination strategy of these multidisciplinary guidelines. We tried to involve the GPs by inviting them during the validation of the draft guideline. Although involvement of the target group by asking their comments on the draft guidelines might be an effective strategy for dissemination, in this project it was not successful. GPs apparently did not feel a need to comment on the guidelines and often draft guidelines were approved without comments as final guidelines. In the end, sending the guidelines by post turned out to be a rather bureaucratic instead of effective dissemination strategy.

In an earlier project on implementation of guidelines to improve test ordering behaviour by means of computerized decision support ${ }^{1}$ useful experience with the implementation of a CRS in the South of the Netherlands had been gained. Because of expertise and insights from that study, the same decision support system could be used as a basis to develop the CRS that is evaluated in this thesis ${ }^{2}$. Eventually, after much time and energy was put into a 
proper installation and guiding of the ICT-application we succeeded to implement a CRS that proofed to work in daily practise. The usability in daily routine practice might seems a strong point of the CRS, since the CRS is still in use by most of the GPs, even after the ending of the study.

At the initial phase of the implementation process of the CRS we experienced practical problems on implementing the computerised intervention into secondary care. Technical restrictions due to a restricted level of computerization, and no use of electronic prescribing in the adhere hospital turned out to be an insurmountable barrier for implementing the CRS in the adhering hospital. Although the CRS was initially meant for physicians both in primary and secondary care, we eventually implemented the system in primary care only. Therefore, this thesis only reports the results of the intervention in primary care, making generalisation of the study results to hospital care an impossible and invalid exercise. The project was initiated to be a multidisciplinary project and limiting the project to primary care caused irritation among GPs, as specialists play an important role in the prescribing process and many drug prescriptions are initiated by specialists.

Another difficulty in CRS implementation of prescription guidelines turned out to be the translation of textual recommendations into a formalised language that can be understood by computers (for example if-then rules). Translating rather vague recommendations or terms such as "rather high blood pressure" turned sometimes out to be impossible. Some recommendations were difficult to quantify, causing difficulties in building in a critical point of decision. For example the translation of a recommendation to prescribe COPD drugs in case of increased sputum production was difficult to translate into formal computerised language.

\section{Evaluation methods}

The design of the financial incentive study was a controlled before-after study with a concurrent control group, with no randomisation. Randomisation was not possible because of the fact that the intervention was already started at the moment an evaluation was considered. The limitation of the design is that results cannot be causally linked to the intervention.

Already existing retrospective databases of the insurance companies were used for data collection. So in this study, we did not deliberately collect the data, but derived them from the health insurance company's database. This was a weakness in the study, as these data were not deliberately tuned to the research questions in the study. The advantages of this method of data collection were low costs and high feasibility, because we did not need to disturb the GPs to ask for information, and completeness, as we did not have to deal with non-response.

The evaluation of the financial incentive could only be executed in global terms, by expressing the outcomes in drug prescription volume measures. Due to the lack of detailed information we could not develop more refined outcome measures, like prescribing indicators or by taking diagnosis related information into account. So, only general drug prescriptions were analysed and no more than a rough calculation of the costs was executed. No attention 
had been paid to a full economic evaluation including health outcome of patients, and involving development cost, execution costs and health care outcome.

In evaluating the effectiveness of multidisciplinary guideline implementation we used a quasiexperimental design instead of a RCT. Due to the pragmatic character of the project the guideline dissemination was restricted to a certain region. Given the size of the region a randomisation within this region was impossible. So, the control group had to be attracted from outside, meaning only a quasi-experimental design turned out to be possible. The prescribing data were derived from the health insurance companies who provided retrospective datasets. These data were not recorded for research purposes. The dataset contained only volume data, and not health related or diagnostic information.

In fact, because two true experiments were integrated in this quality improvement study various study arms can be distinguished: 1) one group receiving the paper guidelines only, compared with a non-randomised control group; 2) the group that received the paper guidelines was randomly allocated for being invited for involvement during the development of the guidelines; and 3) the group of GPs who participated to the CRS with the randomisation on the level of the clinical issues (block design). Randomisation could be executed in arm 2 and 3, which is a strong aspect. The multiple testing on the large amount of guideline recommendations created another possible weakness in this study.

Methodological strong was the use of an incomplete block design in the CRS study. This design offers the opportunity that all GPs could participate immediately, in contrast with the waiting list design or with true controlled studies. The incomplete block design also controls for the Hawthorne effect which is playing a distorting role in this kind of implementation research $^{5}$. A methodological weakness was the choice not to execute a baseline measurement. A baseline measurement in the GP practices was considered not feasible, due to expectations and signals from the GPs that the participants could not be motivated to work with the CRS by entering diagnostic codes without receiving reminders. Dropping the baseline measurement affected the prior executed power analysis. After analysing the data and dealing with unexpectedly high standard deviations the study turned out to be underpowered. Due to the unexpectedly high variation in the primary variable (prescribing volumes per drug or drug group) the power of the study was negatively influenced. So, we ended up with apparently clinical meaningful results, pointing into the desired direction, but with hardly any significant results. Unfortunately, drop-outs further effected the power of the study.

As the CRS filed almost every detail of the prescribing process, the research database contained very detailed information. Due to the CRS we had disposal on unique information in the research database, such as diagnosis, disease related information, and reminder related information, creating the possibility of a more precise judgement of GP's prescribing behaviour. This detailed level of coded information created the possibility to develop a refined set of prescribing indicators, giving detailed insights into prescribing behaviour. Some recommendations in the guidelines gave opposite advises on the same drugs but for different 
diagnoses. Only by selecting on diagnosis level these prescriptions could be split up. So we were able to analyse very refined recommendations on possible improvement.

In the feasibility study following the CRS implementation, both qualitative and quantitative methods were used. This was rather unique and certainly strong in this study, because these methods can be regarded as complementary. Usually only qualitative data are used in a process evaluation. By adding quantitative data to the study, statistical analyses were possible to detect whether a detected learning curve in the number of reminders per GP per month was significant.

Finally the costs of the implementation of the multidisciplinary guidelines and the Computer Reminder System were analysed. Costs were calculated by applying the economic principles of dividing costs into fixed and variable costs, and categorising into development, execution and health care costs. This kind of refined cost calculation has not often been executed in implementation literature and is therefore a strong aspect in this thesis. Although we used a refined method for cost calculation, adding cost information on drug prescription level, the complexity of the study obstructed full economic evaluation. To execute a full economic evaluation patient data regarding health outcome would be needed. This kind of information was not available in the research database. For some recommendations in the guidelines a full economic evaluation would have been preferable. For example, a recommendation to prescribe cholesterol lowering drugs for high risks patients with cholesterol rates over $5.5 \mathrm{mmol}$ would increase costs in the short-term. Only by executing a full economic evaluation, insights could be gained on health effects in the longterm. In our study, health data on patient level were not available. We could have used intermediary results as a basis for the prediction of outcomes over longer times, but given the diversity of diagnoses, patient types, and comorbidities of the recommendations in the CRS this was not practically feasible.

\section{DISCUSSION OF RESULTS}

\section{Implementation theories}

The literature offers a number of theoretical frameworks for planning effective change ${ }^{6,7}$. The implementation model of Grol and Wensing ${ }^{8}$ has also been developed to bridge the gap between scientific evidence and patient care, which in this thesis translates to the observed discrepancy between routine prescribing practice and the prescribing recommendations in the guidelines. To get insight into this gap a so-called "diagnostic analysis" is recommended $^{8,9}$. This includes an analysis of: 1) context of implementation, looking at the involved stakeholders, 2) actual performance in current practice and aspects that need to be improved, 3) barriers and incentives for change, and specific factors within different subgroups, and 4) characteristics of the target group and subgroups within it. After analysing these determinants of change a rational decision can be made on the most appropriate tailored strategy for implementation. 
There is debate in implementation science how to deal with the choice of a certain implementation strategy. Initially, implementation research had been started pragmatically by building evidence on the effectiveness of a number of implementation strategies, thereby focussing on the last step in the model (figure 1).

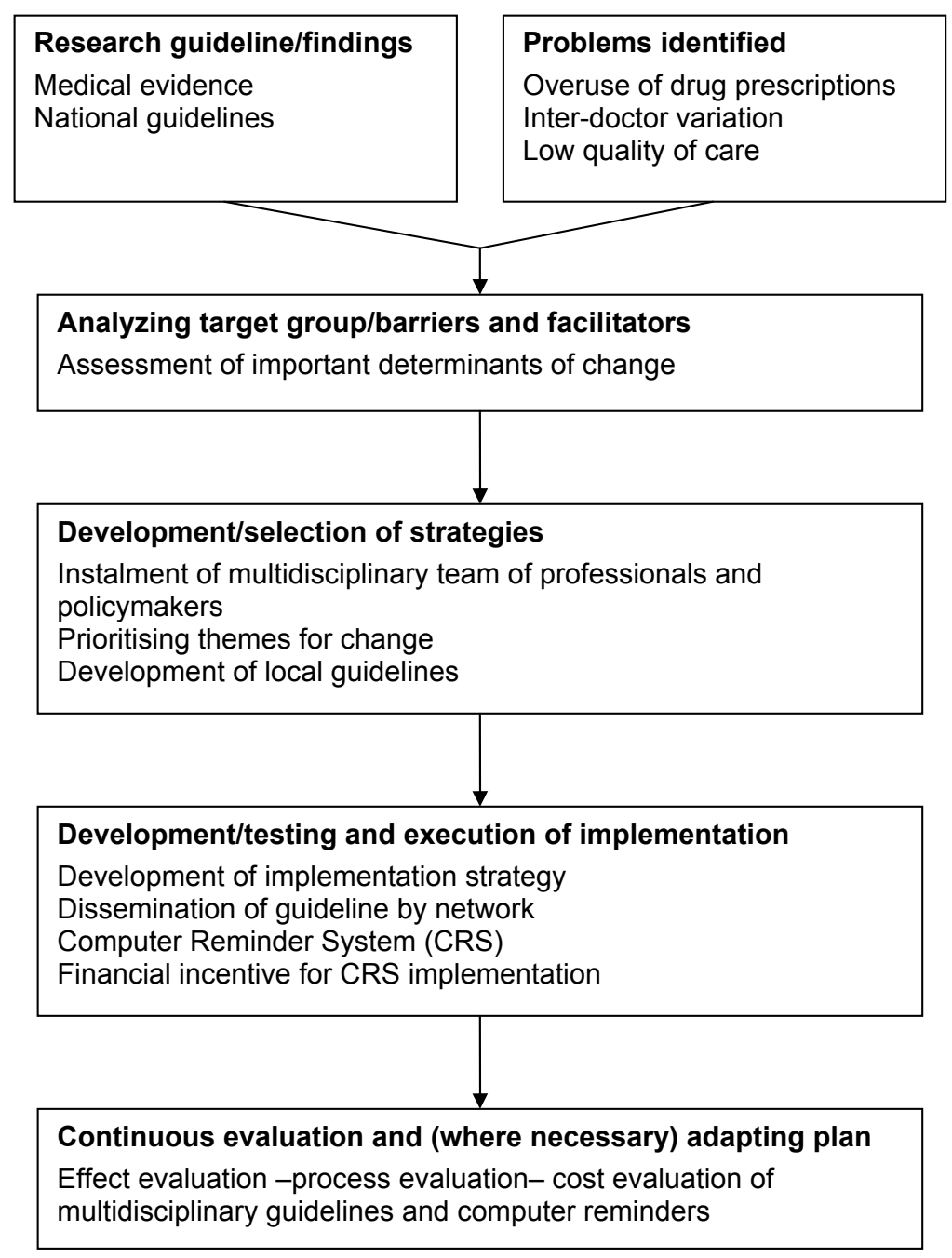

Figure 1: implementation of change(based on Grol/Wensing ${ }^{8}$ )

More recently, implementation research is characterised by first investigating the problem by exploring the barriers to change, and applying theoretical approaches of change in a more systematic way in planning quality improvement strategies ${ }^{10}$. From the field of health promotion, a systematic method called intervention mapping seems to be useful for systematically developing quality improvement strategies. This is a promising structured, 
stepwise method to develop a selection of interventions, linked to the relevant factors. It offers a method to process results from a diagnostic analysis, by integrating a problem analysis, program objectives and determinants, intervention design and intervention evaluation with theories from social sciences and other scientific evidence into a systematic design process to implement change in healthcare ${ }^{11}$.

It is not clear though which methods are most appropriate to identify these relevant barriers of change and which methods should be used to tailor the interventions to those barriers ${ }^{12}$. Moreover, such a diagnostic analysis turned out to be quite time and cost consuming and the effectiveness of the so called "tailored interventions" remains uncertain $^{13,14}$. The strategies in this thesis were not tailored in a determinants analysis, based on pre-defined needs from the target group and barriers of change. Instead of this, the shortcut method was used, selecting convenient, already available implementation strategies, in a faster and cheaper way. Using this short-cut method we were not aware if there were important barriers influencing the effectiveness of our strategies. The barriers of change might have needed more attention to tailor our strategies.

\section{Implementation strategies}

Financial incentives or target payment systems can function as an implementation strategy to improve compliance with guidelines, but the generalisability on the findings from literature is questionable ${ }^{15,16}$. Financial incentives are less difficult to execute, and might be an alternative for the more complex implementation strategies ${ }^{17,18}$. However, there is insufficient evidence to provide a clear answer to whether financial incentives and target payment systems are a (cost)-effective method of improving quality of care ${ }^{18}$. The financial incentive strategy evaluated in this thesis was not effective. The cost-effectiveness cannot be judged, because this has not been evaluated. The effectiveness might be improved by using a combination of a financial incentive and other implementation strategies, depending on the targets $\operatorname{set}^{17}$. A combination of a behaviour dependent financial incentive with an intervention directed at the individual GP like audit and feedback or computer reminders might have improved the guideline implementation $^{19}$.

The multidisciplinary development and dissemination of the locally adapted prescription guidelines was an expensive intervention strategy, with only little effectiveness. It was too simple thought that GPs would feel involved by asking them for feedback. Possibly other more efficient methods should be used to adapt guidelines to the local level and to improve involvement, for example by translating national guidelines into local improvement goals. Recently, recommendations from literature show the importance of developing an additional set of locally agreed prescribing indicators next to the local guideline ${ }^{20}$. First, a small group of local stakeholders translates the national guidelines into a set of locally adapted prescribing indicators ${ }^{21}$. A pilot test and consensus meetings can be used to create broad support and general acceptance. Finally, official authorisation is needed ${ }^{9}$. Segmentation of the target group might have lead to different approaches: for some physicians it is desirable to make evidence available quickly, for others spreading the guidelines through the local network may 
be effective, while for another group a more active, personal approach may be necessary ${ }^{22}$. Nevertheless, literature is lacking evidence about the most (cost)-effective method of developing and disseminating guidelines under different circumstances ${ }^{23}$. Careful planning of guideline dissemination and implementation should promote the chances of successful implementation $^{22}$. The dissemination of the multidisciplinary guidelines in this thesis was rather straightforward. Segmentation of the target group and an analysis of the barriers to change might have improved the effectiveness of the guideline dissemination ${ }^{24}$.

In this study a pragmatic choice to implement a CRS was made, without executing an analysis on determinants of effectiveness using computer reminders for implementing prescribing guidelines. The effects of computerised decision support systems to improve implementation of guidelines have been studied extensively but only part of these studies showed success. Reviews on the effect of computerised decision support systems shows that 43 of 65 studies resulted in an improvement of the doctors' performance ${ }^{25}$. The Cochrane review of computer advice on dosing to improve prescribing found 15 satisfactory trials and concluded that there were significant reductions in the time to achieve therapeutic control and a significantly shortened length of stay. The number of toxic levels and adverse drug reactions were also reduced ${ }^{26}$. The following determinants of the effectiveness of computerized decision support have been described: 1) high workload during patient visits, 2) creating a feedback mechanism for critical comments about the computer reminder in supplying the possibility to document system problems and content related comments, 3) relevance and accuracy of the messages: inapplicability of the computer reminder due to context specific reasons, 4) perceived reduction of quality of physician-patient interaction, 5) length, timing and number of the reminders, and 6) higher perceived utility and ease of use of clinical reminders ${ }^{27-30}$. These human barriers and facilitators may have influenced the implementation of the CRS that is described in this thesis. GPs could not enter their feedback on problems with the system, or on inaccuracy and irrelevance of the reminders. The process evaluation showed that the CRS suffered from inapplicability problems for the cholesterol reminders, as the GP had to switch between two computer programs, which was not possible due to the implementation of the CRS. The GPs varied in their criticism on the number of reminders, which is possibly clarified by the differences in the reminder blocks that had been activated (cholesterol or antibiotics/asthma/COPD). So it is not known to which extend these barriers negatively effected the implementation of the CRS.

A reactive Computer Reminder System (CRS) was developed in this project, which is a system that produces advices after the GP has indicated which drugs (s)he intends to prescribe. Timing of the reminders seems to be a relevant aspect of research ${ }^{31}$. By interfering rather late, the CRS is able to offer rather detailed information on the GP's prescribing action and causes minimal disturbance of the prescribing process. The CRS mainly focussed on appropriateness of the prescription and leaves the decision to the GP, only reacting if the requested drug is not in accordance with the guidelines. Important recommendations from main reviews support the importance to provide decision support automatically as part of the workflow and support the importance to deliver decision support at the time and location of 
decision making ${ }^{31}$. Larger effects can be expected if the reminder is linked closer to the moment of decision making ${ }^{32}$. Proactive systems have also been developed to influence GP's behaviour. In the proactive approach a number of working hypothesis would be presented. To provide the most accurate reminder the GP needs to enter diagnosis and disease related information. The CRS studied could be adapted in becoming a more proactive supporting system by providing diagnosis related drug information. If a CRS is depending on clinician initiative for use, it is recommended that the system use is carefully monitored and steps are taken to ensure that GPs access the system as intended ${ }^{31}$. It remains an issue for future research which type of decision support is most indicated for influencing prescribing.

\section{Drug prescribing behaviour}

The determinants of prescribing behaviour have been studied extensively in the last decades, but an overall model has not been developed to explain prescribing behaviour. From the literature five main theoretical approaches can be taken to explain non-adherence to guidelines in general: 1) cognitive theories and educational approaches, 2) motivational theories, 3) social influence theories, 4) marketing theories, and 5) organisational theories ${ }^{33}$. Cognitive theories and educational approaches refer to a lack of knowledge of the guideline and the consequences of non-adherence to the guidelines. GPs may not always be informed well enough about the consequences of deviating from a certain guideline ${ }^{34}$. In general, the cost-consciousness of prescribers seems to be rather low. Also, information dissymmetry between industry and prescribers encourages marketing activities. These marketing activities influence cost-consciousness negatively ${ }^{35}$. So, better information about the evidence base of drugs and drug costs is certainly needed ${ }^{36}$. Pharmaceutical industries use their own medical representatives to inform GPs about drug developments. A recent Dutch study showed that GPs are interested in receiving drug information when provided by an independent medical representative ${ }^{37}$. Possibly, GPs received other advices from national guidelines or training courses that were not in line with the local advices of the multidisciplinary advices of our guidelines. Another issue deals with the question whether GPs were interested in changing prescribing patterns. If (s)he had not yet experienced a problem with actual prescribing in practice, there may have been no internal drive to change according to adult learning approaches.

Behavioural change theories distinguish between internal and external drives. Internally, change is only possible when one feels the need to reflect on alternative drug solutions themselves and discusses difficulties in drug prescribing with his or her colleagues. In this study it is unknown whether drug prescribing according to multidisciplinary guidelines was really a main issue for the GP practices studied. Behavioural theories stress that change is caused by external stimuli, such as feedback, incentives, modelling and external reinforcement. Although the computer reminders were in fact an instant form of direct feedback, GPs did not receive periodical feedback on their prescribing performance. In this study a deliberate choice was made not to present this feedback, as confounding due discussions with colleagues was feared. Now, after analysing the results and given recent 
literature on the use of computer reminders, a feasible and appropriate CRS should also provide periodic performance feedback and benchmarks to improve the implementation of the $\mathrm{CRS}^{30,38}$. Considering benchmarks it is important that physicians can recognize themselves in the benchmarks presented ${ }^{39}$.

Looking at social theories on prescribing behaviour this involves social values and a possible lack of leadership. In GP practices one could think of the GP practice attitude and values towards prescribing and the attitude in seeing medical representatives from the pharmaceutical industry. In addition, exploring marketing theories especially the drug industry is experienced in using these kinds of strategies for their goals in influencing prescribing behaviour. Independent health organisations should invest more in opposing against these marketing strategies by educating GPs to be aware of framing theories, which are marketing and psychological strategies of mental influencing or mediatic presentation of drugs $^{34,35}$. Also more attention should have been paid to the marketing of the CRS, making clear to GPs from scratch what the benefits could be with regard to improving rational prescribing by using the CRS. Finally, looking at prescribing behaviour from organisational theories, prescribing inconsistency is not just an individual problem, but might also be a system failure. In this study one could think of problems with the GP information system of the practice, but also on difficulties in tuning of the GP information system and the pharmacy system.

All these theories at least partly explain non-rational prescribing behaviour. One consequence of irrational prescribing is a large variety in drug prescribing. Research has focused principally on the quantifiable aspects of prescribing variation, meaning that we lack knowledge on the determinants of this variance ${ }^{40-43}$. A major finding of studies on prescribing patterns is that there are extreme variations in the volume and cost of prescribing between different geographical areas and between individual prescribers. There have been many attempts to relate these variations to differences in the case mix of patients being seen, but most have concluded that there are a variety of other variables operating like local cultural determinants of drug utilization, and characteristics of the prescribing doctors ${ }^{44-49}$.

So, summarising this, using theoretical approaches like cognitive theories and educational approaches, motivational theories, social influence theories, marketing theories, and organisational theories, seems helpful to get grip on the black box of non-adherence to prescription guidelines.

\section{Evaluation Methods}

In this study prescribing quality indicators were important to evaluate the effectiveness of the CRS. Quality indicators can be used to measure the quality of the professional practice performance for which there is evidence or consensus ${ }^{50,51}$. Recently in literature, attention has been paid to their role in the development and implementation of guidelines ${ }^{52-54}$. Quality indicators can be developed in a systematic or non-systematic way. As in this study, nonsystematic approaches often occur because data are available. To enhance involvement of the target group it is often necessary to adjust them ${ }^{20}$. Quality indicators can be valuable in assessing quality improvement, although little is know about the reliability and validity of the 
non-systematic approach ${ }^{55}$. Systematic approaches are preferred because they help maximise the accuracy and face-validity of quality measurement and supply possibility of Benchmark Research. Different systematic development methods can be used, such as the RAND procedure or the Delphi technique ${ }^{56-58}$.

In this study the national and systematically developed prescribing indicators could not be used because they did not match with the computer reminders. It was preferred to develop indicators that were directly tuned to the recommendations of the computer reminders, so they could be used to evaluate the effectiveness of the reminders themselves. Consequently, it was not possible to compare the developed prescription indicators with the national ones. Given recent literature, it possibly would have improved our implementation chances if we would have integrated national target conditions ${ }^{22}$. Another advantage is that this would have created a chance of benchmarking, using valid standards of effectiveness.

Quality indicators are used increasingly in the development and evaluation of a quality improvement strategy for which comparison feedback or accountability is used. They can focus on structure, process or outcome indictors. Outcome indicators are usually used for external accountability, process indicators are more often applied in quality improvement and implementation of change projects. Indicators should be tested for their validity, reliability, acceptability, feasibility and sensitivity to change and how communicable or understandable they are (54). They should measure the quality in a valid and reliable manner with little interand intra-observer variability so that they are suitable for comparisons between professionals, practices, and institutions. Systematic developing and testing of indicators next to the development of guidelines is becoming an important condition of good implementation of multidisciplinary guidelines ${ }^{20}$.

Another evaluation aspect deals with the used analysing method. In this study sumscores of the volume measures were calculated, but not the sumscores of the prescription indicators. Using sumscores for quality indicators seem to be valuable to express the effectiveness of the entire quality improvement strategy ${ }^{59}$.

The cost-effectiveness of the quality improvement strategy remains an important issue in CRS evaluation studies. A full economic evaluation of the CRS including patient outcome measurement was not executed in this study, and therefore we cannot determine the efficiency of the CRS. There is little evidence that decision support is effective in changing patient outcome, and the evaluation in this field is limited in terms of quality and generalisability ${ }^{31,60}$. From a recent review it is known that only very few implementation studies include patient outcome in an economic evaluation ${ }^{61}$. It is difficult to use patient outcome effects in prescribing analyses, because these effects are often only measurable in the long-term. Often practical problems hamper evaluation of patient outcome because patient related information such as diagnoses, patient types, and comorbidities is not available. These problems are often the cause that patient outcome have not been well evaluated in studies related to decision support systems ${ }^{62}$. However, by using patient outcome more insight could be gained in the economical and organisational aspects of implementation strategies ${ }^{63,64}$. 
Recently a model was developed to calculate the total net monetary benefits of implementing a clinical guideline for a target patient population. By combining evidence on guidelines and implementation strategies (costs and effects) with information on clinical practice (for example guideline adherence and prevalence of disease) current practice and implementation strategies, this model allows the determination of the total potential to invest in guideline implementation and the mutual comparison of implementation strategies. The above-mentioned innovative model provides a simple and useful instrument for studying the value for money of guideline implementation and to inform decision makers about efficient allocation of the limited resources ${ }^{61,64}$.

In this study costs were subdivided into different phases of the quality improvement process: development costs, organising and execution costs of the quality improvement strategy $^{65}$. These cost categories are the costs per GP of a quality improvement strategy. Costs of a quality improvement strategy often intend to cause a change in healthcare provision. More specifically, as a result of computer reminders, a GP may for example prescribe fewer antibiotics such as quinolones, but more cholesterol lowering drugs for high risk cardiovascular patients. Health care provision costs may also include a change in the way patients make use of health care, for example more referrals or more diagnostic tests, which can be partly attributed to effects on patient health. These changes in health care provision costs are part of health care costs that should be reflected in a cost-effectiveness model $^{63}$. This stresses the importance to not only calculate costs of a quality improvement strategy, but also calculate health provision costs at the patient level. When choosing the primary outcome parameter of an implementation study, the researcher will have to make sure that the cost-effectiveness of following a guideline is known (desired behaviour) in terms of improved health for the individual patient. In this study we did not pay attention to the above mentioned outcome measure. If this outcome measure was known, it would have been possible to compare the patient's outcome with the costs that results from not following a guideline (undesired behaviour). Although often neglected, implementation of a guideline that does not lead to a patients' health improvement, can never be efficient, no matter how well the guideline has been followed. If they would have been known, the relative costeffectiveness of an implementation strategy can also be determined ${ }^{65}$. With the knowledge of the relative cost-effectiveness of following a guideline compared to not following a guideline, it would also be possible to determine the maximum financial resources within a budget that can be used neutrally to encourage the usage of a guideline ${ }^{61,64}$.

\section{IMPLICATIONS FOR PRACTICE AND FURTHER RESEARCH}

\section{Implementation methods}

The financial incentive strategy evaluated in this thesis was not very effective. The effectiveness might be improved by combining a financial incentive with another quality improvement strategy, fitting to the targets set. Combining a behaviour dependent financial incentive with an intervention directed at the individual GP like audit and feedback or 
computer reminders related to the prescribing behaviour might improve the effectiveness. Carefully developed and executed research is needed to identify which combination of quality improvement strategies seem to be most successful.

The local and multidisciplinary developed guidelines were positively valued by the GPs but showed only little effectiveness. Offering the GPs a possibility to comment on the draft guidelines should help the GPs to internalise the guidelines. But, the development of the local guidelines appeared to be a cost consuming exercise with only small results. Possibly a more effective method should be used to adapt national guidelines to the local level by a selection of a small group of experts from practice. In reaching consensus broad support methods could be used like written surveys, consensus meetings or interviews. Recently, recommendations from literature show the importance of developing next to the local guideline an additional set of upon locally agreed prescribing indicators to improve guideline implementation.

Despite the attempts to involve the GPs more intensively in the development process of the local guidelines and the CRS the GPs did not experience a sense of ownership with the computer reminders. One of the major results was that reminders were ignored or manipulated. More attention should be paid to the needs of the target group and the barriers to change. Given the barriers in implementing computer reminders, more attendance should be paid to give GPs control in the development phase of the CRS, and also to the GP's involvement with the CRS after installation in daily practice. Future qualitative and quantitative studies are necessary to show the reasons for overriding reminders and whether redesigning the system is effective in reducing unnecessary reminders.

The dissemination of the multidisciplinary guidelines in this thesis was rather simple. Segmentation of the target group should lead to approaches targeted to the desires of the physicians for example by making evidence quickly available, for others spreading the guidelines through the local network, while for another group a more active, personal approach may be necessary.

Another feature that should be added to the CRS is a feedback tool for GPs to give comments on the system as well as the content of the recommendation. We advise to develop locally adapted indicators, as this improves the implementation of the underlying guidelines and benchmarking could be based on these indicators. The research database of the CRS could be used providing feedback and benchmarking on the GP's prescribing behaviour, which can be a strong strategy to improve the adoption and implementation of the guidelines.

The CRS should be combined with a financial or an accreditation incentive. From literature there is belief that the adoption and effectiveness of a CRS needs to be driven by financial, regulatory, and/or accreditation incentives. This is because physicians bear a disproportionate share of the costs of implementing and using the system, relative to the financial benefits that result from its use.

During the last decades a numerous number of computerized systems have been developed. However, only a few systems were actually used in daily practice. Nowadays there is an increasing need to shift from a technology-driven approach to one employing the 
most cost-effective method to manage knowledge, regardless of the technology. Critical considerations of the determinants of change should also involve a logical selection of the most appropriate quality improvement strategy, asking whether a CRS is the most appropriate implementation strategy.

\section{Evaluation methods}

As healthcare resources are limited, it becomes increasingly important to determine whether investing in quality improvement strategies is worthwhile. The recently developed model might be useful to calculate the total net monetary benefits of the implementation or the multidisciplinary guidelines and the CRS. The above-mentioned innovative model provides a simple and useful instrument for studying the value for money of the implementation strategies. The promise that this model allows the determination of the potential to invest in guideline implementation and the comparison of implementation strategies needs further studying.

If the relationship between a health action and patient outcomes is well understood from clinical research studies, measurement of (long term) patient outcomes within an implementation study is not necessary. In these situations a short time horizon may be sufficient to demonstrate change in process, for example whether the GPs treat their patients in accordance with the guidelines. These intermediary results could be used as a basis for the prediction of patient outcomes over longer time horizons by decision-analytic models. In this study the relationship between prescribing according to guidelines and improved patient health status has not been proved, although a close relationship might be expected. First of all a further exploration of improved guideline adherences and patient outcome is needed. Given the fact that studies after the use of decision analytic models in economic evaluations in implementation research are still scarce, more exploration in this field should be executed.

During the CRS study, the baseline measurement was finally skipped, due to fear for GPs dropping out of the project if they were asked to register diagnosis codes without receiving reminders. Missing the baseline measurement seriously affected the power of the study, especially since the prescribing rates showed extremely large standard deviations. For future research we stress the importance of a baseline measurement since a strong design has better ability to deal with power problems.

On the whole, the effect of computerised reminder systems on clinical outcomes remains uncertain. Until now, only few studies reported the cost-effectiveness of these systems. Therefore, more evaluations of CRS are needed to produce valid and generalisable findings on clinical, economical and organisational aspects of CRS. 


\section{REFERENCES}

1. Bindels R, Hasman A, Van Wersch JW, Talmon J, Winkens RA. Evaluation of an automated test ordering and feedback system for general practitioners in daily practice. Int $\mathrm{J}$ Med Inform 2004;73(9-10):705-12.

2. de Clercq PA, Hasman A, Blom JA, Korsten HH. Design and implementation of a framework to support the development of clinical guidelines. Int J Med Inform 2001 Dec;64(2-3):285-318.

3. Shekelle PG, Woolf SH, Eccles M, Grimshaw J. Clinical guidelines: developing guidelines. BMJ 1999 Feb 27;318(7183):593-6.

4. Grol R. Development of guidelines for general practice care. $\mathrm{Br} \mathrm{J}$ Gen Pract 1993 Apr;43(369):146-51.

5. Verstappen WH, van der Weijden T, ter Riet G, Grimshaw J, Winkens R, Grol RP. Block design allowed for control of the Hawthorne effect in a randomized controlled trial of test ordering. J Clin Epidemiol 2004 Nov;57(11):1119-23.

6. Moulding NT, Silagy CA, Weller DP. A framework for effective management of change in clinical practice: dissemination and implementation of clinical practice guidelines. Qual Health Care 1999 Sep;8(3):177-83.

7. Grol R, Grimshaw J. Evidence-based implementation of evidence-based medicine. Jt Comm J Qual Improv 1999 Oct;25(10):503-13.

8. Grol R, Wensing M. What drives change? Barriers to and incentives for achieving evidence-based practice. Med J Aust 2004 Mar 15;180(6):S57-60.

9. Burgers J, Grol R, Eccles M, Clinical guidelines as a tool for implementing change in patient care. In: Grol R, Wensing M, Eccles M. Improving Patient Care. The Implementation of Change in Clinical Practice. Oxford: Butterworth-Heinemann 2005:71-92.

10. Grol RP, Bosch MC, Hulscher ME, Eccles MP, Wensing M. Planning and studying improvement in patient care: the use of theoretical perspectives. Milbank Q 2007;85(1):93-138.

11. Van Bokhoven MA, Kok G, van der Weijden T. Designing a quality improvement intervention: a systematic approach Qual Saf Health Care 2003 Jun;12(3):215-20.

12. Bosch $M$, van der Weijden $T$, Wensing $M$, Grol R. Tailoring quality improvement interventions to identified barriers: a multiple case analysis. J Eval Clin Pract 2007 Apr;13(2):161-8.

13. Shaw B, Cheater F, Baker R, Gillies C, Hearnshaw H, Flottorp S, Robertson N. Tailored interventions to overcome identified barriers to change: effects on professional practice and health care outcomes. Cochrane Database Syst Rev 2005 Jul;20(3):CD005470.

14. Fretheim A, Oxman AD, Flottorp S. Improving prescribing of anitihypertensie and cholesterollowering drugs: a method for identifying and addressing barriers to change. BMC Health Services Research 2004;4:23.

15. Gosden T, Forland F, Kristiansen IS, Sutton M, Leese B, Giuffrida A, Sergison M, Pedersen L. Capitation, salary, fee-for-service and mixed systems of payment: effects on the behaviour of primary care physicians. Cochrane Database Syst Rev 2000;3:CD002215. Review.

16. Shortt, SED. General Practice fund holding in the United Kingdom. Do not copy. Canadian Family Physicians 2003;49:279-81.

17. Chaix-Couturier, et al. International Journal for Quality in Health Care Volume 12, 2000. Pages: 133

18. Giuffrida A, Gosden T, Forland F, Kristiansen IS, Sergison M, Leese B, Pedersen L, Sutton M. Target payments in primary care: effects on professional practice and health care outcomes. Cochrane Database of Systematic Reviews 1999, Issue 4. Art. No.: CD000531. DOI: 10.1002/14651858.CD000531.

19. Teich JM, Osheroff JA, Pifer EA, Sittig DF, Jenders RA; The CDS Expert Review Panel. Clinical decision support in electronic prescribing: recommendations and an action plan: report of the joint clinical decision support workgroup. J Am Med Inform Assoc 2005 Jul-Aug;12(4):365-76. 
20. Hermens RP, Ouwens MM, Vonk-Okhuijsen SY, van der Wel Y, Tjan-Heijnen VC, van den Broek LD, Ho VK, Janssen-Heijnen ML, Groen HJ, Grol RP, Wollersheim HC. Development of quality indicators for diagnosis and treatment of patients with non-small cell lung cancer: a first step toward implementing a multidisciplinary, evidence-based guideline. Lung Cancer 2006 Oct;54(1):117-24.

21. Hutchinson A and Baker R (1999). Making Use of Guidelines in Clinical Practice. Abingdon: Radcliffe Medical Press.

22. Grimshaw JM, Thomas RE, MacLennan G, Fraser C, Ramsay CR, Vale L, Whitty P, Eccles MP, Matowe L, Shirran L, Wensing M, Dijkstra R, Donaldson C. Effectiveness and efficiency of guideline dissemination and implementation strategies. Health Technol Assess 2004 Feb;8(6):iii-iv, $1-72$.

23. Mason J, Eccles M, Freemantle N, Drummond M. A framework for incorporating cost-effectiveness in evidence-based clinical practice guidelines. Health policy 1999;47(1):37-52.

24. R Grol, A Zwaard, J Mokkink, J Dalhuijsen and A Casparie. Dissemination of guidelines: which sources do physicians use in order to be informed? International Journal for Quality in Health Care 1998;10:135-40.

25. Hunt DL, Haynes RB, Hanna SE, et al. Effects of computer-based clinical decision support systems on physician performance and patient outcomes: a systematic review. JAMA 1998;280:1360-1.

26. Walton RT, Harvey E, Dovey S, et al. Computerised advice on drug dosage to improve prescribing practice (Cochrane Review). In: The Cochrane Library. Issue 3. Chichester, UK: John Wiley, 2004.

27. Fung $\mathrm{CH}$, Woods JN, Asch SM, Glassman P, Doebbeling BN. Variation in implementation and use of computerized clinical reminders in an integrated healthcare system. Am J Manag Care 2004;10:878-85.

28. Patterson ES, Doebbeling BN, Fung CH, Militello L, Anders S, Asch SM. Identifying barriers to the effective use of clinical reminders: bootstrapping multiple methods. J Biomed inform 2005;38:18999.

29. Patterson ES, Nguyen AD, Halloran JP, Asch SM. Human factors barriers to the effective use of ten HIV clinical reminders. J Am Med Inform Assoc 2004;11:50-9.

30. Saleem JJ, Patterson ES, Militello L, Render ML, Orshansky G, Asch SM. Exploring barriers and facilitators to the use of computerized clinical reminders. J Am Med Inform Assoc 2005;12:438-47.

31. Kawamoto K, Houlihan CA, Balas EA, Lobach DF. Improving clinical practice using clinical decision support systems: a systematic review of trials to identify features critical to success. BMJ 2005;330:765-8.

32. Grimshaw JM, Russell IT. Effect of clinical guidelines on medical practice: a systematic review of rigorous evaluations. Lancet 1993 Nov 27;342(8883):1317-22.

33. Grol R, Grimshaw J. From best evidence to best practice: effective implementation of change in patients' care. Lancet 2003 Oct 11;362(9391):1225-30. Review.

34. Laat de E, Windmeijer F, Douven R. How does pharmaceutical marketing influence doctors' prescribing behaviour? Den Haag, CPB \& Koninklijke De Swart, 2002.

35. Prosser H, Almonda S, and Walley T. Influences on GPs' decision to prescribe new drugs-the importance of who says what. Family Practice 2003;20(1):61-8.

36. Stichting Farmaceutische Kengetallen; Data en Feiten (Foundation for Pharmaceutical Statistics; Data and facts). The Hague/the Netherlands; 2005-2006.

37. Aalst, A van der. Regionale variaties in geneesmiddelengebruik nader bekeken. Een stap naar transparantie. DGV Nederlands instituut voor verantwoord medicijngebruik, Utrecht 2004.

38. Feder G, Eccles M, Grol R, Griffiths C, Grimshaw J. Clinical guidelines: using clinical guidelines. BMJ 1999 Mar 13;318(7185):728-30. 
39. Kiefe $\mathrm{Cl}$, Allison JJ, Williams OD, Person SD, Weaver MT, Weissman NW. Improving quality improvement using achievable benchmarks for physician feedback: a randomized controlled trial. JAMA 2001 Jun 13;285(22):2871-9.

40. Nyquist A, Gonzales R, Steiner J, Sande M. Antibiotic prescribing for adults with colds, upper respiratory tract infections, and bronchitis by ambulatory care physicians. JAMA 1997;278:901-4.

41. Quinn R, Kelly A. How much of a general practitioner's prescribing is outside his/her control? Ir Med J 1998;91:168-72.

42. Rokstad K, Straand J. Drug prescribing during direct and indirect contacts with patients in general practice: a report from the More \& Romsdal Prescription Study. Scand J Prim Health Care 1997;15(2):103-8.

43. Walzak D, Swindells S, Bhardwaj A. Primary care physicians and the cost of drugs: a study of prescribing practices based on recognition and information sources. J Clin Pharmacol 1994;34:1159-63.

44. Martin JP. Social aspects of prescribing. London: William Heinemann, 1957.

45. Macukanovic P, Rabin DL, Mabry JH, Simic D. Use of Medicines. In: Kohn R and White KL (eds) Healthcare - an international study. London: Oxford University. Press 1976:223-77.

46. Bergman U. Studies in drug utilisation. Copenhagen: WHO, 1979.

47. Hartley RM, Charlton JR, Harris CM, Jarman B. Patterns of physician's use of medical resources in ambulatory settings. Am J Public Health 1987;77:565-7.

48. Hartzema AG, Christensen DB. Non-medical factors associated with the prescribing volume among family practitioners. in an HMO. Med Care 1983;21:990-1000.

49. Jaye C, Tilyard M. A qualitative comparative investigation of variation in general practitioners' prescribing patterns. British Journal of General Practice 2002;52:381-6.

50. Donabedian, The quality of care. How can it be assessed?, JAMA 1988;260:1743-8.

51. Lawrence M and Olesen F. Indicators of quality in health care. Eur. J. Gen Pract 1997;3:103-8.

52. Haaijer-Ruskamp FM, Andersen M, Vander Stichele R. Prescribing Quality indicators. In: Hartzema AG, Porta M, Tilson HH. Pharmaco-epidemiology: an introduction. 3rd ed. Cincinnati, OH: Harvey Whitney Books Company, 1998.

53. Campbell SM, Braspenning J, Hutchinson A, Marshall M. Research methods used in developing and applying quality indicators in primary care. Qual Saf Health Care 2002 Dec;11(4):358-64.

54. Wollersheim H, Hermens R, Hulscher M, Braspenning J, Ouwens M, Schouten J, Marres H, Dijkstra R, Grol R. Clinical indicators: development and applications. Neth J Med 2007 Jan;65(1):15-22. Review.

55. Campbell SM, Braspenning J, Hutchinson A, Marshall M. Research methods used in developing and applying quality indicators in primary care. Qual Saf Health Care 2002 Dec;11(4):358-64.

56. Linstone HA and Turoff M (1975). The Delphi Survey. Method, Techniques and Applications. Reading: Addison-Wesley.

57. Dalkey NC (1969). The Delphi Method: An experimental Study of Group Opinion. Santa Monica: The Rand Corporation.

58. Shekelle PG, Kahan JP, Bernstein SJ, Leape LL, Kamberg CJ, Park RE. The reproducibility of a method to identify the overuse and underuse of medical procedures. N Engl J Med 1998 Jun 25;338(26):1888-95.

59. Nietert PJ, Wessell AM, Jenkins RG, Feifer C, Nemeth LS, Ornstein SM. Using a summary measure for multiple quality indicators in primary care: the Summary QUality InDex (SQUID). Implement Sci 2007 Apr 2;2:11.

60. Barber N. Designing information technology to support prescribing decision making. Qual Saf Health Care 2004;13:450-4

61. Hoomans T, Evers SMAA, Ament AJHA, Hubben MWA, Weijden T vd, Grimshaw JM, Severens $\mathrm{JL}$, The methodological quality of economic evaluations of guideline implementation into clinical practice: a systematic review of empirical studies, In:Value in Health, 2006; accepted, 2007 
62. Garg AX, Adhikari NK, McDonald H, Rosas-Arellano MP, Devereaux PJ, Beyene J, et al. Effects of computerized clinical decision support systems on practitioner performance and patient outcomes: a systematic review. JAMA 2005 Mar 9;293(10):1223-38.

63. Sculpher M. Evaluating the cost-effectiveness of interventions designed to increase the utilization of evidence-based guidelines. Fam Pract 2000;17(1):S26-S31.

64. Buxton MJ, Drummond MF, Van Hout BA, et al. Modelling in economic evaluation: An unavoidable fact of life. Health Econ 1997;6:217-27.

65. Severens JL. Value for money of changing healthcare services? Economic evaluation of quality improvement. Qual Saf Health Care 2003;12:366-71. 

Summary 

Clinical guidelines are increasingly becoming a common element of clinical care. The aim of clinical guidelines is to improve patient care by providing appropriate recommendations for daily practice. Preferably, these guidelines are based on the best-available evidence, supplemented with clinical expertise. Prescribing recommendations have often been subject to guideline development. Medication is not always prescribed effectively: drugs may be prescribed unnecessarily and lower-cost alternatives are not always taken into consideration.

Healthcare expenditure in the Netherlands has increased by about $8.5 \%$ per year in the last 30 years. The government has developed a restricted policy for healthcare expenditure to prevent healthcare becoming too expensive. Drug prescribing is an important contributor to this increase in costs, and these costs are expected to continue to increase systematically and relevantly in the coming years. The quality of and variation in drug prescribing can be attributed to physicians' non-rational prescribing behaviour, demographic factors like growth and ageing of the population, the trend towards new but usually more expensive drugs, patients' increased awareness, pressure from the industry and, last but not least, the differences in prescribing practices between primary and secondary care-oriented physicians. Physicians are also known to prescribe more easily as a result of today's high level of work-related stress and routines.

The use of prescribing guidelines in clinical practice is expected to influence prescribing behaviour. Guidelines have often been developed by primary care physicians or specialists alone. In general it is known that there is a failure to align prescribing between primary and secondary care. This may lead to inefficient care and places patients at risk. Recommendations by the European Working Party on Quality in Family Practice stress the need for improving the integration of care by different physicians and stress the importance of establishing clinical guidelines jointly.

However, there is a gap between best practice and actual clinical care. In this case: a discrepancy between the clinical guideline and physicians' actual behaviour. Up till now, no magic bullets have been found for which guideline dissemination and implementation strategies are likely to be most effective. Each implementation strategy can be effective under certain circumstances. A multifaceted strategy seems most likely to achieve change. The strategy should be tailored to suit local circumstances, taking into account any particular potential barriers. It is important to build in support and incentives and to consider the resources needed for successful implementation. These systematic strategies require good planning to be successful, but are also cost-consuming. Taking a cost perspective into account, it is important to consider not just the overall results but also the efforts required to achieve them as well. Literature therefore advises focusing on evaluating the implementation of evidence-based guidelines taking all costs into account by executing a full economic evaluation.

Given the difficulties in improving the rationality of prescribing, the aim of this thesis is to evaluate the development and implementation of a series of guideline implementation strategies that could improve physicians' rational prescribing behaviour. The thesis 
concentrates on three implementation strategies: a financial incentive, the dissemination of intensively developed paper guidelines and a Computer Reminder System (CRS) - a computer system that pops up reminders if the user deviates from the existing guidelines. The CRS strategy was evaluated extensively, executing an effect evaluation on GP's drug prescribing, a process evaluation and a cost analysis. The studies in this thesis were designed to answer the following questions:

a. Does a behaviour-independent financial bonus change the volume of general practitioners' prescribing behaviour in the desired direction?

b. What is the effect of the dissemination of multidisciplinary guidelines on prescribing behaviour, and is this stronger for members of the target group who were involved in the preparation and development of the guidelines?

c. What is the effect of computerised reminders based on the recommendations in the multidisciplinary guidelines on GPs' prescribing behaviour?

d. What are the costs and the effects expressed in costs of a CRS regarding prescribing behaviour differentiated to different phases: development of input (guidelines), development of the CRS, diffusion of the CRS (execution costs), and medication costs (healthcare costs)?

e. How feasible and acceptable was the implementation of the CRS for prescribing behaviour in primary care, how satisfied were the GPs, and what were the barriers and facilitators for working with the CRS?

Chapter 2 reports on the effects of a financial incentive on general practitioners' prescribing behaviour. The financial incentive consisted of a non-recurrent, behaviour-independent oneoff bonus (target payment). In return for the incentive, the GPs were to adhere to relevant prescription guidelines abstracted in a one-page printed formulary developed by a multidisciplinary committee. The intervention group consisted of $119 \mathrm{GPs}$ in a region in the south of the Netherlands. A control region with 118 GPs was selected in another part of the country. Prescription data from each GP every month during the period 2000-2002 were obtained from the regional health insurance companies. Short-term and long-term effects were evaluated by analysing prescription data over the same period in the following years. This study found that the financial bonus had a limited, temporary effect on general practitioners' prescribing behaviour according to existing national and regional guidelines. There was a significant short-term effect in the expected direction for a few drug indicators (amoxicillin plus clavulan acid, trimethoprim, recommended gastric medicine and newly developed drugs). Only the recommended gastric medicine showed a significant effect in the long-term as well. In the longer term, the modest impact of this financial incentive disappeared. Possibly, the GPs were not familiar with the intervention and were apparently little motivated to participate. The behaviour-independent character seemed not to be sufficiently binding and, during the study, the GPs were not informed in any way nor reminded about their participation in the trial. In conclusion, this study showed that a behaviour-independent financial incentive had only small-scale and temporary effects on changing prescription behaviour. 
The multi-design of the main project, the development and implementation of multidisciplinary guidelines using computer reminders to affect prescribing behaviour is presented in Chapter 3. A combination of designs - varying from a quasi-experimental to a pragmatic clustered Randomised Controlled Trial (RCT) following an incomplete block design - were used to study the computer reminder strategy to improve the rationality of prescribing behaviour among GPs. The main outcome measures were satisfaction scores, application scores, performance indicators, prescription volumes and costs. Unless we were faced with several drawbacks and practical barriers in the preparation of the study, all parts of the study, including the pragmatic trial could be implemented and performed as planned. It can be concluded that, despite the complexity of the study environment, the study was able to be performed successfully. The rather comprehensive design of the study turned out to be appropriate and feasible. The combination of several study parts in one large study offered us the opportunity to assess the effects of the intervention on a broad range and on various aspects. The evaluation of the effects of implementing guidelines through a reminder system was more than just their technical applicability or the effects on doctors' behaviour. The total set of data allowed us to get a reasonably complete view of the different outcome in daily healthcare expressed in effects, but also in process and cost parameters.

The effects of a joint development and dissemination of multidisciplinary paper guidelines to improve GPs' prescribing behaviour are described in Chapter 4. The purpose of this study was to assess the effectiveness of the dissemination of multidisciplinary guidelines on the volume of drug prescribing. The study included two designs, a quasi-experimental pre/post study with concurrent control group and a random sample of GPs within the intervention group. The intervention area with 53 GPs was compared with a control group of 54 randomly selected GPs in the south and centre of the Netherlands. Additionally, randomisation was carried out in the intervention group to create two arms with 27 GPs who were more intensively involved in the development of the guidelines and 26 GPs in the control group.

The multidisciplinary guidelines were developed by a multidisciplinary committee (pharmacists, specialists, GPs, representatives from the insurance company). Subsequently these guidelines were disseminated to all GPs in the intervention region. Additional effects were studied in the subgroup trial in which GPs were invited to be more intensively involved in the guideline development procedure. The guidelines contained 14 recommendations on antibiotics, asthma/COPD drugs and cholesterol drugs.

The main outcome measures were prescription data over a three-year period (one year before and two years after guideline dissemination) and proportion of change according to the recommendations. Significant short-term improvements were seen for one recommendation: mupirocin. Long-term changes were found for cholesterol drug prescriptions. No additional changes were seen for the randomised controlled study in the subgroup. The standard deviation of prescribing drugs per GP turned out to be unexpectedly large. So, although small changes could be seen on other indicators, no significant effects 
were seen for these other drugs. The invitation to GPs to become involved in the development procedure caused no desirable effects in the subgroup.

It can be concluded that disseminating the rigorously developed multidisciplinary guidelines had no clear effect on GPs' prescribing performance even though the GPs and specialists were involved more intensively in their development. Apparently, more effort is needed to bring about change.

A more intensive strategy to improve prescribing behaviour is described in Chapter 5. This chapter reports on the effectiveness of a Computer Reminder System (CRS) on GPs' prescribing behaviour. The purpose of this study was to assess the effects of implementing prescribing guidelines by means of a reactive CRS on prescribing behaviour. The previously described multidisciplinary prescription guidelines (Chapter 4) were integrated into a CRS. This CRS was linked to a specific GP information system (MicroHis) on the computers in the GP practices. If a GP's specific drug prescription was not in line with prescribing guidelines the CRS popped up a reminder. The guidelines contained recommendations about antibiotics, asthma/COPD drugs and cholesterol drugs.

In a cluster RCT with an incomplete block design in the south of the Netherlands, 25 GPs (in $11 \mathrm{GP}$ practices) received reminders about antibiotics and asthma/COPD prescriptions, and 28 GPs (in 12 GP practices) received reminders about cholesterol prescriptions. Both performance indicators and prescription volumes were calculated as the main outcome measures. Next to individual volume measure, sum scores were constructed on the volume measures per drug group (antibiotics, asthma/COPD and cholesterol). The variation between GPs turned out to be larger and more skewed than expected. No differences between groups were found for indicators and volumes related to recommendations advocating certain drugs. Although there was a tendency towards clinically relevant results for prescription volumes that were supposed to drop, the difference in sum scores between the groups was not significant. For antibiotic prescriptions that were supposed to drop, the sum score for the intervention group was 28.2 (95\% Cl: 20.8-44.5) prescriptions per 1000 patients per GP, while this was $39.7(95 \% \mathrm{Cl}: 29.7-64.1)$ for the control group $(p=0.2)$. For asthma/COPD prescriptions that were supposed to drop, the sum score for the intervention group was 1.1 (95\% Cl: 0.6-2.6) prescriptions per 1000 patients per GP, while this was 2.2 (95\% Cl: $1.4-$ 4.3) for the control group $(p=0.1)$. In conclusion, the study turned out to be underpowered due to high inter-doctor variation in prescribing behaviour. Nevertheless, computerised reminders sometimes had a favourable effect on restricting certain drugs that were not or no longer indicated in general practice.

The most intensive strategy, the implementation of the CRS, was evaluated extensively in this thesis. The effects of this strategy were reported in Chapter 5. Chapter 6 reports on the Cost Effects of the CRS. In order to determine the cost of implementing a CRS, the development, execution and healthcare costs were calculated, aimed at improving GPs' drug prescribing behaviour and reducing healthcare costs. In the same cluster RCT with an incomplete block design in the south of the Netherlands, the prescription costs of antibiotics, 
asthma/COPD and cholesterol prescriptions were calculated based on volume data and multiplied by the cost prices per tablet, during a 12-month follow-up period. Fixed and variable costs per GP per year were calculated for different phases of the quality improvement process: developmental costs of the prescribing guidelines, developmental costs of the CRS strategy, execution costs of the CRS and prescription costs were calculated per GP per year. Prescription data from 34 GPs were able to be evaluated. The total cost of the CRS was $€ 15,239$ per GP (over 4.3 years of the project). Guideline development: $€ 7,685$ per GP; CRS development: $€ 4,130$ per GP; execution costs: $€ 3,424$ per GP. Significant results were seen for redundant prescriptions for antibiotics, asthma, and COPD: €291 per GP per year in the intervention group versus $€ 430$ per GP per year in the control group $(p=0.05)$. A trend in the desired direction was seen for medication costs for antibiotics, asthma and COPD that were supposed to increase based on recommendations from the guidelines: $€ 501$ per GP per year in the intervention group versus $€ 394$ per GP per year in the control group $(p>0.2)$. This difference was not seen for redundant cholesterol-lowering drug prescriptions: $€ 0$ per GP per year in the intervention group and $€ 6$ per GP per year in the control group $(p>0.2)$ and for cholesterol-lowering drug prescriptions that were supposed to increase: $€ 55$ per GP per year in the intervention group versus $€ 35$ per GP per year in the control group ( $p>0.2)$.

It proved possible to evaluate costs and cost reductions resulting from the CRS in improving GP's prescribing behaviour, but we could not perform a full economic evaluation taking the benefits of better adherence into account. This study turned out to be underpowered due to high inter-doctor variation in prescribing behaviour. Nevertheless, improved adherence to the guideline resulted in medication cost changes in the desired direction. However, these cost changes were smaller than the input costs. Nonetheless, this strategy might still reduce costs in the long run, because the initial investments were relatively high. The development costs are once-only and will be reduced by extrapolating the strategy over time to a larger population with more guidelines, and by applying the strategy to already existing guidelines. Implementing this intervention throughout the country would mean that we could distribute the fixed costs of the CRS intervention $(€ 769,666$ in total) over all Dutch GPs, being about 8,000 GPs. Expecting a participation rate of $90 \%$ would mean that the fixed costs would be hugely reduced to $€ 107$ per GP. So we recommend a further extension of the number of guidelines in the CRS and further expansion of the CRS among GP practices in the Netherlands. Although initial investments were high, we expect this strategy to reduce costs in the long run.

The implementation of the CRS strategy was planned to be evaluated extensively. After reporting the effects (Chapter 5) and the cost effects (Chapter 6), Chapter 7 reports a process evaluation of the implementation of the CRS. The main objectives were to evaluate the feasibility and acceptability of a Computer Reminder System (CRS) on improving prescribing behaviour in general practice and to explore the strengths and weaknesses of the CRS. In a process evaluation, the CRS, being used by 53 GPs in 23 practices, was evaluated by means of an analysis of the research database of the CRS. In addition, a 
questionnaire and semi-structured face-to-face interview were conducted with all GP practices, two project leaders, and one technical consultant. The strategy was largely carried out as planned, although the development period for the CRS had to be extended. $9 \%$ of the GPs dropped out.

Firstly, a significant learning curve was found in terms of GPs' behaviour as a result of the antibiotics asthma and COPD reminders from the CRS. The largest effects were seen in the first months after installation. This finding is probably a confirmation of the learning effect of reminders.

Secondly, the questionnaire showed that, in general, GPs were satisfied with the userfriendliness and the content of the different types of reminders, but less satisfied with certain specific technical performance issues of the system. The GPs reported mixed feelings towards the CRS in the interviews. The GPs turned out to be satisfied about the CRS on the following subjects: stability and speed of the CRS, the instructiveness and brevity of the reminders, the user-friendliness, layout, and support from the helpdesk. GPs were not satisfied with some technical problems that caused delay during prescribing. The sensitivity to new updates and their delay also caused irritation among GPs. Moreover they sometimes or often manipulated the CRS to bypass reminders. Thirdly, interviews with the project leaders and technical consultant revealed barriers to cooperation and miscommunication between the different parties, and technical problems with multiple updates of the GP information system and the operating system.

To sum up, this process evaluation demonstrated that the implementation of the CRS was mainly carried out as planned, but the subjective experience of working with the CRS was not only positive. Participating GPs had mixed feelings, and quite a number of barriers need to be addressed to facilitate large-scale implementation of the CRS. Costs cannot be neglected, so it is important to analyse the balance between cost and effects.

Chapter 8 presents a general discussion of the most important findings from the different studies and relates the conclusions of the earlier chapters under the topics 'financial incentive', 'multidisciplinary guidelines', and 'computerised reminders'. Some methodological considerations that did not receive attention earlier are discussed. Subsequently, this chapter discusses the results of the studies in relation to implementation theories, implementation strategies, prescribing theories and evaluation theories. Further details of these theories and the relation with our findings are discussed in chapter 8 . Based on the results described in this thesis, implications for healthcare practice and further research are given.

The main results are discussed with respect to the primary aim of evaluating different implementation strategies that could improve physicians' rational prescribing behaviour and with respect to executing this evaluation extensively. The behaviour-independent financial incentive strategy had only minor and short-term effects on prescribing behaviour. A possible combination of the financial incentive with an intervention like feedback or computer reminders would improve the effectiveness. The development and dissemination of the multidisciplinary local guidelines appeared to be a cost-consuming exercise with only small results. Perhaps a more effective method should be used to adapt national guidelines to the 
local level. The dissemination could be improved by segmentation of the target group leading to an approach which is more targeted to the physicians' desires.

The CRS strategy was evaluated extensively by studying the different aspects in an effect evaluation, a process evaluation and a cost analysis. The CRS study turned out to be underpowered due to high inter-doctor variation in prescribing behaviour. Nevertheless, computerised reminders sometimes had a favourable effect on restricting certain drugs that were not or no longer indicated in general practice: a significant improvement of over $30 \%$ was found for the antibiotics, asthma and COPD guidelines. Despite attempts to involve the GPs more intensively in the development process of the local guidelines and the CRS, the GPs did not experience a sense of ownership of the computer reminders. More attention should be paid to the needs of the target group and the barriers to change. Future qualitative and quantitative studies will be necessary to explore the reasons for overriding reminders and whether redesigning the system would be effective in reducing these barriers to change. If the CRS were to be implemented all over the country, this would mean a huge reduction of the fixed costs to $€ 107$ per GP. Given the possible savings as a consequence of the CRS and the possibility of reducing development costs, a further extension of the number of guidelines in the CRS and a further expansion of the CRS among GP practices in the Netherlands is to be recommended.

The research database of the CRS provides useful tools for providing feedback and benchmarking GP's prescribing behaviour, which can be a strategy for improving the adoption and implementation of the guidelines. As there is belief expressed in the literature that the adoption and effectiveness of a CRS needs to be driven by financial, regulatory, and/or accreditation incentives, the CRS might in the future be combined with a financial or an accreditation incentive. Physicians bear an unequal share of the cost of implementing and using the system, relative to the financial benefits that result from its use.

As healthcare resources are limited, it becomes increasingly important to determine whether investing in quality improvement strategies is worthwhile. It was not possible to execute a full economic evaluation taking the health benefits into account. A recently developed model might be helpful in calculating the total net monetary benefits of the implementation of the multidisciplinary guidelines and the CRS. The promise that this model enables the determination of the potential to invest in guideline implementation and the comparison of implementation strategies needs further study. 

Samenvatting 

Klinische richtlijnen maken steeds vaker een standaard onderdeel uit van de klinische zorg. Deze richtlijnen zijn bedoeld om door middel van het verstrekken van de juiste aanbevelingen voor de dagelijkse praktijk de patiëntenzorg te verbeteren. Deze klinische richtlijnen zijn bij voorkeur gebaseerd op het beste beschikbare feitenmateriaal (evidence), aangevuld met klinische expertise. Aanbevelingen voor het voorschrijven van medicatie zijn al vaak aan de orde geweest bij de ontwikkeling van richtlijnen. Medicatie wordt niet altijd effectief voorgeschreven: geneesmiddelen kunnen onnodig worden voorgeschreven en minder dure alternatieven worden niet altijd in overweging genomen.

De uitgaven voor de gezondheidszorg zijn in Nederland de afgelopen 30 jaar met circa $8,5 \%$ per jaar gestegen. De regering voert een restrictief beleid op het gebied van de uitgaven voor de gezondheidszorg om te voorkomen dat de gezondheidszorg te duur wordt. Het voorschrijven van geneesmiddelen draagt in belangrijke mate bij aan deze kostenstijging en het ligt in de verwachting dat deze kosten de komende jaren systematisch en in aanzienlijke mate zullen blijven toenemen. De kwaliteit van en de verschillen bij het voorschrijven van geneesmiddelen kunnen worden toegeschreven aan niet-rationeel voorschrijfgedrag van artsen, demografische factoren zoals vergrijzing en groei van de bevolking, de neiging om nieuwe en meestal duurdere geneesmiddelen voor te schrijven, toegenomen mondigheid van patiënten, druk vanuit de industrie en last but not least, de verschillen tussen de manier van voorschrijven door artsen uit de eerste en de tweede lijn. Het is ook bekend dat artsen gemakkelijker voorschrijven als gevolg van gewoontes en het huidige hoge aan werk gerelateerde stressniveau.

Men verwacht dat het gebruik van voorschrijfrichtlijnen in de klinische praktijk het voorschrijfgedrag zal beïnvloeden. Richtlijnen zijn vaak uitsluitend ontwikkeld door artsen uit de eerstelijnszorg of door specialisten. Het is algemeen bekend dat het voorschrijfbeleid tussen de eerste en tweede lijn niet goed op elkaar is afgestemd. Dit kan leiden tot inefficiënte zorg en kan patiënten in gevaar brengen. Aanbevelingen van de European Working Party on Quality in Family Practice benadrukken de noodzaak om de integratie van zorg door verschillende artsen te verbeteren, en wijzen op het belang van het gezamenlijk opstellen van klinische richtlijnen.

Er bestaat echter een kloof tussen best practice en de feitelijke klinische zorg. In dit geval: een discrepantie tussen de klinische richtlijn en het feitelijke gedrag van artsen. Tot op heden is er nog geen effectieve methode gevonden voor het verspreiden van richtlijnen en implementeren van strategieën. Elke implementatiestrategie kan onder bepaalde omstandigheden effectief zijn. Een gecombineerde strategie heeft waarschijnlijk de meeste kans om een verandering teweeg te brengen. De strategie zou dan naadloos moeten aansluiten op lokale omstandigheden en rekening moeten houden met alle mogelijke barrières. Het is belangrijk om hierbij ondersteuning en prikkels in te bouwen en na te gaan welke hulpmiddelen ingezet kunnen worden voor een succesvolle implementatie. Om succesvol te kunnen zijn vereisen deze systematische strategieën een goede planning. Deze vereisten werken echter wel weer kostenverhogend. Vanuit een kostenperspectief bekeken, is het belangrijk om niet alleen te letten op de totale resultaten, maar ook op de geleverde 
inspanningen die noodzakelijk waren voor het bereiken van die resultaten. In de literatuur wordt daarom aangeraden om zich te richten op de evaluatie van de implementatie van evidence-based richtlijnen en hierbij rekening te houden met alle kosten, door een volledige economische evaluatie uit te voeren.

Gezien de problemen bij het verbeteren van de rationaliteit van het voorschrijven, is het doel van dit proefschrift om de ontwikkeling en implementatie te evalueren van een serie strategieën voor de implementatie van richtlijnen die het voorschrijfgedrag van artsen rationeler zouden kunnen maken. Het proefschrift concentreert zich op drie implementatiestrategieën: een financiële incentive, de verspreiding van intensief ontwikkelde papieren richtlijnen en een Computer Reminder Systeem (CRS) - een systeem waarbij de computer mededelingen en adviezen op het scherm presenteert als de gebruiker afwijkt van overeengekomen richtlijnen. De CRS-strategie werd uitgebreid geëvalueerd door middel van een effectevaluatie van de door huisartsen voorgeschreven geneesmiddelen, een procesevaluatie en een kostenanalyse. De studies in dit proefschrift waren opgezet om een antwoord te krijgen op de volgende vragen:

a. Verandert een gedragsonafhankelijke financiële incentive de omvang van het voorschrijfgedrag van huisartsen in de gewenste richting?

b. Wat is het effect van de verspreiding van multidisciplinaire richtlijnen op het voorschrijfgedrag, en is dit sterker bij de leden van de doelgroep die betrokken waren bij de voorbereiding en ontwikkeling van de richtlijnen?

c. Welk effect hebben computer reminders die gebaseerd zijn op de aanbevelingen in multidisciplinaire richtlijnen, op het voorschrijfgedrag van huisartsen?

d. Wat zijn de kosten en de baten met betrekking tot het voorschrijfgedrag gedifferentieerd naar de verschillende fasen, uitgedrukt in kosten van een CRS: ontwikkeling van input (richtlijnen), ontwikkeling van het CRS, verspreiding van het CRS (uitvoeringskosten), en medicatiekosten (kosten van de gezondheidszorg)?

e. Hoe haalbaar en acceptabel was de implementatie van het CRS voor voorschrijfgedrag in de eerste lijn, hoe tevreden waren de huisartsen, en waardoor werd het werken met het CRS vergemakkelijkt respectievelijk bemoeilijkt?

Hoofdstuk 2 beschrijft de effecten van een financiële incentive op het voorschrijfgedrag van huisartsen. De financiële incentive bestond uit een eenmalige, gedragsonafhankelijke bonus (target payment). In ruil voor de incentive moesten de huisartsen zich houden aan een aantal belangrijke voorschrijfrichtlijnen die op een formulier van één pagina samengevat waren door een multidisciplinaire commissie. De interventiegroep bestond uit 119 huisartsen in een regio in Zuid-Nederland. In een ander deel van het land werd een controleregio met 118 huisartsen geselecteerd. Gedurende de periode 2000-2002 verstrekten de regionale ziektekostenverzekeraars elke maand de receptgegevens van iedere huisarts. Korte en lange termijneffecten werden geëvalueerd door de receptgegevens voor dezelfde periode in de volgende jaren te analyseren. Deze studie toonde aan dat de financiële bonus een beperkt, tijdelijk effect had op het voorschrijfgedrag van huisartsen volgens bestaande 
nationale en regionale richtlijnen. Er was een significant korte termijneffect in de verwachte richting voor een klein aantal geneesmiddelindicatoren (amoxicilline plus clavulaanzuur, trimethoprim, aanbevolen maagmiddelen en recent ontwikkelde geneesmiddelen). Alleen de aanbevolen maagmiddelen lieten ook een significant effect op lange termijn zien. Op langere termijn verdween de bescheiden invloed van deze financiële incentive. De huisartsen waren mogelijk niet bekend met de interventie en waren blijkbaar niet erg gemotiveerd om deel te nemen. Het gedragsonafhankelijke karakter leek niet voldoende bindend te zijn en de huisartsen werden gedurende het tijdsverloop van de studie op geen enkele manier geïnformeerd over of herinnerd aan hun deelname aan het experiment. Samenvattend liet deze studie zien dat een gedragsonafhankelijke financiële incentive slechts kleinschalige en tijdelijke effecten had op veranderend voorschrijfgedrag.

Het complexe design van het hoofdproject, de ontwikkeling en implementatie van multidisciplinaire richtlijnen met behulp van computer reminders om voorschrijfgedrag te beïnvloeden, wordt gepresenteerd in Hoofdstuk 3. Voor het bestuderen van het voorschrijfgedrag van huisartsen met behulp van computer reminders, werd gebruik gemaakt van een combinatie van ontwerpen - variërend van een quasi-experimenteel tot een pragmatisch cluster gerandomiseerd gecontroleerd experiment (RCT - randomised controlled trial) en een incompleet block-design. De voornaamste meetresultaten waren tevredenheidsscores, applicatiescores, prestatie-indicatoren, aantal recepten en kosten. Ondanks dat we geconfronteerd werden met een aantal tegenslagen en praktische beperkingen bij de voorbereiding van de studie, hebben we alle onderdelen van de studie, inclusief het pragmatische experiment, volgens planning kunnen implementeren en uitvoeren. De conclusie kan dan ook zijn dat de studie succesvol kon worden uitgevoerd ondanks de complexiteit van het studiegebied. Het tamelijk complexe design van de studie bleek uiteindelijk juist en haalbaar te zijn. De combinatie van verschillende studieonderdelen in één grote studie bood ons de mogelijkheid om de effecten van de interventie in een breed spectrum en op diverse aspecten te beoordelen. De evaluatie van de effecten van de implementatie van voorschrijfrichtlijnen met behulp van een Computer Reminder Systeem bevatte meer dan alleen de technische toepasbaarheid ervan of de evaluatie van de effecten op het gedrag van artsen. De totale gegevens stelden ons in staat een redelijk compleet beeld te krijgen van de verschillende uitkomsten voor de dagelijkse gezondheidszorg, uitgedrukt in effecten, maar ook in proces- en kostenparameters.

De effecten van de ontwikkeling en verspreiding van transmurale papieren richtlijnen om het voorschrijfgedrag van huisartsen te verbeteren worden beschreven in Hoofdstuk 4. Het doel van deze studie was om de effectiviteit van de verspreiding van multidisciplinaire richtlijnen op de hoeveelheid voorgeschreven geneesmiddelen vast te stellen. De studie bestond uit twee ontwerpen, een quasi-experimentele pre/post studie met een simultane controlegroep en een aselecte steekproef van huisartsen binnen de interventiegroep. Het interventiegebied met 53 huisartsen is vergeleken met een controlegroep van 54 willekeurig geselecteerde huisartsen in het zuiden en midden van Nederland. Aanvullend is randomisatie uitgevoerd in 
de interventiegroep om twee subgroepen te maken: 27 huisartsen die intensiever betrokken werden bij de ontwikkeling van de richtlijnen, en 26 huisartsen in de controlegroep.

De transmurale richtlijnen zijn ontwikkeld door een multidisciplinaire commissie (stadsen ziekenhuisapothekers, specialisten, huisartsen, en vertegenwoordigers van de betrokken zorgverzekeraars). Deze richtlijnen werden vervolgens verspreid onder alle huisartsen in het interventiegebied. Extra effecten werden bestudeerd in het experiment met de subgroep waarin artsen waren uitgenodigd om zich intensiever bezig te houden met het ontwikkelproces van de richtlijnen. De richtlijnen bevatten 14 aanbevelingen voor antibiotica, astma- en COPDmiddelen en cholesterolverlagende middelen.

De voornaamste meetresultaten betroffen receptgegevens over een periode van drie jaar (een jaar voor en twee jaren na de verspreiding van richtlijnen) en de mate van verandering volgens de aanbevelingen. Significante korte termijnverbeteringen werden gezien bij één aanbeveling: mupirocine. Lange termijnveranderingen werden gevonden bij het voorschrijven van cholesterolverlagende middelen. Er werden geen extra veranderingen aangetroffen bij de gerandomiseerde gecontroleerde studie in de subgroep. De standaarddeviatie van de voorgeschreven geneesmiddelen per huisarts bleek onverwacht groot te zijn. Hoewel er kleine veranderingen gezien werden bij andere indicatoren, waren er bij deze andere middelen geen significante effecten zichtbaar. De uitnodiging aan huisartsen om actief betrokken te worden bij het ontwikkelproces leidde niet tot het gewenste effect in de subgroep.

Er kan worden geconcludeerd dat de verspreiding van de zorgvuldig ontwikkelde multidisciplinaire richtlijnen geen duidelijk effect gehad heeft op het voorschrijfgedrag van huisartsen, ook al waren de huisartsen en specialisten intensiever betrokken bij de ontwikkeling hiervan. Er moet blijkbaar meer moeite worden gedaan om een verandering teweeg te brengen.

Een intensievere strategie om het voorschrijfgedrag te verbeteren wordt beschreven in Hoofdstuk 5. Dit hoofdstuk beschrijt de effectiviteit van een Computer Reminder Systeem (CRS) op het voorschrijfgedrag van huisartsen. Het doel van de studie beschreven in dit hoofdstuk, was om de effecten van de implementatie van voorschrijfrichtlijnen door middel van een reactief CRS op voorschrijfgedrag in kaart te brengen. De hierboven beschreven multidisciplinaire voorschrijfrichtlijnen (hoofdstuk 4) werden geïntegreerd in een CRS. Dit CRS werd geïnstalleerd binnen een specifiek huisartsinformatiesysteem (MicroHIS) op de computers in de huisartsenpraktijken. Als een huisarts een geneesmiddel voorschreef dat niet in overeenstemming was met de voorschrijfrichtlijnen, verscheen vanuit het CRS een pop-up met een remindertekst. De richtlijnen bevatten aanbevelingen voor antibiotica, astmaen COPDmiddelen en cholesterolverlagende geneesmiddelen.

In een cluster RCT met een incompleet blockdesign in het zuiden van Nederland kregen 25 huisartsen (in 11 huisartsenpraktijken) reminders bij het voorschrijven van antibiotica, astma- en COPDmiddelen en 28 huisartsen (in 12 huisartsenpraktijken) kregen reminders bij het voorschrijven van cholesterolverlagende geneesmiddelen. De voornaamste meetresultaten werden uitgedrukt in prescriptie-indicatoren en receptaantallen. Naast 
individuele volumemetingen werden tevens somscores berekend uit de volumemetingen per geneesmiddelengroep (antibiotica, astma- en COPDmiddelen en cholesterolverlagende middelen). De variatie tussen huisartsen bleek groter en meer vertekend te zijn dan verwacht. Tussen de groepen werden geen verschillen gevonden voor indicatoren en volumes in relatie tot de aanbevelingen voor bepaalde geneesmiddelen. Hoewel er een tendens was naar klinisch relevante resultaten voor receptaantallen waarvan een daling verwacht werd, was het verschil in somscores tussen de groepen niet significant. Voor antibioticamiddelen waarvan verwacht werd dat ze in aantal zouden afnemen, was de somscore voor de interventiegroep 28,2 (95\% Cl: 20,8-44,5) recepten per 1000 patiënten per huisarts, terwijl deze 39,7 (95\% Cl: $29,7-64,1)$ was voor de controlegroep $(p=0,2)$. Voor astma- en COPDmiddelen waarvan verwacht was dat ze zouden afnemen, was de somscore voor de interventiegroep 1,1 (95\% Cl: 0,6-2,6) recepten per 1000 patiënten per huisarts, terwijl deze 2,2 (95\% Cl: 1,4-4,3) was voor de controlegroep $(p=0,1)$. De conclusie was dat de power berekend voor aanvang van de studie uiteindelijk te laag bleek om voor een dergelijke grote variatie van het voorschrijfgedrag van huisartsen te corrigeren. Computer reminders leken desalniettemin soms een gunstig effect op het voorschrijfgedrag te hebben, met name daar waar het reminders betrof om af te zien van het voorschrijven van bepaalde geneesmiddelen omdat het middelen betrof die niet of niet langer geïndiceerd waren.

De meest intensieve strategie, de implementatie van het CRS, wordt in dit proefschrift uitgebreid geëvalueerd. De effecten van deze strategie werden beschreven in Hoofdstuk 5 . Hoofdstuk 6 beschrijft de kosteneffecten van het CRS. Voor het bepalen van de kosten van de implementatie van een CRS werden de kosten voor ontwikkeling, uitvoering en gezondheidszorg berekend, met de bedoeling het voorschrijfgedrag van huisartsen te verbeteren en de kosten voor de gezondheidszorg te reduceren. Gedurende een 12 maanden durende follow-up periode werd in de zelfde cluster RCT met een incompleet blockdesign in het zuiden van Nederland de voorschrijfkosten van antibiotica, astma/COPDen cholesterolverlagende middelen berekend op basis van volumegegevens en vermenigvuldigd met de kostprijs per tablet. Vaste en variabele kosten per huisarts per jaar werden voor verschillende stadia van het kwaliteitsverbeteringtraject berekend: ontwikkelkosten van de voorschrijfrichtlijnen, ontwikkelkosten van de CRS-strategie, uitvoeringskosten van het CRS en voorschrijfkosten werden per huisarts per jaar berekend. Van 34 huisartsen konden receptgegevens worden geëvalueerd. De totale kosten van het CRS bedroegen $€ 15.239$ per huisarts (gedurende 4,3 jaar van het project). Richtlijnontwikkeling: $€ 7.685$ per huisarts; CRS-ontwikkeling: $€ 4.130$ per huisarts; uitvoeringskosten: $€ 3.424$ per huisarts. Er werden significante resultaten gevonden bij nietgeïndiceerde antibiotica, astma- en COPDmiddelen: €291 per huisarts per jaar in de interventiegroep versus $€ 430$ per huisarts per jaar in de controlegroep $(p=0,05)$. Een trend in de gewenste richting was zichtbaar bij de medicatiekosten voor geïndiceerde antibiotica, astma- en COPDmiddelen, waarvan op basis van de aanbevelingen in de richtlijnen een stijging werd verwacht: $€ 501$ per huisarts per jaar in de interventiegroep versus $€ 394$ per huisarts per jaar in de controlegroep $(p>0,2)$. Dit verschil trad niet op bij het niet-geindiceerd 
voorschrijven van cholesterolverlagende middelen: $€ 0$ per huisarts per jaar in de interventiegroep en $€ 6$ per huisarts per jaar in de controlegroep $(p>0,2)$ en bij het geïndiceerd voorschrijven van cholesterolverlagende middelen die op basis van de adviezen zouden moeten stijgen: $€ 55$ per huisarts per jaar in de interventiegroep versus $€ 35$ per huisarts per jaar in de controlegroep $(p>0,2)$.

Het bleek mogelijk om de kosten voor de ontwikkeling van het CRS en de kostenreducties door een verbetering van het voorschrijfgedrag als gevolg van het CRS te evalueren. Er kon echter geen volledige economische evaluatie worden uitgevoerd waarbij patiëntgerelateerde opbrengsten als gevolg van een betere opvolging van de richtlijnen werden betrokken. Ook in deze studie bleek dat de power berekend voor aanvang van de studie uiteindelijk te laag was om voor een dergelijke grote variatie van het voorschrijfgedrag van huisartsen te corrigeren. Een verbeterde opvolging van de richtlijnen resulteerde toch in veranderingen van de medicatiekosten in de gewenste richting. De kostenbesparingen waren echter kleiner dan de invoeringskosten. Deze strategie zou op lange termijn de kosten kunnen blijven verlagen, gezien het feit dat de aanvangsinvesteringen relatief hoog waren. De ontwikkelkosten waren eenmalig en zouden kunnen worden teruggebracht door het CRS te extrapoleren over een langere periode, naar een grotere groep artsen en met meer (bestaande) richtlijnen. Implementatie van deze interventie over het hele land zou betekenen dat de vaste kosten van de CRS-interventie (in totaal $€ 769.666$ ) zouden worden verspreid over alle circa 8.000 Nederlandse huisartsen. Uitgaande van een deelnemingspercentage van $90 \%$ zou dit betekenen dat de vaste kosten sterk gereduceerd zouden kunnen worden naar $€ 107$ per huisarts. Onze aanbevelingen zijn dan ook om het aantal richtlijnen in het CRS verder uit te breiden en het CRS in meer huisartsenpraktijken in Nederland te implementeren. Hoewel de aanvangsinvesteringen hoog waren, verwachten wij dat deze strategie op lange termijn kostenbesparend zal zijn.

De opzet was om de implementatie van de CRS-strategie uitgebreid te evalueren. Na het beschrijven van de effecten (Hoofdstuk 5) en de kosteneffecten (Hoofdstuk 6), beschrijft Hoofdstuk 7 een procesevaluatie van de implementatie van het Computer Reminder Systeem (CRS). De hoofddoelstellingen waren om de haalbaarheid en acceptatie van een CRS voor de verbetering van voorschrijfgedrag in de huisartsenpraktijk te evalueren en de sterke en zwakke kanten van het CRS te onderzoeken. Het door 53 huisartsen in 23 praktijken gebruikte CRS werd in een procesevaluatie geëvalueerd door middel van een analyse van de onderzoeksdatabase van het CRS. Alle huisartsen kregen een enquête voorgelegd. Bovendien werden een aantal huisartsen, twee projectleiders en een technische adviseur in een semi-gestructureerd interview ondervraagd.

De strategie werd grotendeels volgens plan uitgevoerd, al moest de ontwikkelperiode voor het CRS worden verlengd. $9 \%$ van de huisartsen haakte af. Allereerst werd er een significante leercurve gevonden als gevolg van de computer reminders voor antibiotica, astma- en COPDmiddelen. De grootste effecten waren zichtbaar in de eerste maanden na installatie. Deze bevinding lijkt een bevestiging van het leereffect van computer reminders. 
Ten tweede liet de enquête zien dat de huisartsen over het algemeen tevreden waren over de gebruikersvriendelijkheid en de inhoud van de verschillende soorten reminders, maar minder tevreden over bepaalde specifieke technische aspecten van het systeem. In de interviews uitten de huisartsen hun gemengde gevoelens over het CRS. De huisartsen bleken tevreden te zijn over het CRS op de volgende punten: stabiliteit en snelheid van het CRS, leerzaamheid en bondigheid van de reminders, de gebruikersvriendelijkheid, lay-out en ondersteuning van de helpdesk. De huisartsen waren niet tevreden over technische problemen die oponthoud veroorzaakten tijdens het voorschrijven. De gevoeligheid voor nieuwe updates en de vertragingen die het CRS veroorzaakte, wekten ook irritatie onder de huisartsen. Daarnaast manipuleerden huisartsen soms of zelfs dikwijls het CRS door reminders te omzeilen. Tenslotte, kwam in interviews met de projectleiders en de technische adviseur aan het licht dat de samenwerking en communicatie tussen de verschillende partijen niet altijd goed verlopen was en dat er technische problemen waren met de veelvuldige updates van het huisartsinformatiesysteem en het operating system.

Samenvattend kunnen we stellen dat deze procesevaluatie liet zien dat de implementatie van het CRS grotendeels volgens plan is uitgevoerd, maar dat de subjectieve ervaring van het werken met het CRS niet alleen positief was. De deelnemende huisartsen hadden gemengde gevoelens over het systeem en er zullen een aantal knelpunten moeten worden aangepakt om een grootschalige implementatie van het CRS mogelijk te maken. Kosten mogen hierbij niet verwaarloosd worden, daarom is het essentieel om de verhouding tussen kosten en baten te blijven analyseren.

Hoofdstuk 8 vormt een algemene bespreking van de belangrijkste bevindingen uit de verschillende studies en verbindt de conclusies van de eerdere hoofdstukken door een bespreking van de onderwerpen 'financiële incentive', 'multidisciplinaire richtlijnen' en 'computer reminders'. Verder wordt een aantal methodologische overwegingen die niet eerder aan bod kwamen, besproken. Vervolgens bespreekt dit hoofdstuk de resultaten van de studies met betrekking tot implementatietheorieën, implementatiestrategieën, theorieën over het voorschrijfgedrag en evaluatietheorieën. De relatie tussen deze theorieën en onze bevindingen worden in hoofdstuk 8 verder uitgewerkt. Op basis van de in dit proefschrift beschreven resultaten worden aanbevelingen voor de gezondheidszorg en aanbevelingen voor verder onderzoek gedaan.

De belangrijkste resultaten worden besproken met betrekking tot de primaire doelstelling om verschillende implementatiestrategieën te evalueren die het doelmatig voorschrijfgedrag van artsen zouden kunnen verbeteren waaronder ook het uitgebreid evalueren van de CRSstrategie. De gedragsonafhankelijke financiële incentive had slechts geringe en kortetermijneffecten op het voorschrijfgedrag. Een mogelijke combinatie van een financiële incentive met feedback of met computer reminders zou de effectiviteit kunnen verbeteren. De ontwikkeling en verspreiding van de multidisciplinaire lokale richtlijnen bleken een kostbare operatie te zijn met slechts geringe resultaten. Er zou misschien een effectievere methode moeten worden gebruikt om nationale richtlijnen aan te passen aan het lokale niveau. De 
verspreiding van richtlijnen zou verbeterd kunnen worden door segmentatie van de doelgroep, wat leidt tot een benadering die meer gericht is op de wensen van de artsen.

De CRS-strategie werd uitgebreid geëvalueerd door de verschillende aspecten te bestuderen in een effectevaluatie, een procesevaluatie en een kostenanalyse. Tijdens de CRS-studies bleek dat de power berekend voor aanvang van de studie uiteindelijk te laag was om voor een dergelijke grote variatie van het voorschrijfgedrag van huisartsen te corrigeren. Computer reminders hadden desalniettemin soms een gunstig effect op het beperken van geneesmiddelen die niet of niet langer in de huisartsenpraktijk geïndiceerd waren: de computer reminders voor antibiotica, astma- en COPDmiddelen lieten een significante verbetering van meer dan 30 procent zien. Ondanks pogingen om huisartsen intensiever te betrekken bij het ontwikkelproces van de lokale richtlijnen en het CRS, ervoeren de huisartsen de computer reminders niet als iets van henzelf. Er zou meer aandacht moeten worden besteed aan het creëren van betrokkenheid en draagvlak bij de doelgroep. Daarnaast zou meer aandacht moeten worden besteed aan de behoeften van de huisartsen en het opheffen van barrières. Tenslotte zijn in de toekomst meer kwantitatieve en kwalitatieve studies nodig naar knelpunten zoals het omzeilen en manipuleren van reminders en naar de vraag of herinrichting van het CRS de knelpunten zou kunnen verlagen. Als het CRS in het hele land zou worden geïmplementeerd, zou dit betekenen dat de vaste kosten sterk gereduceerd zouden kunnen worden, naar $€ 107$ per huisarts. Gezien de mogelijke besparingen op het voorschrijven door het CRS en de mogelijkheid om ontwikkelkosten te reduceren, is het aanbevelenswaardig om meer richtlijnen in het CRS op te nemen en het CRS bij meer huisartsenpraktijken in Nederland te implementeren.

De onderzoeksdatabase van het CRS biedt relevante en waardevolle informatie voor het verstrekken van feedback aan huisartsen en voor het benchmarken van hun voorschrijfgedrag. Een dergelijke combinatie van strategieën zou de aanvaarding en implementatie van de richtlijnen kunnen verbeteren. Aangezien in de literatuur de verwachting wordt uitgesproken dat aanvaarding en implementatie van een CRS gestimuleerd zou moeten worden door financiële, regulatieve en/of accreditatie-incentives, zou het CRS in de toekomst gecombineerd kunnen worden met een financiële of een accreditatie-incentive. In verhouding tot de voordelen die voortvloeien uit het gebruik van een dergelijk systeem dragen de huisartsen tenslotte een onevenredig deel bij aan de kosten voor implementatie en gebruik van het systeem.

Aangezien de financiële middelen voor de gezondheidszorg gelimiteerd zijn, wordt het steeds belangrijker om te bepalen of een investering in kwaliteitsverbeterende strategieën de moeite waard is. Het was niet mogelijk om in dit proefschrift een volledige economische evaluatie uit te voeren die rekening houdt met de voordelen voor de gezondheidszorg. Een recent ontwikkeld model zou bruikbaar kunnen zijn bij het berekenen van de totale netto financiële voordelen van de implementatie van de multidisciplinaire richtlijnen en het CRS. De belofte dat met dit model de vaststelling van het potentieel om te investeren in dergelijke strategieën, en de vergelijking van implementatiestrategieën vergemakkelijkt wordt, behoeft verdere studie. 
Dankwoord 

$\mathrm{Na}$ heel veel werk ligt het proefschrift nu echt voor jullie. Het leek zo ideaal om onderzoek te doen op basis van bestaande en automatisch gegenereerde databestanden, maar niks was minder waar. Het te onderzoeken datamateriaal was weerbarstig en de ICT waar wij van afhankelijk waren dreef mij regelmatig tot wanhoop. Maar nu is het af, het karwei is geklaard! En nu is het de hoogste tijd om iedereen, die op één of andere manier een bijdrage heeft geleverd aan de totstandkoming van dit boekwerkje, heel hartelijk te bedanken.

Mijn speciale dank gaat uit naar mijn promotor en co-promotoren. Allereerst wil ik mijn promotor Hans Severens bedanken voor zijn deskundige begeleiding. Hans, dankjewel voor de tijd die je aan dit onderzoek hebt besteed en de aandacht waarmee je mijn stukken hebt beoordeeld en gecorrigeerd. Mijn co-promotoren, Ron Winkens en Trudy van der Weijden wil ik hierbij bijzonder bedanken voor kun vakbekwame begeleiding. Ron, jij hebt aan de wieg van dit onderzoek gestaan en ik ben blij dat je jouw idee voor dit onderzoek toen hebt uitgewerkt tot een 'promovabel' onderzoek. Je weet als geen ander tegen welke problemen we in het onderzoek aanliepen en hebt keer op keer meegedacht om tot een oplossing te komen. Trudy, al ben je op een later moment aan de begeleidergroep toegevoegd, toch werd jij degene die tijd vond om vanaf dat moment de dagelijkse begeleiding voor je rekening te nemen. Jouw inhoudelijke opmerkingen en tekstueel commentaar waren zeer waardevol en tilden dit onderzoek naar een hoger plan.

Mijn dank gaat ook uit naar de leden van de beoordelingscommissie, prof. dr. J. Metsemakers, prof. dr. F Haaijer-Ruskamp, prof dr. ir. A. Hasman en prof dr. F. van Merode. Ik wil hen bedanken voor de aandacht die zij aan mijn proefschrift hebben geschonken en voor hun bereidheid om het te beoordelen op zijn kwaliteit.

De zorgverzekeraars VGZ en CZ hebben een bijzondere plaats gehad in het onderzoek. Ik ben hen dank verschuldigd, zowel voor de processturing in algemene zin, als ook voor de financiële steun en het leveren van alle benodigde databestanden. Ik hoop dat voor jullie dit proefschrift een mooi en tastbaar resultaat is van alle investeringen. In het bijzonder gaat mijn dank uit naar Jos Steens en Jan Broeren van VGZ en René Bekhuis en Paul Muijrers namens CZ.

Nadrukkelijk wil ik mijn dank uitspreken naar de huisartsen in de regio Maastricht en Heuvelland, Westelijke Zuid Limburg en Oostelijk Zuid Limburg, die hebben geparticipeerd in de diverse studies. In het bijzonder alle huisartsen die bereid waren om in hun praktijk te gaan werken met het CRS. Zonder deze groep artsen was het niet mogelijk geweest om dit onderzoek uit te voeren. Ik ben me bewust dat we voor dit onderzoek veel van jullie vroegen. In de meeste gevallen hebben jullie jarenlang gewerkt met het CRS terwijl we geen feedback konden verschaffen, omdat dit de evaluatie van het CRS zou vertroebelen. Ik hoop dat we dit in de nabije toekomst kunnen compenseren door deze feedback alsnog te verstrekken en jullie een volwassen versie van het CRS aan te bieden. In het bijzonder gaat mijn dank uit 
naar Jos Boesten voor het vele testwerk en het meedenken over de ontwikkeling van het CRS vanuit het huisartsenperspectief.

Hans Fiolet, directeur-bestuurder van de RVE Transmurale Zorg van het academisch ziekenhuis Maastricht, wil ik bedanken voor de ruimte die hij gaf om het onderzoek uit te voeren, en het vertrouwen dat hij in mij stelde, om dit onderzoek tot een goed einde te brengen.

Speciale dank gaat eveneens uit naar de leden en oud-leden van de stuurgroep van het FTTO-Maastricht en Heuvelland. De mix van huisartsen, specialisten, stadsapothekers en ziekenhuisapotheek, zorgverzekeraars en beleidsmakers is bijzonder en maakte het mogelijk om het onderzoek vanuit al deze disciplines te belichten. Als stuurgroep hebben jullie ieder op je eigen wijze inbreng gehad bij de procesmatige sturing van het onderzoek tijdens stuurgroepvergaderingen, maar ook in diverse praktische situaties zoals bij het testen van het CRS.

Mijn dank gaat eveneens uit naar alle werkgroepleden uit de eerste en tweede lijn die bereid waren mee te werken aan de ontwikkeling van een grote groep transmurale richtlijnen, die de basis vormen voor wat binnen het FTTO wordt beoogd: doelmatiger voorvoorschrijven door verbeterde afstemming van het prescriptiebeleid tussen beide lijnen.

Onze VGZ en CZ data werden op zorgvuldige wijze beheerd door het MEMIC. In het bijzonder dank ik Alfons Schroten voor het opzetten van en het meedenken over het databeheer. Eveneens gaat mijn dank uit naar Medecs in de persoon van Paul de Clercq, die het CRS en het analyseprogramma CRSAM heeft ontwikkeld en aangepast aan onze wensen, en aan Harald van den Meerendonk, die diverse richtlijnen in het CRS heeft ingevoerd. Dank ook aan Edumedica voor hun testwerk van het CRS binnen MicroHIS, vooral in de beginfase. In het bijzonder wil ik Arnoud Feekes danken voor de talloze installaties van het CRS in de huisartsenpraktijken in de regio. Tenslotte wil ik de overige leden van de werkgroep Informatisering bedanken voor hun inbreng gedurende de ontwikkelings- en implementatiefase van het CRS.

Voor de uiterst complexe analyses werd ik bijgestaan door Arnold Kester. Arnold, ik wil je graag bedanken voor alle methodologische en statistische kennis van zaken die je inbracht, jouw bereidheid om telkens weer mee te denken hoe we lastige kwesties konden oplossen, en de vele complexe analyses die je voor de diverse studies in dit proefschrift hebt uitgevoerd.

Patricia Geerts en Mirjam Werkhoven, bedankt dat de keus voor jullie afstudeeronderzoek voor Gezondheidswetenschappen en voor jullie scriptie, viel op ons FTTO. Jullie kwaliteitsscripties vormen de basis voor een deel van dit proefschrift. Ik denk met plezier terug aan de periodes waarin jullie binnen het FTTO jullie stageonderzoeken uitvoerden. 
Verder gaat mijn dank uit naar de overige collega's van de Transmurale Zorg op de gang in het MECC en in het provisorium voor hun praktische hulp, interesse en medeleven. In het bijzonder bedank ik Peter, Audrey, Liesbeth, Mariëlle, Monique, Yvonne, Pytha en Helene. Ik leek het wel altijd druk te hebben, maar hopelijk komen er nu betere tijden.

Ik wil ook graag mijn collega's bij de KEMTA bedanken, waarmee ik de eerste jaren van het onderzoek nauw heb opgetrokken. Binnen de KEMTA heb ik op een hele prettige manier kennis gemaakt met de wereld, die MTA-onderzoek heet. Gelukkig is het contact blijven bestaan, dat blijkt wel uit ons recentelijk congresbezoek aan de iHEA in Kopenhagen. Zowel inhoudelijk als ook op persoonlijk vlak heb ik veel aan jullie gehad. In het bijzonder bedank ik Brigitte, Thea en Ghislaine Hopelijk kunnen we onze etentjes voortzetten tot ver nadat we alle vier gepromoveerd zijn.

Chantal wil ik graag bedanken voor het prachtige kunstwerk dat speciaal voor de kaft van dit proefschrift is ontworpen. Je hebt in beeld weten te vatten wat in graag wilde. Bijzonder knap!

Mijn directe omgeving tijdens het onderzoek werd gevormd door de medewerkers van het FTTO. Binnen ons projectteam beleefden we zeer roerige jaren. Bijna allemaal zijn we gemangeld door zeer ingrijpende persoonlijke gebeurtenissen, sommige mooi, maar helaas vele verdrietig. Dat in een projectteam in een zestal jaren zoveel kon gebeuren, is onvoorstelbaar. Ziekte en verlies maakten dat we ook bij elkaar thuis kwamen. De gesprekken die we voerden gingen meestal niet over het project, maar over wat er in onze levens speelde. We zijn nu zes jaar verder en met een kleiner team, dat door die jaren heen wel een heel hecht team is geworden. Dat we nu samen de promotie mogen meemaken is daardoor extra bijzonder. Ik hoop dat we samen deze dag mogen vieren, ook als team. Ik ben bijzonder blij dat jullie mijn directe omgeving tijdens dit onderzoek vormden!

In het bijzonder wil ik graag Henk van Zutphen, oud-projectleider FTTO, en Karen Takx, huidig projectleider bedanken. Henk, dankjewel voor het vertrouwen dat je in mij gesteld hebt en de warme interesse in alles wat er in mijn leven speelde. Karen, jouw geloof in mij en de ruimte die je me gaf om dit onderzoek te kunnen afronden, waardeer ik enorm en heeft er mede voor gezorgd dat ik dit onderzoek tot een goed einde heb kunnen brengen.

Ik bedank ook mijn directe collega's van het FTTO voor alle praktische hulp, steun en gezelligheid: Greet, Diana, Viviane, Carla, en Bert, Daisy en Alied. Ik ben blij met zulke fijne collega's! In het bijzonder ook Viviane, ondanks dat zij in 2005 is overleden. Haar accuratesse, gedrevenheid, vrolijkheid en compassie zijn nog dagelijks een inspiratiebron voor ons team. Greet en Diana, dankjewel voor de vele hand- en spandiensten die jullie hebben verleend, maar ook voor alle gesprekken en gezelligheid. Daisy, je hebt oneindig veel analysewerk gedaan voor mijn onderzoek. Niets was je hierbij teveel. Jouw inzet en je betrokkenheid zijn van groot belang geweest bij dit onderzoek. Ik heb het nooit zo expliciet gezegd, maar ik ben je hier buitengewoon dankbaar voor. Alied, dankjewel voor alle hulp, je relativeringsvermogen en de grote hoeveelheid gezelligheid. Jouw bijdrage is groot, zowel in 
het onderzoek als in de privésfeer. Daisy en Alied, we hebben samen heel wat wel en wee gedeeld en zijn collega-vriendinnen geworden. Ik kan altijd bij jullie terecht, jullie zijn me zeer dierbaar. Ik vind het een eer dat jullie mijn paranimfen zijn!

Mijn familie en vrienden wil ik bedanken voor het feit dat jullie er waren en zijn. leder op je eigen wijze. Door jullie interesse in mij en mijn onderzoek voelde ik me steeds gesteund. Ik hoop dat er nu eindelijk weer tijd is om elkaar regelmatiger te gaan zien en spreken.

Lieve Ad en Thea, ik wil jullie bedanken voor jullie steun en medeleven en de wetenschap dat ik altijd op jullie kan terugvallen.

Lieve Wout, Jules en Liselotte, de essentie van familie tijdens de afgelopen jaren is me wel duidelijk geworden. Ik dank jullie voor alle bemoedigingen, interesse en gewoon een luisterend oor. Ik ben blij met zulke fijne familie.

Lieve mama, jij en papa stonden altijd voor me klaar. Dat was vroeger zo en nu nog steeds! Niets was jullie teveel, of het nou ging om praktische klussen, een luisterend oor, een uitvallende auto of om oppasdagen, jullie waren altijd bereid om mee te denken voor een oplossing. Voor alles wat jullie voor me hebben gedaan wil ik jullie bedanken. Mede dankzij jullie heb ik het proefschrift kunnen afronden. Papa, wat zou je trots op me zijn geweest. Jammer genoeg kun je dit niet meer lijfelijk meemaken, maar ik weet zeker dat je 'boven' straalt van trots om jouw dochter. Dit proefschrift is daarom opgedragen aan jou. En de feestlocatie is ter ere van jou!

Tot slot, lieve Paul, het aantal keren dat jij mij gemotiveerd hebt om vol te houden zijn ontelbaar. Evenals jouw geduld en je hulp om dit onderzoek tot een goed einde te brengen. Er zijn geen woorden genoeg om jou te bedanken voor wat jij in de afgelopen jaren allemaal voor mij gedaan hebt. Ik kom niet verder dan een dankjewel uit de grond van mijn hart dat ik altijd op je kan rekenen. Dit is voor heel lang de laatste promotie, afgesproken?

Lieve Jasmijn, jij kleurt mijn leven en geeft het glans. Door jou besef ik wat echt belangrijk in het leven is. Ik ben trots op een dochter zoals jij! Paul en Jasmijn, ik hou van jullie. 


\section{CurRiculum VitaE}

Jody Martens werd geboren op 18 november 1971 te Stadskanaal. In 1990 behaalde zij het diploma gymnasium $\beta$ aan het Ubbo Emmius Lyceum aldaar. Nadat zij uitgeloot was voor de studie geneeskunde en nadacht over een goed alternatief, werkte zij gedurende een jaar als vrijwilliger op een internationaal seminarium in Zürich (Zwitserland). In het jaar erop, startte zij met de studie Gezondheidswetenschappen aan de Rijksuniversiteit Limburg (tegenwoordig: Universiteit van Maastricht). Zij studeerde in 1998 af op twee studierichtingen: Gezondheidsvoorlichting, en Beleid en Beheer van de Gezondheidszorg. De onderzoeksstage voor haar studie voerde zij uit bij de Klachtencommissie van het academisch ziekenhuis Maastricht (azM). Deze stage kreeg reeds in 1997 vervolg in een aanstelling als klachtenfunctionaris en bemiddelaar binnen het stafdirectoraat Patiëntenzorg van het azM. In 1998 kreeg zij een vaste aanstelling binnen het azM als stafmedewerker patiëntencommunicatie. In het najaar van 2001 startte zij in een nieuwe dubbele functie binnen dezelfde organisatie. In deze functie hield zij zich als staffunctionaris binnen de afdeling Epidemiologie \& Medical Technology Assessment (KEMTA) bezig met onderzoek en ontwikkeling van patiëntenclassificatie systematiek. Daarnaast startte zij met het promotieonderzoek aan de Universiteit Maastricht en het academisch ziekenhuis Maastricht binnen het FTTO project waarvan dit proefschrift verslag doet. Sindsdien werkt zij als onderzoeker en projectmedewerker voor het project binnen de afdeling Transmurale Zorg. 



\section{Publications}

\section{Papers}

- Martens JD, van der Weijden T, Winkens RAG, Kester AD, Geerts P, Evers SMAA, Severens JL. Feasibility and acceptability of a computerized system with automated reminders for prescribing behaviour in primary care. International Journal of Medical Informatics $2007 \mathrm{Jul}$ 13; [Epub ahead of print].

- Martens JD, Werkhoven MJ, Severens JL, Winkens RAG., Effects of a behaviour independent financial incentive on prescribing behaviour of general practitioners. Journal of Evaluation in Clinical Practice 2007;13(3):369-73.

- Martens JD, van der Weijden T, Severens JL, de Clercq PA, de Bruijn DP, Kester AD, Winkens RA. The effect of computer reminders on GPs' prescribing behaviour: A clusterrandomised trial. International Journal of Medical Informatics 2007 Jun 12; [Epub ahead of print].

- Martens JD, Winkens RAW, Van der Weijden T, De Bruyn DD, Severens JL., Does a joint development and dissemination of multidisciplinary guidelines improve prescribing behaviour: a pre/post study with concurrent control group and a randomised trial. BMC Health Services Research 2006;6:145-52.

- Martens JD, Van der AA A, Panis B, Van der Weijden T, Winkens RAW,Severens JL. Design and evaluation of a computer reminder system to improve prescribing behaviour of GPs. Studies Health Technology Informatics 2006;124:617-23.

- Severens JL, Martens JD, Wensing M, Economic evaluation of implementation strategies., In: Grol R, Wensing M, Eccles M. Improving patient care. The implementation of change in clinical practice., 2005; London: Elsevier Butterworth Heinemann. ISBN 07506-8819-X.

- Martens JD, Winkens RAG, Severens JL., Beter antibioticabeleid. Richtlijn heeft gunstig effect op. voorschrijfgedrag. Medisch Contact 2003;58(36):1345-7.

\section{Abstracts}

- Martens JD, Winkens RAG, Severens JL. Effect van farmacotherapeutische transmurale richtlijnen; Doematiger en kwatlitatief hoogwaardig antibioticabeleid. Nationaal congres Kennis Beter Delen II. Veldhoven, oktober 2003 [poster].

- Martens JD, Winkens RAG, Van der Weijden T, de Bruyn D, Kester AD, Severens JL. The effects of computer reminders on GPs'prescribing behaviour. Nationaal congres Kennis Beter Delen III . Veldhoven, maart 2006.

- Van der Aa A, Martens JD, de Clercq PA, Panis BJ, WINKENS RA. Increasing General Practioners' Adherence to Prescribing Guidelines by Means of a Computer Reminder System Medical Informatics Europe (MIE) Maastricht, the Netherlands. August 2006 Maastricht [poster]

- Martens JD, Severens JL, Van der Weijden T, De Bruyn D, Winkens RAG. Cost Effects of Computer Reminders to Improve Prescribing Behaviour among GPs. International Health Economics Association (iHEA) World Congress. Copenhagen, Denmark. July 2007. 
